\title{
TESTE ESTRUTURAL \\ BASEADO EM FLUXO DE DADOS \\ DE PROGRAMAS CONCORRENTES
}

José Craveiro da Costa Neto

Orientador: Prof. Dr. José Carlos Maldonado

Dissertação apresentada ao Instituto de Ciências Matemáticas de São Carlos-USP, como parte dos requisitos para obtenção do título de Mestre em Ciências, Área: Ciências de Computação e Matemática Computacional.

São Carlos, janeiro de 1995. 
A Célia, minha mulher, e a meus filhos, Gisele, Silvia e Jaime. 
Olhem os pássaros do céu;

Eles não semeiam, não colhem, Nem ajuntam em armazéns.

No entanto, o Pai que está no céu os alimenta.

Será que vocês não valem mais que os pássaros?

Olhem como crescem os lírios do campo;

Eles não trabalham nem fiam.

Porém, eu lhes digo:

Nem o rei Salomão em toda sua glória,

Jamais se vestiu como um deles.

Mt, cap 6, vs 26, 28 e 29 


\section{Agradecimentos}

Ao meu orientador, Prof. Dr. José Carlos Maldonado, por sua orientação segura e confiante e pelo incentivo a que eu levasse em frente o tema a que nos propusemos a desenvolver.

Ao Prof. Dr. Paulo César Masiero, pela atenção a mim dispensada, principalmente durante o período de cumprimento do Programa de Mestrado.

Aos membros da banca examinadora de qualificação e aos membros da banca examinadora de dissertação pelas sugestões e contribuições a este trabalho.

Aos companheiros do Grupo de Engenharia de Software do ICMSC, em especial ao João Cangussu e ao Márcio Delamaro pelo apoio e companheirismo e à Sandra Fabbri e ao Fernando Ramos pelo apoio.

À disponibilidade sempre presente do pessoal da secretaria da Pós, da Portaria, da Biblioteca e da Gráfica.

Aos amigos Marcelo Siqueira, Flávia Barreto, Vera Lúcia e Lilian Kato, pessoas que me apoiaram muito em alguns dos meus momentos mais dificeis e que foram e continuam os amigos de sempre.

Ao Sadao Massago pela beleza de pessoa que é e pela disponibilidade que sempre tem para com os amigos.

Aos companheiros e amigos da roda de tereré, aos companheiros de república, a todos que no dia-a-dia, com pequenos grandes gestos contribuíram para o meu crescimento pessoal e profissional.

Aos meus amigos do Departamento de Computação e Estatística da Universidade Federal de Mato Grosso do Sul, com destaque para os professores Jair Biscola e Marcelo de Carvalho pelo incentivo nos momentos iniciais e para os professores Nalvo Junior e Edson Cáceres pelo apoio nos momentos finais do mestrado.

Ao Irineu Sotoma pela importante colaboração na parte final do exercício de implementação desta dissertação.

A minha mulher e filhos pela paciência, compreensão e apoio.

À CAPES pelo suporte financeiro parcial.

À Universidade Federal de Mato Grosso do Sul pelo apoio logístico e financeiro.

Às demais pessoas e organizações que, direta ou indiretamente, contribuíram para a execução do presente trabalho. 


\section{Resumo}

O teste de programas concorrentes tem sido objeto de preocupação nos últimos anos; mesmo assim, as iniciativas tomadas nesta área têm sido tímidas, com um número pequeno de publicações. A maioria das propostas para teste de programas concorrentes procura usar ao máximo o que já se tem feito para o teste de programas seqüenciais, procurando tratar com mais atenção aquelas construções que são específicas para programas concorrentes.

Nesta dissertação estudam-se o teste estrutural de programas seqüenciais e a ferramenta POKE-TOOL, que apóia a aplicação dos critérios Potenciais Usos; discutem-se propostas de teste de programas concorrentes, objetivando a configuração da POKE-TOOL para o teste de programas concorrentes. Dentro deste escopo, propõe-se uma linguagem intermediária para programas concorrentes (LIConc), procurando considerar vários aspectos de linguagens de programação concorrente do tipo procedimental e implementa-se o módulo que mapeia programas escritos em Occam para programas escritos na LIConc. Essa abordagem possibilita que a extensão da POKETOOL para apoiar o teste de programas concorrentes mantenha a característica de multilinguagem já apresentada pela POKE-TOOL para programas seqüenciais. 


\section{Abstract}

Concurrent program testing has been object of worry in recent years; even though, initiatives in this area have been very few, with a low number of publications. Most of these proposals for concurrent program testing explore mainly the theory developed for sequential program testing, giving more atention to constructions that are exclusive to concurrent programs.

In this thesis sequential program testing and the testing tool named POKE-TOOL, that aids the application of Potential Uses criteria, are studied. Implementation models of POKE-TOOL are revisited aiming at supporting concurrent program testing. An intermediate language for concurrent programs (LIConc) is proposed, considering various aspects of concurrent programming languages. The implementation of a POKE-TOOL program module that translates programs written in Occam to LIConc is described. This approach aims at keeping the characteristic of a multilanguage tool already hold by POKE-TOOL for sequential program testing. 


\section{Conteúdo}

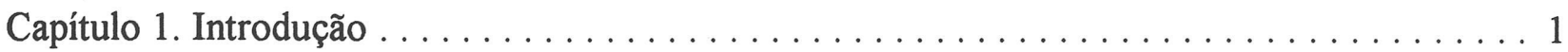

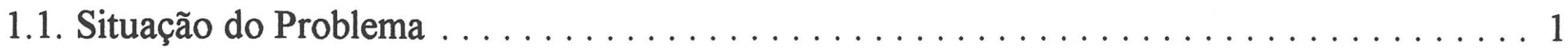

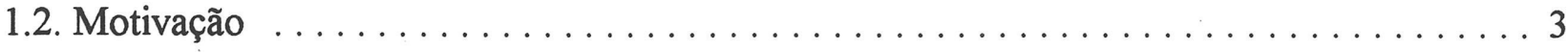

1.3. Objetivos do Trabalho $\ldots \ldots \ldots \ldots \ldots \ldots \ldots \ldots \ldots \ldots \ldots \ldots \ldots \ldots \ldots$

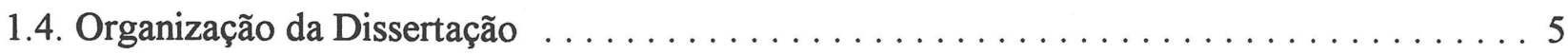

Capítulo 2. Software Concorrente e Paralelo $\ldots \ldots \ldots \ldots \ldots \ldots \ldots \ldots \ldots \ldots \ldots \ldots$

2.1. Multiprocessamento e Aplicações . . . . . . . . . . . . . . . . . 6

2.2. Paralelismo, Comunicação e Sincronização . . . . . . . . . . . . . . . 7

2.3. Linguagens de Programação Concorrente . . . . . . . . . . . . . . . 8

2.3.1. CSP: Uma Linguagem de Especificação de Processos . . . . . . . . . . . . 9

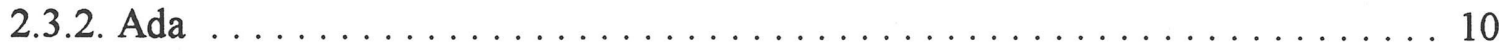

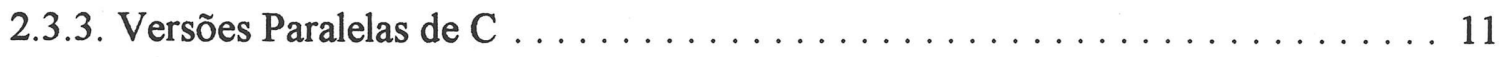

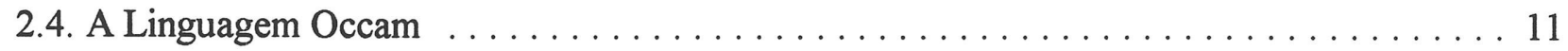

2.4.1. Atribuição e Comunicação . . . . . . . . . . . . . . . . . . . . . . 12

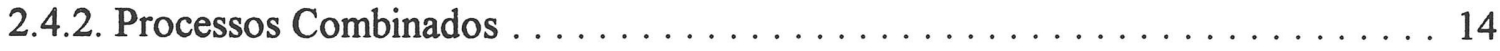

2.4.3. Caracterização de Unidade em Programas Occam . . . . . . . . . . . . . 18

2.4:4. Timers . . . . . . . . . . . . . . . . . . . . . 19

2.4.5. TDS - Um Ambiente para Desenvolvimento de Programas Occam . . . . . . . . 19

2.5. Considerações Finais . . . . . . . . . . . . . . . . . . . . . . . . . . . 21

Capítulo 3. Teste Estrutural de Programas Concorrentes $\ldots \ldots \ldots \ldots \ldots \ldots \ldots$

3.1. Teste de Software . . . . . . . . . . . . . . . . . . . . 23

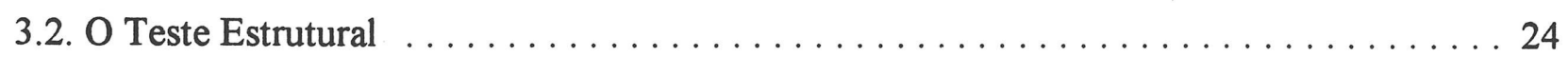

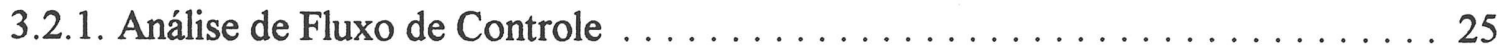

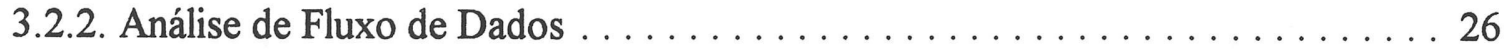

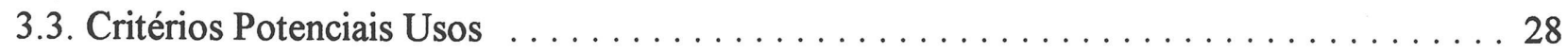

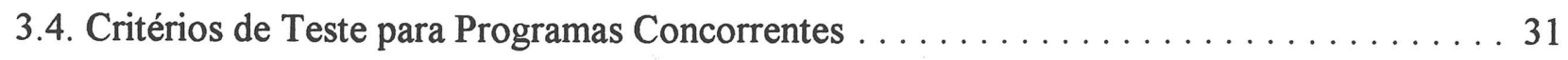

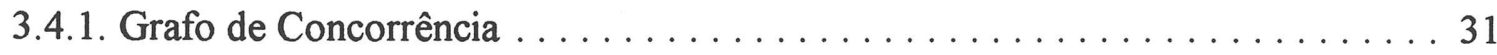

3.4.2. Critérios de Cobertura de Programas Concorrentes . . . . . . . . . . . . . 34

3.4.3. Uso dos Critérios de Cobertura . . . . . . . . . . . . . . . . . . . . 34

3.5. Grafo de Processo e Grafo de Sincronização . . . . . . . . . . . . . . . . . . . . 35

3.5.1. Modelagem de Programas Concorrentes . . . . . . . . . . . . . . 35 
3.5.2. O Teste de Análise de Caminho . . . . . . . . . . . . . . . . . 39

3.5.3. Teste de Execução Determinística . . . . . . . . . . . . . . 43

3.6. Ferramentas de Teste $\ldots \ldots \ldots \ldots \ldots \ldots \ldots \ldots \ldots \ldots \ldots \ldots \ldots \ldots . \ldots . \ldots . \ldots 4$

3.7. Ferramentas para Teste de Programas Concorrentes . . . . . . . . . . . . . 45

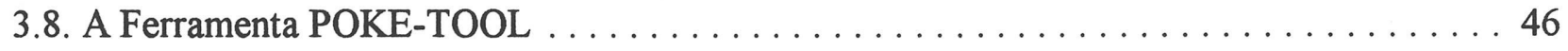

3.8.1. Modelos de Implementação . . . . . . . . . . . . . . . . . . . 46

3.8.2. Arquitetura da Ferramenta . . . . . . . . . . . . . . . . 47

3.8.3. Implementação da Ferramenta . . . . . . . . . . . . . . . . 49

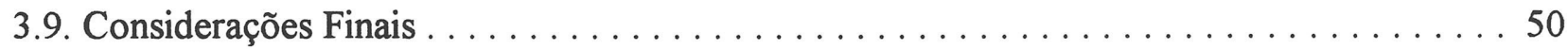

Capítulo 4. A LIConc e Diretrizes para a Aplicação dos Modelos de Implementação dos Critérios Potenciais Usos para a Linguagem Occam . . . . . . . . . . . . . . . . . . 51

4.1. LIConc - Linguagem Intermediária para Programas Concorrentes . . . . . . . . . . . 52

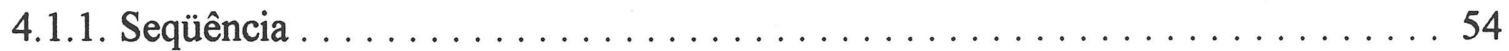

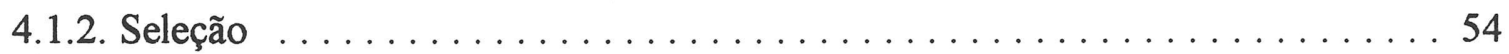

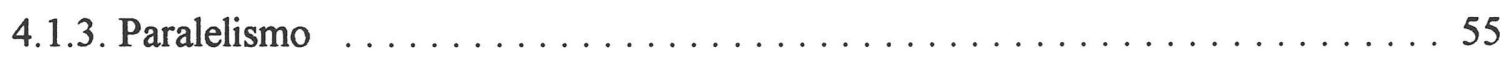

4.1:4. Repetição . . . . . . . . . . . . . . . . . . . 55

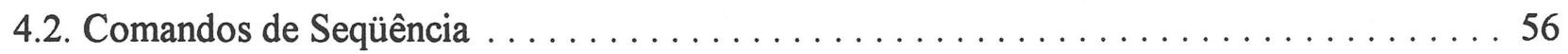

4.2.1. Comandos Simples . . . . . . . . . . . . . . . . . . . . . . 56

4.2.2. Comando SEQ . . . . . . . . . . . . . . . . . . . . . . 58

4.3. Comandos de Seleção . . . . . . . . . . . . . . . . . . . . . 60

4.3.1. Comando IF . . . . . . . . . . . . . . . . . . 60

4.3.2. Comando CASE ........................... 63

4.3.3. Comando ALT . . . . . . . . . . . . . . . . . . . . . . . 65

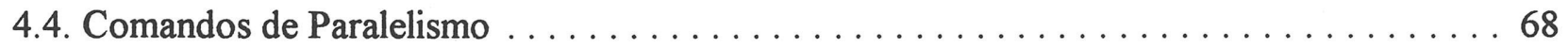

4.4.1. Comando PAR . . . . . . . . . . . . . . . . . . 68

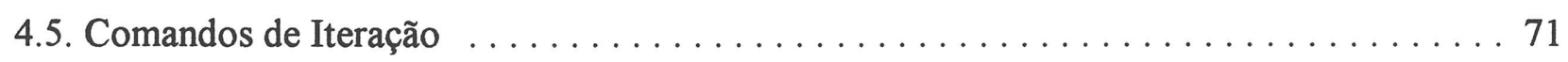

4.5.1. Comando WHILE ... . . . . . . . . . . . . . . . . . . . 71

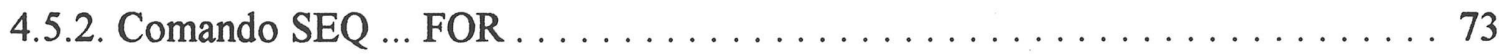

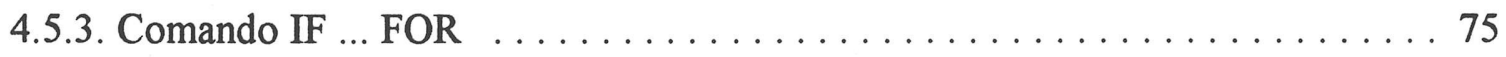

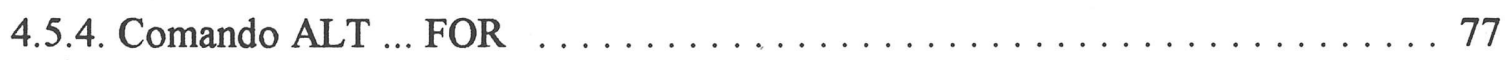

4.5.5. Comando PAR ... FOR . . . . . . . . . . . . . . . . . . 79

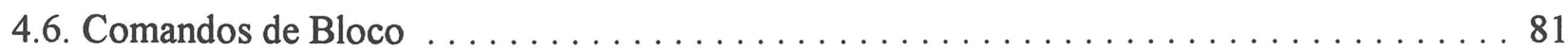

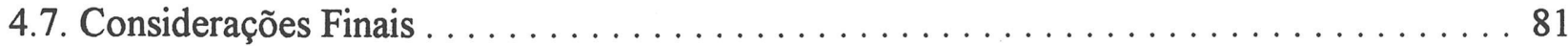


Capítulo 5. Aspectos do Mapeamento de Occam para a LIConc . . . . . . . . . . . 82

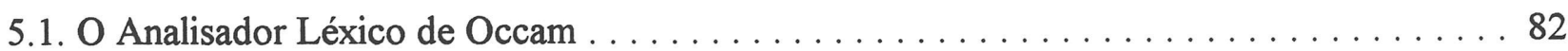

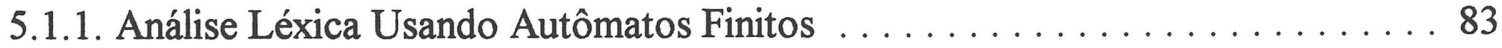

5.1.2. Tabela de Transições do Autômato . . . . . . . . . . . . . . . 83

5.1.3. Tabela de Palavras Reservadas da Linguagem Occam . . . . . . . . . . . . . 84

5.1.4. Implementação do Algoritmo de Análise Léxica . . . . . . . . . . . 85

5.2. Análise Sintática . . . . . . . . . . . . . . . . . . . . . . . . . . . . . 87

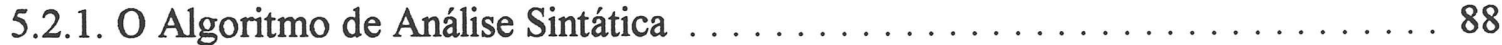

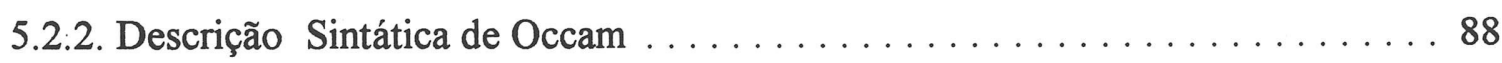

5.3. Um Exemplo . . . . . . . . . . . . . . . . . . . . . . . . 94

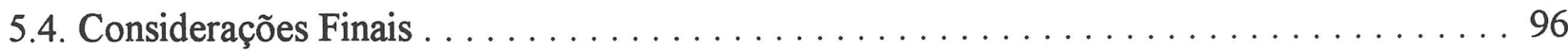

Capítulo 6. Conclusões e Trabalhos Futuros $\ldots \ldots \ldots \ldots \ldots \ldots \ldots \ldots \ldots$

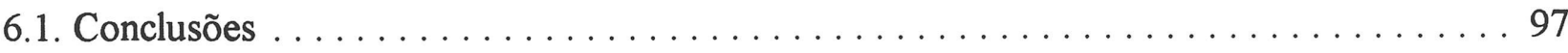

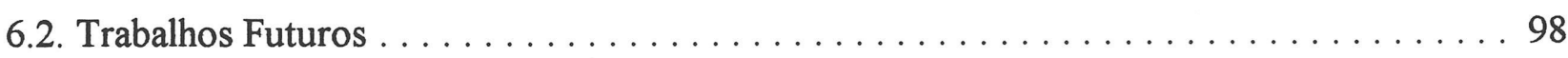

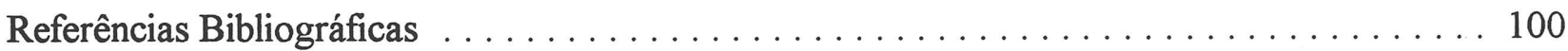

Apêndice A. A LIConc - Linguagem Intermediária para Programas Concorrentes . . . . . . 104

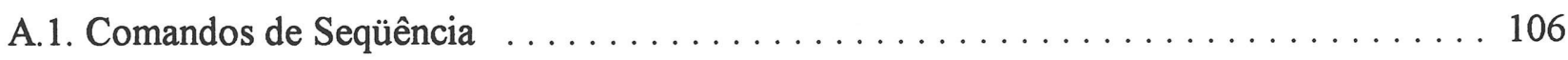

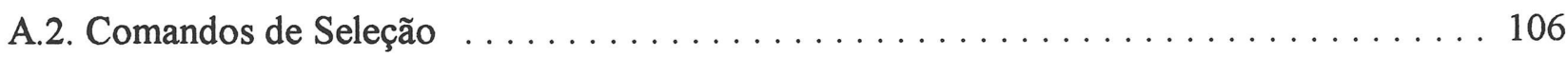

A.2.1. Seleção Simples . . . . . . . . . . . . . . . . . . . . . . . 106

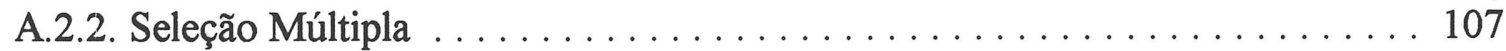

A.2.3. Seleção Não Determinística . . . . . . . . . . . . . . . . . . . 107

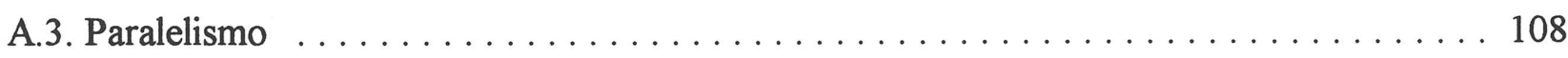

A.4. Iteração . . . . . . . . . . . . . . . . . . . . . . . . . . . 109

A.5. Desvio Incondicional $\ldots \ldots \ldots \ldots \ldots \ldots \ldots \ldots \ldots \ldots \ldots \ldots \ldots \ldots \ldots$

A.6. Comandos de Bloco . . . . . . . . . . . . . . . . . . . . . . . . . . . . . . . 112

Apêndice B. Ações Semânticas do Analisador Léxico de Occam . . . . . . . . . . . . . 113

Apêndice C. Rotinas Semânticas do Analisador Sintático de Occam . . . . . . . . . . . . . 118

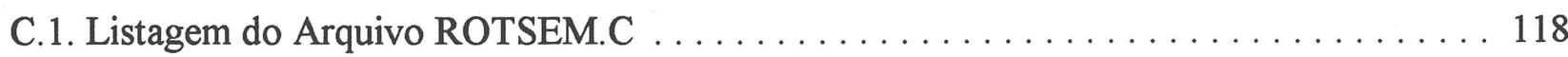

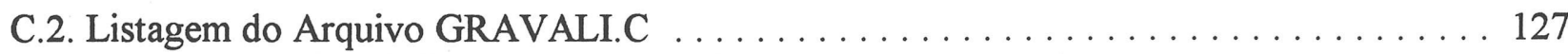

Apêndice D. Um Exemplo Completo . . . . . . . . . . . . . . . . . . . . . . . . 130 


\section{Lista de Figuras}

Figura 2.1. Estrutura de um Programa Occam . . . . . . . . . . . . . . 12

Figura 2.2. Listagem de Programa Occam $\ldots \ldots \ldots \ldots \ldots \ldots \ldots \ldots \ldots \ldots$

Figura 3.1. Hierarquia de Critérios de Teste . . . . . . . . . . . . . . . 28

Figura 3.2. Ordem Parcial entre a Família de Critérios Potenciais Usos e a Família de

Critérios de Fluxo de Dados . . . . . . . . . . . . . . . . . . . . 30

Figura 3.3. Grafos de Sincronização dos Processos do Programa Jantar_dos_Filósofos . . . . . 32

Figura 3.4. Grafo de Concorrência para o Programa Jantar_dos_Filósofos . . . . . . . . . . 33

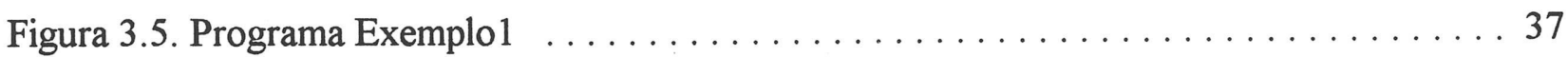

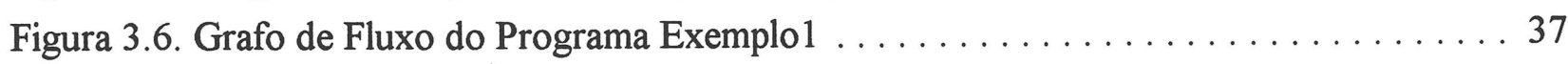

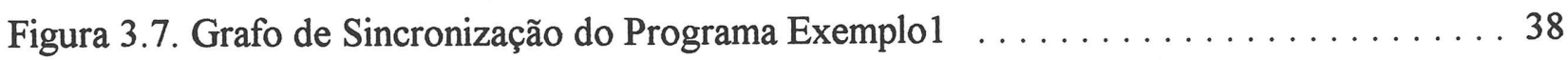

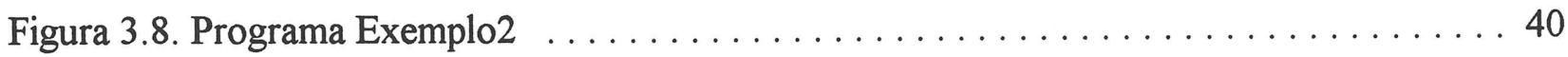

Figura 3.9. Grafo de Fluxo do Programa Exemplo2 . . . . . . . . . . . . . . 41

Figura 3.10. Grafo de Sincronização do Programa Exemplo $2 \ldots \ldots \ldots \ldots \ldots \ldots \ldots \ldots . \ldots 4$

Figura 4.1. Grafo de Fluxo de Controle: Comandos de seqüência . . . . . . . . . . . 57

Figura 4.2. Grafo de Fluxo de Controle: Comando SEQ . . . . . . . . . . . . . . 59

Figura 4.3. Grafo de Fluxo de Controle: Comando IF . . . . . . . . . . . . . 61

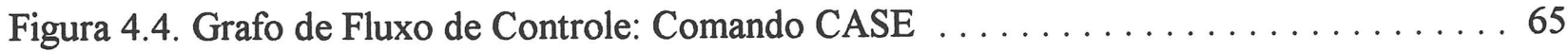

Figura 4.5. Grafo de Fluxo de Controle: Comando ALT . . . . . . . . . . . . . 67

Figura 4.6. Grafo de Fluxo de Controle: Comando PAR . . . . . . . . . . . . . . 70

Figura 4.7. Grafo de Fluxo de Controle: Comando WHILE . . . . . . . . . . . . . . 72

Figura 4.8. Grafo de Fluxo de Controle: Comando SEQ ... FOR . . . . . . . . . . . . . 74

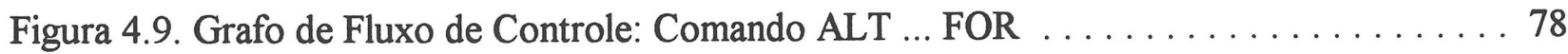

Figura 4.10. Grafo de Fluxo de Controle: Comando PAR ... FOR . . . . . . . . . . . . 80 


\section{Lista de Tabelas}

Tabela 3.1. Estados de Concorrência para o Problema Jantar_dos_Filósofos . . . . . . . . 33

Tabela 4.1. Extensões de terminais da LIConc . . . . . . . . . . . . . . . 53

Tabela 4.2. Mapeamento dos comandos de seqüência para a LIConc . . . . . . . . . . . 58

Tabela 4.3. Mapeamento do comando SEQ para a LIConc . . . . . . . . . . . . . . . . 59

Tabela 4.4. Mapeamento do comando IF para a LIConc . . . . . . . . . . . . . . . . . . 62

Tabela 4.5. Mapeamento do comando CASE para a LIConc . . . . . . . . . . . . . . . . . . 64

Tabela 4.6. Mapeamento do comando ALT para a LIConc . . . . . . . . . . . . . . 67

Tabela 4.7. Mapeamento do comando PAR para a LIConc . . . . . . . . . . . . . . . 69

Tabela 4.8. Mapeamento do comando WHILE para a LIConc . . . . . . . . . . . . . 72

Tabela 4.9. Mapeamento do comando SEQ ... FOR para a LIConc . . . . . . . . . . . . . . . . 74

Tabela 4.10. Mapeamento do comando ALT ... FOR para a LIConc . . . . . . . . . . . . . . 77

Tabela 4.11. Mapeamento do comando PAR ... FOR para a LIConc . . . . . . . . . . . . . 79

Tabela 5.1. Tabela de Transições do Autômato de Occam . . . . . . . . . . . . . . . 84

Tabela 5.2. Tabela de Palavras Reservadas de Occam . . . . . . . . . . . . . . . . . . 85

Tabela 5.3. Equivalência de Símbolos entre a BNF e a POKE-TOOL . . . . . . . . . . . . . . 89

Tabela A. 1. Extensões de terminais da LIConc . . . . . . . . . . . . . . . . . 105 


\section{Capítulo 1. Introdução}

\subsection{Situação do Problema}

Um dos grandes desafios, hoje em dia, consiste em reduzir o custo e melhorar a qualidade do software para que se possa atender melhor à demanda de novos programas e à manutenção dos sistemas existentes. Em resposta a esses problemas surgiu a Engenharia de Software, que consiste no estabelecimento e uso de princípios de engenharia para produzir software de alta qualidade a um baixo custo.

Qualidade de software é definida como conformidade a requisitos funcionais e de desempenho estabelecidos explicitamente, a padrões de desenvolvimento explicitamente documentados e a características implícitas que são esperadas de um software desenvolvido profissionalmente [PRE92]. A avaliação da qualidade de um software é uma tarefa complexa que depende da aplicação, do tipo de usuário e do estágio em que se encontra a cultura de qualidade da organização [YOU90]. Segundo Pressman [PRE92], vários fatores correspondentes a aspectos do software devem ser medidos, deduzindo-se daí a medida da qualidade do software. Esses fatores estão relacionados com três importantes aspectos de um produto de software: suas características operacionais, sua capacidade de absorver mudanças e sua adaptabilidade a novos ambientes. A 
qualidade deve ser medida a longo de todo o ciclo de vida do software. Portanto, são estabelecidas atividades de garantia de qualidade de software com o objetivo de assegurar níveis de qualidade especificados ao processo de desenvolvimento e ao produto final. Deve-se fazer a descrição de uma estratégia que integre atividades de análise, revisão e teste para permitir a avaliação do produto durante o ciclo de vida do software. A cada fase do ciclo de vida associa-se um conjunto de atividades e produtos.

O processo de engenharia de software compreende o uso de três elementos-chave: métodos, ferramentas e procedimentos. Os métodos estabelecem como será feita a construção do software, as ferramentas fornecem suporte aos métodos e os procedimentos permitem aglutinar métodos e ferramentas no sentido de construir software de uma forma racional num prazo apropriado.

No ciclo de vida de um software observa-se, basicamente, três fases: definição, construção e manutenção. As duas primeiras fases ocorrem antes da entrega do software para o usuário e compreendem o que se denomina de etapa de desenvolvimento do software. Na fase de definição, fazse o estudo do problema: traçando um plano de trabalho e deduzindo os requisitos para solução do mesmo. Na fase de construção, escolhe-se um modo de resolver o problema, com o estabelecimento do projeto do software e executa-se o projeto com a codificação dos programas e faz-se a verificação, validação e teste do produto que está sendo construído. A fase de manutenção ocorre a partir do momento em que o software é liberado para produção e compreende o conjunto de mudanças efetuadas para eliminar os defeitos existentes ou introduzir melhorias solicitadas pelo usuário.

Ambientes e ferramentas têm sido construídos para o desenvolvimento de programas concorrentes [ALM94]. Um programa concorrente corresponde a uma coleção de processos que executam simultaneamente e requerem uso de comunicação e sincronização. Linguagens seqüenciais de largo uso -- como C, Pascal e FORTRAN -- têm recebido extensões para lidar com aspectos de paralelismo [ALM94]; como também têm surgido linguagens específicas para programação concorrente, tais como Ada e Occam [ALM94, BAL89, BAR89, INM88]. Occam [INM88] é a linguagem alvo do presente trabalho; foi projetada especificamente para programação concorrente $\mathrm{e}$ vem tendo uma boa aceitação no meio científico. Foi construída para programação dos transputers, da INMOS. Para apoiar o desenvolvimento de programas Occam, a INMOS construiu o ambiente TDS (Transputer Development System) [INM90].

Recentemente, foram propostas técnicas para o teste de programas concorrentes inspiradas 
na teoria construída para o teste de programas seqüenciais. Yang e Chung [YAN92] modelam cada processo de um programa concorrente por um grafo de fluxo de controle (GFC), que será referenciado por grafo de processo; a união dos grafos de processo constitui o grafo de programa concorrente. De modo análogo, modela-se a sincronização dos processos obtendo-se o grafo de sincronização. Outra abordagem nessa mesma direção foi proposta por Taylor et al. [TAY92] e consiste em modelar o comportamento de um programa concorrente por meio de um grafo de concorrência. É importante observar que características específicas de programas concorrentes permitem a ocorrência do não determinismo, possibilitando a introdução de novos tipos de defeitos.

Nas estratégias apresentadas para teste de programas concorrentes, diversos autores têm procurado tirar o máximo proveito dos métodos/critérios estabelecidos para o teste de programas seqüenciais. Assim, pode-se concentrar esforço maior sobre as dificuldades específicas apresentadas pelos programas concorrentes. Existe uma grande quantidade de critérios de teste propostos para o teste de programas seqüenciais. Dentre eles, há os denominados critérios de fluxo de dados, que exploram associações entre definições e usos de variáveis; no contexto deste trabalho, estuda-se mais detalhadamente os critérios Potenciais Usos [MAL91]. A aplicação desses critérios é viabilizada pela ferramenta de teste POKE-TOOL [CHA91, MAL89], que está operacional atualmente para as linguagens C, COBOL e FORTRAN. A POKE-TOOL realiza análise estática, instrumentação do código fonte, execução e análise de cobertura e fornece informações adicionais pertinentes a uma sessão de teste. Esta ferramenta consiste de dois conjuntos de módulos: um dependente e outro independente das características da linguagem, de forma que, uma vez configurados os módulos dependentes da linguagem, viabiliza-se a aplicação dos critérios Potenciais Usos para a linguagem alvo.

\subsection{Motivação}

Os pontos determinantes para a condução do presente trabalho são:

- A programação concorrente, paralela e distribuída é um fato e seu uso tende a se popularizar nos próximos anos [ALM94];

- Programas concorrentes, paralelos e distribuídos possuem um grau de complexidade mais 
elevado do que os programas seqüenciais; deste modo, a atividade de teste torna-se mais significativa, uma vez que a confiabilidade dessa classe de programas é cada vez mais relevante, dada a criticidade das aplicações;

- O teste de programas concorrentes, paralelos e distribuídos tem tido uma atenção maior somente nos últimos anos, demandando a necessidade de estudos adicionais nessa área;

- O suporte automatizado aos métodos técnicas e critérios propostos para o desenvolvimento de software é essencial, do ponto de vista de produtividade e

- Os resultados da atividade de teste são fundamentais para as atividades de depuração e manutenção de software.

A motivação maior do presente trabalho foi estudar um assunto que dará origem a aplicações práticas de grande relevância num futuro próximo; principalmente pelo uso crescente da programação concorrente, paralela e distribuída nos próximos anos.

\subsection{Objetivos do Trabalho}

Um dos objetivos do presente trabalho é estudar e abstrair características de programas concorrentes escritos em linguagens de programação procedimentais e, a partir daí, estabelecer uma linguagem intermediária para programas concorrentes (LIConc), que possibilite o mapeamento dessa classe de linguagens para a LIConc, de forma que os conceitos e características próprias da atividade de teste, mais especificamente dos critérios Potenciais Usos, possam ser desenvolvidos independentemente da linguagem alvo e fortemente baseados no grafo de programa concorrente. A obtenção do grafo de sincronização está fora do escopo do presente trabalho. 
A definição e implementação da LIConc viabilizará a continuidade do presente trabalho objetivando o uso de critérios de fluxo de dados, neste contexto. Além de definir a LIConc, este trabalho tem por objetivo especificar os modelos de implementação da ferramenta POKE-TOOL para gerar o teste de programas concorrentes: modelo de fluxo de programa, modelo de fluxo de dados e modelo de instrumentação, com base nos modelos definidos para o teste de programas seqüenciais. A definição da LIConc viabilizará também o desenvolvimento de recursos de visualização de grafos de programas concorrentes.

\subsection{Organização da Dissertação}

O presente trabalho busca fornecer uma base de conceitos para configuração da ferramenta POKETOOL para a linguagem Occam, estando organizado em seis capítulos e quatro apêndices..

Este capítulo apresentou de forma sucinta o problema, procurando caracterizar o objetivo e a relevância do trabalho proposto para a dissertação. 0 Capítulo 2 dá ênfase ao progresso obtido pela área de programação concorrente/paralela e a conceitos necessários para o desenvolvimento de linguagens de programação concorrente; descreve algumas linguagens de programação concorrente, com um maior nível de detalhamento para a linguagem Occam. O Capítulo 3 versa sobre o teste de programas e ferramentas de teste, com dedicação maior ao teste estrutural e à ferramenta de teste POKE-TOOL, e sintetiza propostas para o teste de programas concorrentes. O Capítulo 4 estabelece diretrizes para a configuração da ferramenta POKE-TOOL visando à aplicação dos critérios Potenciais Usos para a linguagem Occam. O Capítulo 5 aborda aspectos de implementação da configuração da POKE-TOOL para Occam. O Capítulo 6 apresenta as conclusões do trabalho e sugere trabalhos que poderão advir dos resultados obtidos.

O Apêndice A apresenta um resumo da LIConc - Linguagem Intermediária para Programas Concorrentes; o Apêndice $\mathrm{B}$, as ações semânticas do analisador léxico de Occam para a POKETOOL; o Apêndice $C$, as rotinas semânticas do analisador sintático de Occam para a POKE-TOOL e, o Apêndice D, um exemplo completo. 


\section{Capítulo 2. Software Concorrente e Paralelo}

A cada dia que passa aumenta a participação das arquiteturas paralelas e distribuídas com relação às arquiteturas de hardware. Com isto, surge a necessidade de desenvolvimento de técnicas para construção de software concorrente. Se por um lado o uso da concorrência e da comunicação permite a construção de software que execute com maior eficiência, por outro lado, exige a aplicação de técnicas de desenvolvimento que tenham melhor qualidade. É necessário desenvolver modos de pensar sobre o paralelismo como também é necessário ter à mão linguagens adequadas para expressálo, porque, de modo geral estamos habituados a construir soluções seqüenciais para os problemas que nos são colocados, apesar da natureza paralela de muitos deles [ALM94].

A construção de software concorrente implica no uso de linguagens de programação concorrente, que devem possuir novas construções além daquelas oferecidas por uma linguagem de programação seqüencial. Linguagens de programação tradicionais com largo uso no meio científico têm suas extensões concorrentes ou paralelas, como FORTRAN e C; outras, já incluem, desde o projeto inicial, o tratamento da concorrência ou do paralelismo, como Ada e Occam.

\subsection{Multiprocessamento e Aplicações}

Elemento de processamento é um dispositivo físico que tem habilidade para executar um processamento. Processadores paralelos são uma coleção de elementos de processamento que podem comunicar-se e cooperar para resolver problemas grandes, rapidamente [ALM94]. Os modelos de computação paralela mais tradicionais são o modelo de memória compartilhada e o modelo de troca de mensagens. No modelo de memória compartilhada cada elemento de processamento tem acesso a qualquer módulo de memória do sistema e no modelo de troca de mensagens cada elemento de processamento tem sua própria memória e comunica-se com os outros elementos de processamento fazendo troca de mensagens. O mecanismo de memória compartilhada é um mecanismo de comunicação mais poderoso mas com custo de implementação mais alto [ALM94]. Já o mecanismo de troca de mensagens, que é a base das arquiteturas distribuídas, permite uma modelagem mais estruturada da comunicação tendo sua eficiência restringida pela velocidade da rede de interconexão dos elementos de processamento [BAL89]. 
Existem muitas aplicações que são resolvidas mais eficientemente com o uso de arquiteturas paralelas ou distribuídas. São exemplos o processamento de imagens, sistemas de bancos de dados, controle de processos, previsão do tempo, etc. O requisito principal para este tipo de aplicação é o alto desempenho, para que se possa obter resposta num tempo aceitável.

Para poder utilizar os múltiplos processadores de um computador, um problema é dividido em módulos, que são chamados processos ou tarefas, pois processamento paralelo é essencialmente um problema de "divisão e conquista" ("divide and conquer") e há muitos modos para modularizar um problema [ALM94]. A execução paralela de processos, em geral, enseja a necessidade de comunicação entre os processos em execução, o que exige atividades de sincronização.

\subsection{Paralelismo, Comunicação e Sincronização}

Milner [MIL89] afirma que comunicação e concorrência são noções complementares, ambas essenciais para o entendimento de sistemas complexos. Um programa concorrente especifica dois ou mais processos seqüenciais que podem ser executados simultaneamente. A execução concorrente de processos é uma composição de paralelismo (real ou virtual) com cooperação. Quando se executa um programa concorrente usando um único processador não ocorre um paralelismo verdadeiro, mas sim um pseudo-paralelismo, isto é, o processo que está executando, quando for necessário, é interrompido, seu estado atual é guardado e outro processo passa a ser executado. Os processos podem executar paralelamente quando vários processadores estão disponíveis para o programa.

Processos são criados ou implicitamente, por sua declaração, ou explicitamente, por alguma construção de criação de processo. A criação de um processo pode ser estática ou dinâmica. $\mathrm{Na}$ criação estática é necessário definir, já de início, o número máximo de processos que serão criados, o que não é necessário na criação dinâmica. A cooperação entre processos envolve dois tipos de interação: comunicação e sincronização. Os mecanismos de comunicação e sincronização estão fortemente relacionados. Quando processos se comunicam, de modo geral, é necessário que haja sincronização entre eles. A sincronização consiste no conjunto de restrições aplicadas à ordem dos eventos. A cooperação entre processos pode ser baseada no uso de variáveis compartilhadas ou em troca de mensagens. A execução concorrente de processos não garante um estado global para o sistema, ocasionando dificuldade na determinação da ordem precisa dos eventos [FID89]. Assim, em 
programas concorrentes, os relacionamentos temporais entre eventos só são definidos parcialmente.

Na sincronização com o uso de variáveis compartilhadas, um dos tipos de sincronização mais empregados é a exclusão mútua, onde uma seqüência de instruções é tratada como uma operação indivisível. Deste modo, variáveis comuns a dois ou mais processos determinam regiões críticas.

A sincronização baseada em troca de mensagens ocorre com o envio e recebimento de mensagens entre os processos. $\mathrm{O}$ mecanismo de sincronização de troca de mensagens determina quem envia (emissor), o que é enviado (mensagem) e para quem é enviado (receptor). Um tipo bastante comum de troca de mensagens é a troca de mensagens ponto-a-ponto, que pode ser síncrona ou assíncrona. Na troca de mensagens ponto-a-ponto síncrona o emissor é bloqueado até que o receptor receba a mensagem, enquanto que na troca de mensagens assíncrona o emissor preocupa-se somente com o envio da mensagem.

Existe um mecanismo de troca de mensagens ponto-a-ponto, chamado rendezvous, que estabelece cooperação entre dois processos em uma direção. 0 modelo de rendezvous está baseado em 3 conceitos: 1) declaração de entrada (como se fosse declaração de procedimento); 2) chamada de entrada (como se fosse chamada de procedimento) e 3 ) instrução de aceitação (instruções a serem executadas).

Uma questão relacionada à sincronização é o não determinismo. Execuções de uma mesma coleção de processos com a mesma entrada podem gerar comportamentos diferentes quando esta coleção de processos permite o estabelecimento de diferentes sincronizações, gerando comportamento não determinístico [BAL89]. O controle da execução de um programa que apresenta características não determinísticas pode ser obtido com o uso de um escalonador, que permite registrar as alternativas escolhidas pela execução do programa.

\subsection{Linguagens de Programação Concorrente}

Uma linguagem de programação concorrente deve oferecer outras construções além daquelas oferecidas por uma linguagem de programação seqüencial. Uma linguagem de programação concorrente deve ter a capacidade de 1) definir quais processos serão executados em paralelo, 2) 
iniciar e parar uma execução paralela, 3) viabilizar a cooperação entre processos durante a execução [BAL89].

Algumas linguagens de programação executam automaticamente decomposição de programa e sincronização; outras, porém, necessitam que algumas construções específicas da linguagem e primitivas de sincronização sejam especificadas. Há linguagens com paralelismo explícito, especificado pelo programador, ou implícito, quando deduzido pelo compilador ou outro processador de linguagem. A maioria das linguagens concorrentes apresenta paralelismo até o nível de processo. As principais linguagens de programação concorrente têm mecanismos de cooperação por troca de mensagens [BAL89].

Adicionalmente, as principais linguagens seqüenciais têm recebido extensões visando incorporar as novas primitivas necessárias para uma linguagem concorrente [BAL89]; FORTRAN é um dos exemplos. Devido à grande quantidade de programas em FORTRAN existentes no meio científico, foram produzidas versões paralelas da linguagem. Com a popularização do UNIX em multiprocessadores, várias variantes paralelas de $\mathrm{C}$ têm aparecido. Pascal Concorrente é uma linguagem paralela de memória compartilhada que estende o Pascal seqüencial com ferramentas de programação concorrente chamadas processos e monitores. Entretanto, um monitor é um mecanismo de sincronização bloqueante, o que não é apropriado para paralelismo de larga escala [ALM94]. Modula [WIR77], uma evolução de Pascal, combina a estrutura de bloco e de tipos de Pascal com a construção de módulos para definição de tipos abstratos de dados. Nas seções seguintes far-se-á a descrição de CSP, Ada e C Concorrente. Na Seção 2.5, a linguagem Occam é apresentada mais detalhadamente.

\subsubsection{CSP : Uma Linguagem de Especificação de Processos}

Modelos teóricos como CSP (Communicating Sequential Processes) [HOA78, HOA85] e CCS (Calculus of Communicating Systems) [MIL80] descrevem computação paralela usando somente sincronização. Hoare descreveu CSP para uso em especificações formais, para apoiar a correção de programas [BAL89]. Na realidade, CSP não é uma linguagem de programação, pois não chegou a ser implementada., mas teve influência decisiva no projeto das principais linguagens de programação concorrente. $\mathrm{O}$ modelo CSP consiste de um número fixo de processos seqüenciais que se comunicam somente por meio de troca síncrona de mensagens. Um processo consiste de um nome, de variáveis 
locais e de uma seqüência de instruções [BAL89].

Toda a comunicação interprocesso é feita por instruções send e receive síncronas. $\mathrm{O}$ processo emissor especifica o nome do processo destino. $\mathrm{O}$ processo receptor especifica o nome do processo emissor e fornece uma variável para a qual o valor recebido é atribuído. Para implementar o não determinismo, existe a construção alternative, que consiste num conjunto de guardas seguidos por ações a serem executadas.

\subsubsection{Ada}

Ada é uma linguagem que foi desenvolvida com financiamento do Departamento de Defesa do governo americano. Com a presença de muitos pesquisadores no projeto, muitos artigos foram publicados envolvendo vários aspectos da linguagem. Ada foi projetada para processos grandes que não exijam grande quantidade de cooperação [BAL89], apresentando paralelismo até o nível de processo. É uma linguagem de propósito geral que foi influenciada por Pascal e CSP e suporta tanto o modelo de troca de mensagens como o modelo de variáveis compartilhadas. Seu mecanismo de rendezvous implementa o modelo de troca de mensagens de CSP. O mecanismo de rendezvous foi projetado para ser usado em Ada; depois, foi estendido a outras linguagens.

Processos em Ada têm pontos de comunicação e sincronização denominados entradas que podem ser chamadas por outros processos [BAL89, BAR89, BUR88]. Uma chamada de entrada é sintaticamente semelhante a uma chamada de procedimento. A cooperação entre dois processos ocorre quando um processo requisita uma chamada de entrada e o processo aceitante da chamada de entrada estabelece um rendezvous.

O paralelismo é baseado em processos seqüenciais chamados tasks. Uma task tem uma parte de especificacão que descreve como as outras tasks podem se comunicar com ela e um corpo, com as instruções executáveis [BAR89]. Tasks comunicam-se, basicamente, por meio do mecanismo de rendezvous. Podem comunicar-se por variáveis compartilhadas, mas a atualização de uma variável compartilhada nem sempre é imediatamente visível para as outras tasks. Ada usa a instrução select para expressar o não determinismo. 


\subsubsection{Versões Paralelas para C}

Existem várias versões concorrentes/paralelas para C. Aqui serão feitos alguns comentários sobre o C Concorrente [GEH89], que estende a linguagem C com o acréscimo de suporte para a programação distribuída., e sobre o CPAR [SAT93], desenvolvido na Escola Politécnica da USP.

O C Concorrente é baseado no modelo de rendezvous de Ada. Um processo em C Concorrente tem uma parte de especificação e um corpo como acontece na linguagem Ada. Os processos são criados explicitamente e comunicam-se utilizando o mecanismo de rendezvous. Não é proibida a comunicação por variáveis compartilhadas. A linguagem suporta transações assíncronas. Sua instrução accept é mais poderosa que a de Ada. O não determinismo é expresso por uma instrução select, tal como Ada. As primeiras implementações da linguagem foram numa rede local e num equipamento multiprocessador com memória compartilhada [BAL89].

Sato [SAT93] apresenta o sistema CPAR, um sistema de programação e processamento para sistemas multiprocessadores, mostrando o modelo de programação e algumas características da linguagem CPAR. Enquanto C Concorrente explora o paralelismo de processo, CPAR também trata o paralelismo no nível de instrução, permitindo a paralelização de loops e de grupos de comandos.

\subsection{A Linguagem Occam}

As idéias do paralelismo por troca de mensagens de CSP foram incorporadas na linguagem Occam [INM88], que foi projetada para programação dos transputers da INMOS [BAL89]. Transputers são unidades de processamento que permitem conexão a 4 outras unidades de processamento através de canais. Uma rede de transputers é obtida a partir da ligação de vários transputers.

A linguagem Occam é voltada para aplicações científicas que são caracterizadas por grande demanda de cálculos, muitas delas permitindo paralelismo em larga escala -- até o nível de instrução -e exigindo pouca comunicação. O propósito do projeto da linguagem Occam foi fornecer uma linguagem de programação concorrente que fosse simples, elegante e poderosa [BUR88]. A linguagem foi desenvolvida por David May [MIT88] nos laboratórios da INMOS, contando com a ajuda de Hoare no estágio inicial de definição da linguagem. Uma das características atrativas de Occam é a de ter sido projetada com técnicas de especificação formal em mente. 
Occam permite que uma aplicação seja escrita como uma coleção de processos, onde processos rodam concorrentemente e comunicam-se por meio de canais. Cada processo descreve um aspecto particular de implementação e cada canal descreve uma conexão entre dois processos [INM88].

Um programa fonte Occam é escrito como uma seqüência de linhas, cada linha precedida de uma indentação, sendo que a profundidade da indentação é significativa para a estrutura do programa. É composto por blocos onde cada bloco é formado por especificações e comandos. Especificações são abreviações, declarações e definições. Uma abreviação consiste na atribuição de uma constante a um identificador ou na modificação do nome de uma variável ou de um canal. Numa construção de declaração determina-se o tipo e o nome de uma variável ou o protocolo e o nome de um canal. São permitidas definições de protocolos, de procedimentos e de funções. Na Figura 2.1. vê-se a estrutura geral de um programa Occam.

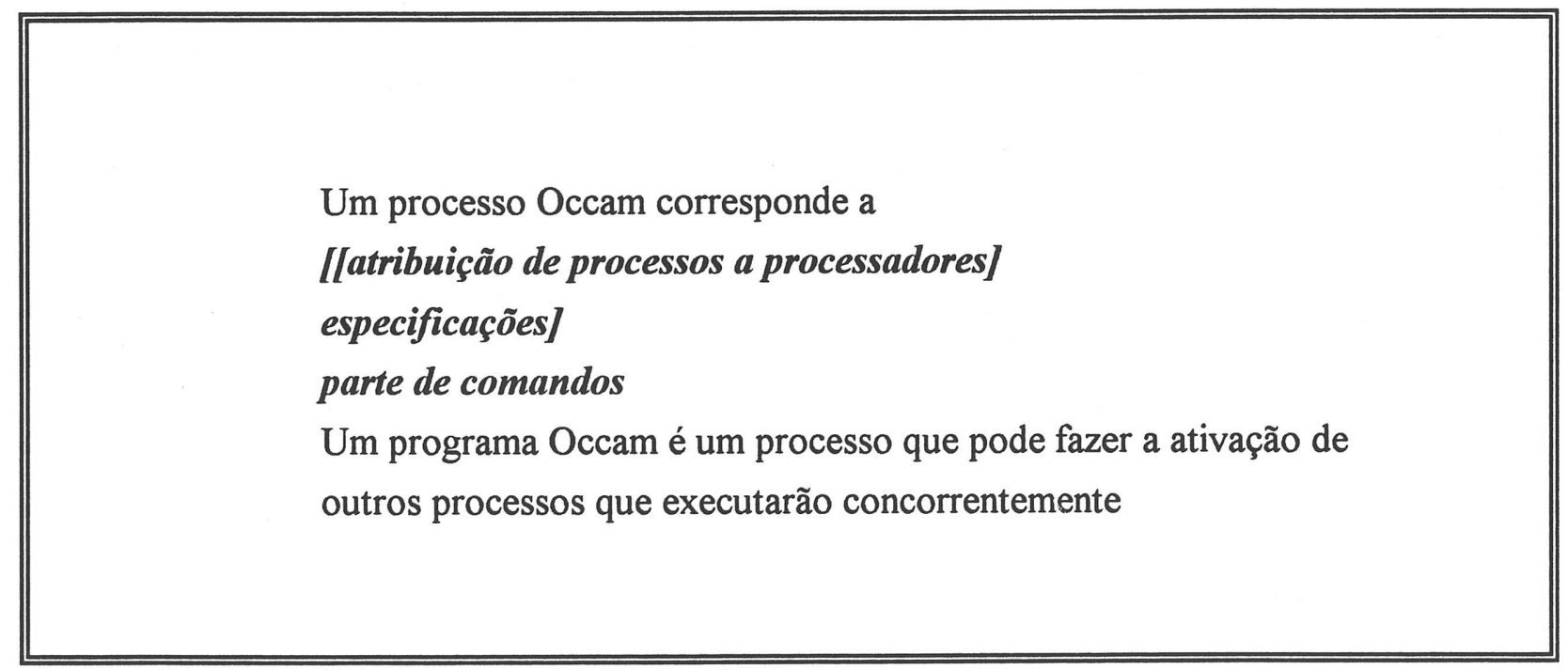

Figura 2.1. Estrutura de um Programa Occam

\subsubsection{Atribuição e Comunicação}

Há três comandos básicos em Occam: de atribuição, de entrada e de saída. Cada comando é considerado um processo atômico. Existem dois modos essencialmente diferentes para comunicação de informação entre dois processos de um programa: ou por modificação de valores de variáveis ou pelo envio de valores através de canais. Uma variável é um nome, com um tipo específico, associada 
a um valor que pode ser mudado pelo programa. A comunicação através de variáveis é essencialmente seqüencial. Uma variável é declarada pelo seu tipo e pelo seu nome. Exemplo:

INT p.use, c.use :

O valor de um variável pode ser mudado por uma atribuição. Após a execução de variável := expressão

o valor da variável é o valor da expressão antes da execução do comando de atribuição.

Occam permite atribuição múltipla:

$$
v_{1}, v_{2}, \ldots, v_{n}:=e_{1}, e_{2}, \ldots, e_{n}
$$

onde os $v_{i}$ são variáveis e os $e_{i}$ são expressões.

O análogo de uma variável num programa paralelo é o canal, servindo como ligação entre os processos. Numa arquitetura com multiprocessamento, o canal é implementado pela ligação física entre os processadores [JON88]. Em Occam, entrada e saída são processos, assim como atribuição. O formato e o tipo de comunicação sobre um canal é especificado por um protocolo de canal dado na sua declaração. Uma entrada recebe um valor de um canal e o atribui a uma variável. Uma saída transmite o valor de uma expressão para um canal. Exemplo:

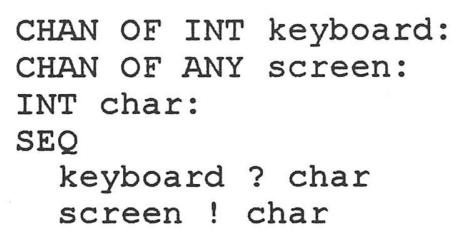

Neste exemplo, o canal keyboard envia um valor para a variável char. A seguir, o canal screen recebe o valor da variável char.

Em circunstâncias apropriadas -- quando os dois lados de uma comunicação são implementados num processador simples -- uma entrada e uma saída correspondem a uma atribuição e a alguma sincronização para garantir que os dois lados da comunicação ocorram simultaneamente [JON88]. Assim:

um processo de saída

canal ! expressão

mais um processo de entrada

canal ? variável

correspondem à atribuição

variável := expressão 
Um canal é usado para comunicação em somente uma direção: Se dois processos concorrentes usam um só canal, um deles deve usá-lo só para entrada enquanto o outro, só para saída. A sincronização da entrada e da saída é uma parte importante da comunicação. Uma entrada não está completa enquanto a correspondente saída não se completou e vice-versa; assim, cada parceiro numa comunicação tem que esperar o outro ficar pronto para completar a comunicação [JON88].

\subsubsection{Processos Combinados}

Programas Occam são construídos a partir de comandos. Comandos podem ser agrupados, de vários modos, para formar comandos mais complexos. Então, cada comando pode ser um comando simples ou um comando composto, quando corresponde a uma combinação de especificações e comandos mais simples. A execução seqüencial ou paralela de um grupo de comandos deve ser explicitamente estabelecida através dos comandos SEQ ou PAR, respectivamente. A execução iterativa faz uso do comando WHILE; a execução condicional faz uso dos comandos IF e CASE e a execução de uma entre alternativas de comunicação faz uso do comando ALT. Esses comandos podem encerrar uma lista de comandos mais simples ou podem ser acompanhados de uma construção de repetição.

O comando SEQ é usado quando se deseja agrupar comandos que devem ser executados seqüencialmente.

Exemplo:

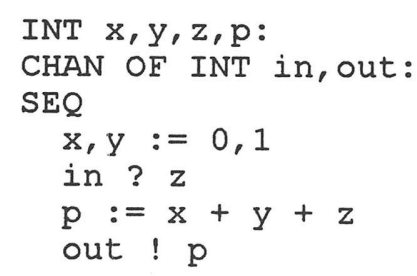

O comando WHILE de Occam corresponde ao comando while das linguagens seqüenciais estilo ALGOL.

\section{Exemplo:}

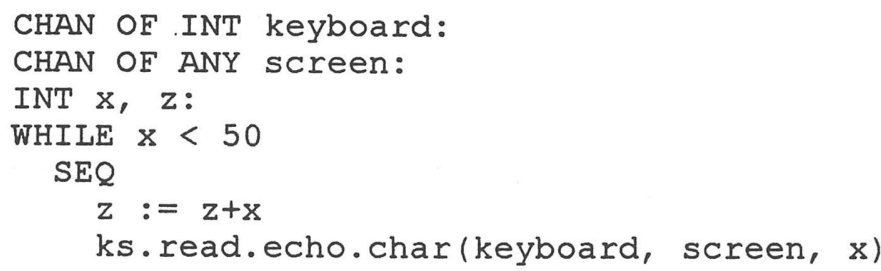


Um comando condicional é formado por um IF acompanhado de uma seqüência de escolhas onde cada escolha corresponde a uma condição seguida de uma lista de ações. Exemplo:

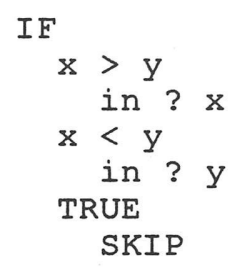

Em situações específicas IF pode ser substituído por CASE. Exemplo:

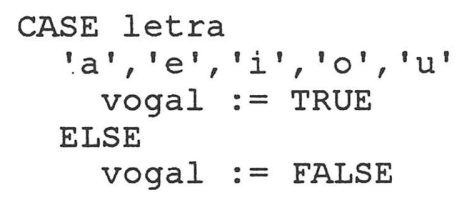

Um comando paralelo é definido pela palavra-chave PAR seguida de uma lista de comandos que serão executados em paralelo. Uma vez que não pode ocorrer interferência mútua, processos concorrentes só podem comunicar-se por entradas e saídas sobre canais.

Exemplo:

PAR

in ? $x$

$y, z:=y+1, z * 2$

out ! $2+w$

executa, em paralelo, uma entrada pelo canal in, uma atribuição múltipla às variáveis y e $\mathrm{z}$ e uma saída pelo canal out.

Para expressar o não determinismo, existe o comando ALT. O comando de alternativa reúne um número de processos guardados por entradas, executando o comando que está associado à guarda; se mais de uma guarda estiver pronta, uma delas é escolhida não deterministicamente e o processo correspondente é executado; se nenhuma guarda estiver pronta, a execução é suspensa até alguma guarda tornar-se pronta para, daí, passar à execução do processo sob guarda. $\mathrm{O}$ comando ALT corresponde a uma distribuição de decisões ao longo de vários processos.

Exemplo: 


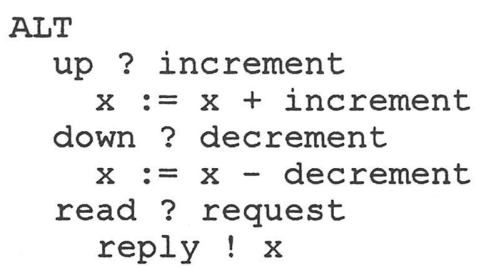

executa esperando até outro processo estar pronto para executar uma saída nos canais up, down e read. Se as entradas não são executadas a alternativa não é completada. Se várias das entradas estiverem disponíveis antes que a alternativa seja executada ou se várias tornarem-se disponíveis simultaneamente, só uma delas é escolhida. No exemplo, a alternativa atua como uma guarda para a variável $x$, que é efetivamente compartilhada pelos três processos distintos (presumivelmente) que comunicam-se sobre up, down e read.

Os comandos SEQ, IF, PAR e ALT podem estar associados à construção de repetição vvel.de.controle = val.inicial $\mathrm{FOR}$ num.vezes

cujo significado é o seguinte : vvel. de.controle é incrementada a partir de val.inicial de tal modo que o corpo da repetição seja executado num.vezes vezes. Exemplo:

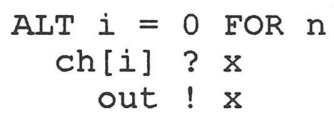

A Figura 2.2. ilustra um pequeno programa, sem declaração de procedimentos e de funções, onde se pode observar a estrutura geral de um programa Occam, bem como a forma como comandos são combinados para formar comandos mais complexos. Os comentários colocados ao longo do programa ilustram a sua funcionalidade, apesar de que a intenção foi mostrar, num programa, comandos típicos de Occam. 


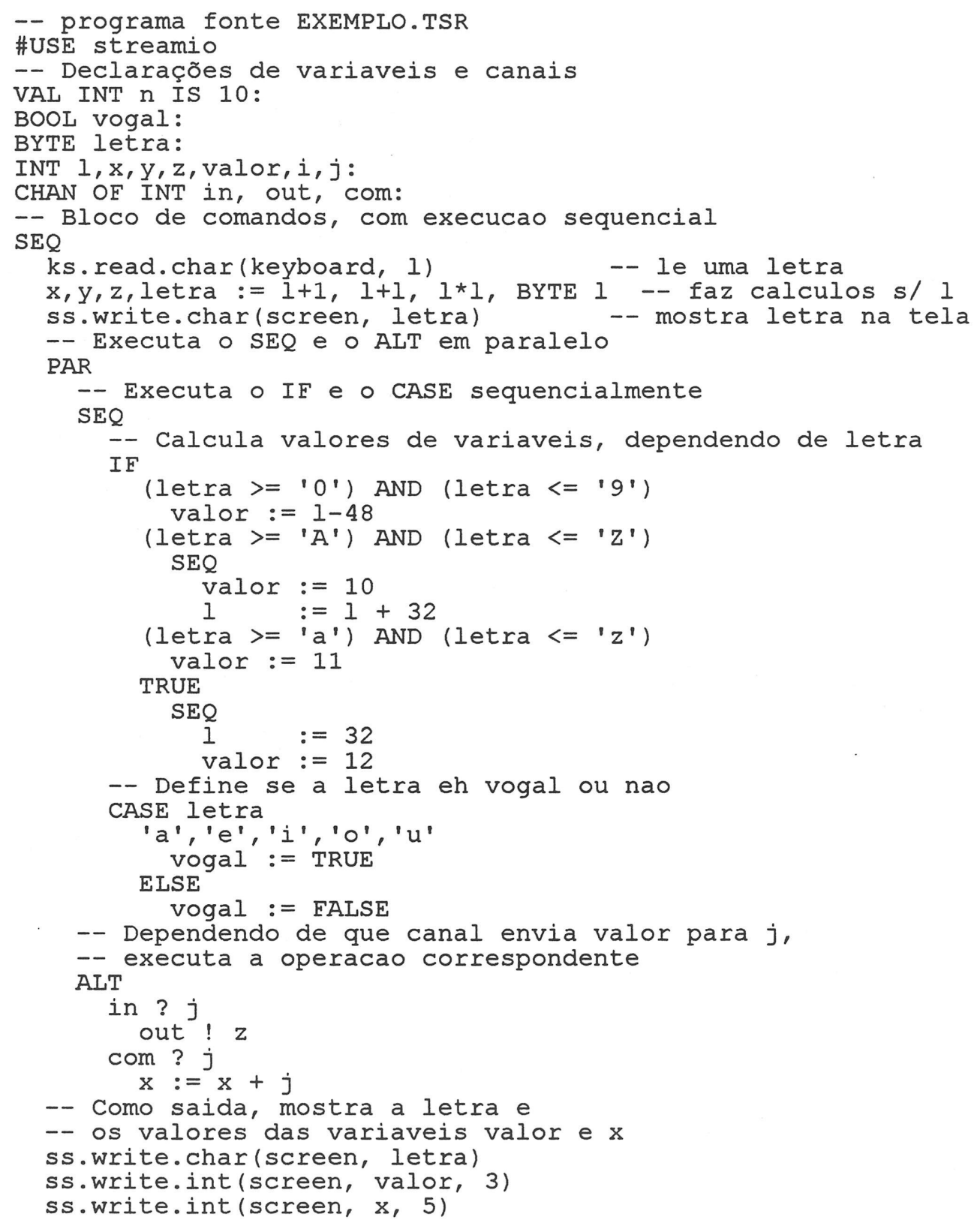

Figura 2.2. Listagem de Programa Occam 


\subsubsection{Caracterização de Unidade em Programas Occam}

Em Occam, um bloco pode ser definido como um procedimento ou uma função associando-se a ele um nome e a palavra-chave PROC ou FUNC, correspondente a procedimento ou a função, respectivamente. Uma definição de procedimento determina um nome para um processo. Tem sintaxe semelhante à da declaração de procedimento das linguagens estilo ALGOL.

Exemplo:

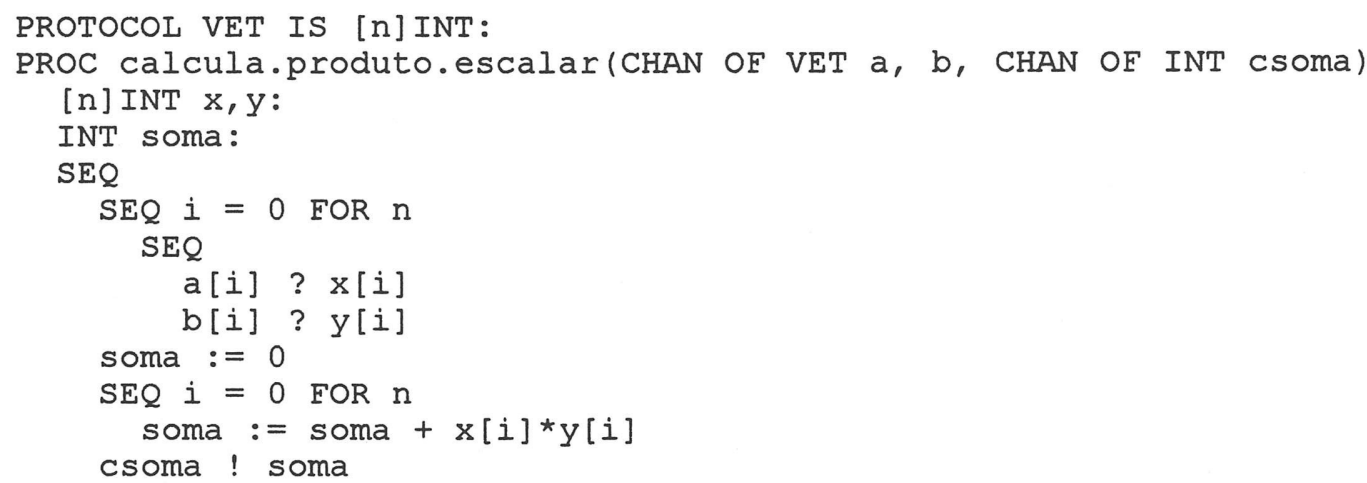

Uma função define um nome para um tipo especial de procedimento: o procedimento que devolve valores. Sua definição é semelhante à declaração de função das linguagens estilo ALGOL. Exemplo:

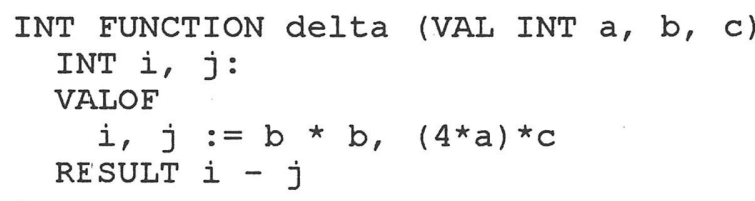

A unidade que é caracterizada pelo driver de controle (similar à função main da linguagem C [KER88]) é a seqüência de instruções após a parte de especificação. Assim, uma unidade de programa Occam é caracterizada

1 - pelas instruções que constituem o driver de controle do programa, de onde se iniciam as chamadas das demais unidades;

2 - pelas instruções que constituem o bloco de comandos de um procedimento ou de uma função. 


\subsubsection{Timers}

Occam permite o desenvolvimento de aplicações embutidas -- programas a serem executados em um computador que é só uma parte de uma máquina ou sistema -- que exigem interação com o mundo exterior, havendo necessidade de medir e registrar o passar do tempo. Para tanto, foi criada a declaração TIMER, destinada à leitura do tempo. Um timer é semelhante a um canal. Cada timer é associado a um relógio, que é como outro processo executando em paralelo com o programa. Cada relógio tem um período característico e incrementa sua leitura com a passagem de cada período [JON88]. Timers são lidos por entradas especiais, entradas de timer, semelhantes a entradas de canais. Exemplo:

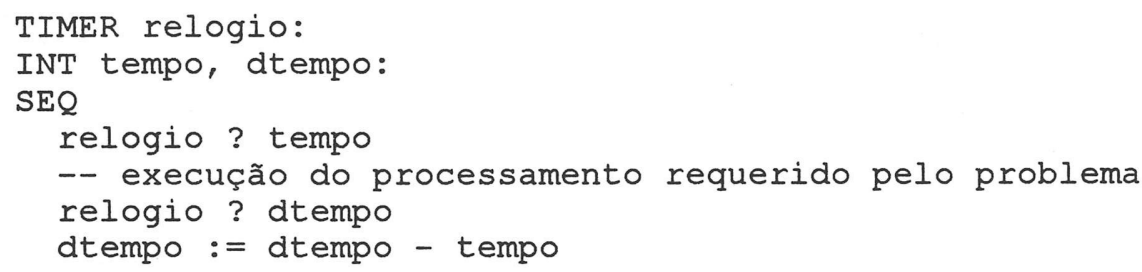

Occam permite atribuir processos a processadores. Se vários ramos de um processo devem ser executados por um processador simples, pode ocorrer que um deles tenha que esperar por outro, não devido à comunicação entre eles, mas porque cada um deles precisa do processador. Além disto, Occam permite o estabelecimento de prioridades entre processos, com a recomendação de seu uso só nas ocasiões estritamente necessárias [JON88].

\subsubsection{TDS - Um Ambiente para Desenvolvimento de Programas Occam}

O ambiente TDS (Transputer Development System) foi desenvolvido pela INMOS [INM90] para apoiar o desenvolvimento de programas Occam, compreendendo um editor, um compilador e um depurador. O TDS explora a concorrência de processos através do uso da linguagem Occam e possibilita o paralelismo de uma rede de transputers [INM90]. Um programa rodando num transputer é formalmente equivalente a um processo Occam, assim como uma rede de transputers pode ser 
descrita diretamente como um programa Occam. Cada processo pode ser visto como uma caixa preta com estado interno. Uma vez que um processo é composto de processos, alguns dos quais podem ser executados em paralelo, um processo pode ter uma quantidade de concorrência interna [INM90].

A interface do editor é baseada num conceito chamado folding [INM90]. Um elemento do ambiente é denominado fold. O editor tem funções para criar e para remover um fold, para se mover ao longo dos "folds" subordinados e superiores, além daquelas funções usuais para a tarefa de edição. Os folds, em geral, têm tamanho menor ou igual que o da tela. Dois atributos de interesse são o tipo do fold -- que expressa a natureza geral do conteúdo -- e o conteúdo do fold -- com apresentação detalhada do seu conteúdo.

Para compilar e ligar programas Occam, deve-se considerar se a sua execução será feita dentro do TDS, sobre uma rede de transputers ou de forma stand alone [INM90]. Programas Occam podem ser compilados, ligados e executados sem sair do ambiente de execução. Para tanto, o conjunto de utilitários do compilador deve ser carregado para o ambiente de desenvolvimento.

O depurador do TDS viabiliza um ambiente iterativo para depuração post-mortem de programas Occam rodando numa rede de transputers. Permite inspecionar os processos que estiveram rodando em cada transputer tanto no nível de instrução fonte Occam como no nível de instrução de transputer [INM90]. Pode também exibir conteúdo de variáveis, canais e outros itens de dados para qualquer processo rodando em qualquer transputer. Os mecanismos que o depurador usa também são descritos em [INM90]. Um programa Occam em execução pode parar por uma série de razões como, por exemplo, um processo STOP ou um processo que se comporta como STOP; um acesso a vetor fora do limite do intervalo; um erro aritmético de overflow, etc.

As facilidades oferecidas pelo depurador são divididas, basicamente, em dois conjuntos: o primeiro, relacionado com o código fonte Occam, permite ao usuário observar a rede de transputers num nível de linguagem de alto nível e, o segundo, permite observar a rede de transputers num nível de código de montagem [INM90]. Dado um endereço de instrução de transputer, o depurador pode localizar a linha fonte Occam correspondente, em particular, quando se trata da instrução executada pelo último transputer ou de qualquer processo executando em paralelo ou de um processo esperando por um timer ou de um processo esperando comunicação com uma ligação de transputer. 


\subsection{Considerações Finais}

Uma forma de obter desempenho em produtos de software é fazendo o uso de arquiteturas paralelas ou distribuídas. Para tanto, novas técnicas para desenvolvimento de software devem ser desenvolvidas. Linguagens de programação que exploram os recursos oferecidos pelo multiprocessamento devem oferecer suporte ao paralelismo, à comunicação e à sincronização além do que é oferecido por uma linguagem de programação seqüencial.

Várias linguagens de programação concorrente foram construídas: algumas, como evolução de linguagens seqüenciais já popularizadas, outras, desenvolvidas especificamente para programação concorrente.

A opção pelo estudo de Occam deveu-se à sua simplicidade e importância no campo da programação concorrente e, ainda, pela disponibilidade de um ambiente para desenvolvimento de programas Occam no ICMSC-USP.

Assim, no próximo capítulo será feita a apresentação da teoria de teste e a descrição de ferramentas de teste, sendo dedicada uma atenção especial ao teste de programas concorrentes. 


\section{Capítulo 3. Teste Estrutural de Programas Concorrentes}

O principal objetivo do teste de software é revelar a presença de defeitos ou erros no produto. Idealmente, o programa deveria ser exercitado por todos os possíveis valores do domínio de entrada; no entanto, é conhecido que, na prática, o teste exaustivo é impraticável devido a restrições de tempo e custo. Técnicas de teste têm sido desenvolvidas no sentido de conciliar tempo e custo de teste, tais como a técnica funcional, a técnica estrutural e a técnica baseada em erros. Na condução do teste estrutural, considera-se o fluxo de controle do programa e, em certos casos, o fluxo de dados. Critérios de teste têm sido elaborados fornecendo uma forma sistemática e rigorosa para selecionar um subconjunto do domínio de entrada -- um conjunto de casos de teste $\mathbf{T}$-- que seja efetivo em evidenciar a presença de erros e defeitos. Os critérios Potenciais Usos requerem, essencialmente, a extensão de caminhos livres de definição a partir de cada nó i contendo definições de variáveis, mesmo se não existir uso dessas variáveis através desses caminhos. Ressalte-se que a aplicação desses critérios sem o apoio de uma ferramenta de software é ineficaz, pois fica-se sujeito a erros na condução da própria atividade de teste, além da ineficiência pela aplicação manual [MAL91]. A POKE-TOOL foi desenvolvida para permitir a aplicação dos critérios Potenciais Usos. Por ser uma ferramenta multilinguagem, na atividade de configuração para uma nova linguagem, só algumas funções da ferramenta precisam ser modificadas.

Com relação ao teste de programas concorrentes, tem-se procurado aproveitar o máximo do que foi estabelecido para o teste de programas seqüenciais. Com essa abordagem, pode-se tratar as particularidades do teste de programas concorrentes com maior tranquilidade, bastando estudar os efeitos da comunicação, do paralelismo e do não determinismo devidos à existência de várias linhas de controle (threads) e à sincronização de processos. Um programa concorrente permite a introdução de novos tipos de defeitos tais como o impasse (deadlock) e a inanição (starvation).

É pequeno o número de trabalhos publicados que tratam do teste estrutural de programas concorrentes. Taylor [TAY83] propõe a construção de um grafo de sincronização, onde são mostrados os estados de concorrência e as transições entre estados de concorrência. Sobre o grafo de concorrência, Taylor et al. [TAY92] estabelecem uma hierarquia de critérios de teste para 
programas concorrentes e apresentam questões práticas para aplicação desses critérios. Yang e Chung [YAN92] apresentam a proposta de teste de análise de caminho, construindo grafos de computação e grafos de sincronização e retirando destes grafos as informações necessárias para o teste. Tai et al. [TAI91] definem um mecanismo de controle de execução projetado para sensibilizar uma seqüência de sincronização do programa por meio de execução determinística.

\subsection{Teste de Software}

Teste representa a última revisão de especificação, projeto e codificação. A atividade de teste é sujeita a limitações de ordem teórica -- problemas de indecidibilidade, por exemplo. Não existe um procedimento de teste de propósito geral que garante a ausência de erros. Mais concretamente, dados dois programas, ou dois caminhos, é indecidível se computam a mesma função; dado um caminho de um programa, é indecidível a sua executabilidade [MAL91].

O teste de programas tem se tornado um processo sofisticado com várias ferramentas e estratégias para construção e demonstração de confiança no programa testado. Para tanto, critérios de teste devem ser estabelecidos, tanto para a seleção dos casos de teste como para decidir quando parar a atividade de teste. A escolha de que critério aplicar vai depender do grau de confiança determinado para o teste. Um critério $\mathrm{C} 1$ inclui um critério $\mathrm{C} 2$ se qualquer conjunto de caminhos que satisfaz $\mathrm{C} 1$ também satisfaz $\mathrm{C} 2$. Um critério $\mathrm{C} 1$ inclui estritamente $\mathrm{C} 2$ se $\mathrm{C} 1$ inclui $\mathrm{C} 2$ mas $\mathrm{C} 2$ não inclui C1. Dois critérios C1 e C2 são incomparáveis quando nenhum deles inclui o outro. A notação $\mathrm{C} 1$ => 2 indica que $\mathrm{C} 1$ inclui $\mathrm{C} 2$.

Myers [MYE79] afirma que 1) teste é um procedimento onde se executa um programa com o intuito de achar erros; 2) um bom caso de teste é aquele com alta probabilidade de achar erros; 3 ) um teste bem sucedido é aquele que detecta um erro até então não descoberto.

Não há uma classificação de erros única. Uma classificação de erros interessante é apresentada por Beizer [BEI90]; nesta classificação tem-se

- erros de sistema.

- erros de requisitos ou funcionais e

- erros estruturais.

Os erros estruturais, na maioria dos casos, são erros de controle, mais afeitos à lógica do programa, 
ou erros computacionais, ligados, principalmente, ao comportamento dos dados.

Existem, basicamente, três técnicas de teste: a técnica funcional, a técnica estrutural e a técnica baseada em erros. A técnica funcional verifica as funções do sistema, sem se preocupar com detalhes de implementação. Exemplo de critérios da técnica funcional são os critérios de particionamento em classes de equivalência, de análise de valores-limite, grafo de causa-efeito, o teste de validação de dados e o critério error guessing. $O$ teste estrutural, em geral, considera a estrutura interna da implementação a partir de sua representação por um grafo de fluxo de controle. Exemplos de critérios de teste estrutural são o teste de caminhos básicos (de Mc Cabe), o teste de laços e o teste de fluxo de dados. No caso da técnica baseada em erros, o foco está nos erros que o programador ou o projetista pode cometer durante o processo de desenvolvimento e nas abordagens que podem ser usadas para detectar a sua ocorrência [HOW89]. A análise de mutantes, a semeadura de erros e a análise de perturbação são critérios típicos que se concentram em erros. Delamaro [DEL93] apresenta o teste baseado em erros de forma detalhada com uma ênfase maior para o critério análise de mutantes. $O$ presente trabalho ocupa-se principalmente da técnica de teste estrutural; por este motivo, esta técnica será apresentada com mais detalhes na próxima seção.

\subsection{O Teste Estrutural}

O teste estrutural é provavelmente a técnica mais usada. Baseia-se fundamentalmente na estrutura do software, na estrutura interna da implementação, em oposição à técnica funcional, que enfatiza as especificações.

Nenhuma das técnicas de teste pode ser aplicada isoladamente, porque cada uma delas é mais apropriada para descobrir determinado tipo de erro. Assim, a técnica estrutural é uma técnica complementar à técnica funcional [PRE92]. A popularidade da técnica estrutural deve-se à sua simplicidade e à disponibilidade de ferramentas de software para a sua aplicação. Os principais inconvenientes da técnica estrutural resultam de sua dependência da estrutura de controle do programa, que pode estar incorreta. A ferramenta básica para o teste estrutural é o grafo de fluxo de controle ou grafo de programa. 


\subsubsection{Análise de Fluxo de Controle}

Um programa pode ser decomposto em um conjunto de blocos de instruções tal que a execução da primeira instrução de um bloco acarreta a execução de todas as outras instruções do bloco na ordem dada e não existe desvio para o meio do bloco. A representação de um programa como um grafo de fluxo de controle (grafo de programa) consiste em estabelecer uma correspondência entre nós e blocos e em indicar possíveis fluxos de controle entre nós através de arcos. $\mathrm{O}$ grafo de fluxo de controle ( $\underline{\text { GFC }})$ é um grafo dirigido com um único nó de entrada e um único nó de saída.

A maior parte dos critérios da técnica estrutural de teste baseia-se no grafo de fluxo de controle para estabelecer os requisitos de teste. Um caminho é uma seqüência de nós onde existem arcos no grafo ligando esses nós. Um caminho simples é um caminho formado por nós distintos, exceto, possivelmente, o primeiro e o último. Se todos os nós do caminho são distintos tem-se um caminho livre de laço. Um caminho completo é um caminho que vai desde o nó de entrada até o nó de saída.

Os primeiros critérios de teste baseados no grafo de fluxo de controle a serem estabelecidos foram os critérios todos os nós, todos os ramos e todos os caminhos. O critério todos os nós exige que cada instrução do programa seja executada pelo menos uma vez; o critério todos os ramos, que cada transferência de controle entre blocos seja exercitada pelo menos uma vez e o critério todos os caminhos, que todos os caminhos do grafo sejam exercitados. É fácil verificar que o critério todos os ramos inclui estritamente o critério todos os nós e que o critério todos os caminhos inclui o critério todos os ramos.

Quando se deseja definir que critério aplicar no teste de um programa, deve-se considerar custo de aplicação e eficácia do critério. O critério todos os caminhos é um critério eficaz, mas de custo proibitivo. Por outro lado, os critérios todos os nós e todos os ramos não são critérios eficazes para certas classes de erros. Por isto, busca-se criar critérios de teste mais fortes que o critério todos os ramos, que não sejam tão dispendiosos quanto o critério todos os caminhos. Dentro do domínio da análise de fluxo de controle existem critérios definidos nesta faixa tais como o teste de caminho estruturado, o teste de caminho fronteira-interior e critérios baseados em LCSAJ (Linear Code Sequence And Jump). Os dois primeiros critérios são versões restritas do critério todos os caminhos; o número de casos de teste é limitado fazendo-se agrupamento de caminhos que diferem apenas no número de vezes que eles iteram laços (loops), testando poucos caminhos representantes dos grupos. 
Os critérios baseados em LCSAJ são definidos em termos do texto do programa; uma seqüência de instruções consecutivas no texto do programa, começando em um ponto de entrada ou depois de um desvio e terminando em um desvio ou em um ponto de saída [NTA88].

\subsubsection{Análise de Fluxo de Dados}

A introdução de critérios de teste baseados em fluxo de dados foi motivada pela observação que, em geral, o critério todos os caminhos é impraticável e que, mesmo para pequenos programas, os critérios que utilizam essencialmente informação de fluxo de controle, para caracterizar os requisitos de teste, não são eficazes para revelar a presença de erros computacionais. Os critérios baseados em fluxo de dados são mais adequados para revelar erros computacionais, pois requerem que associações (caminhos) sejam exercitadas entre pontos nos quais ocorrem definições de variáveis e pontos nos quais essas variáveis são utilizadas.

Os tipos de ocorrências de variáveis em um programa são definidos por um modelo de fluxo de dados que é usado nesta classe de critérios; uma ocorrência de variável caracteriza uma definição, um uso ou uma indefinição. A ocorrência de uma variável é um uso se a referência a esta variável não a estiver definindo; um uso computacional ( $\underline{\text { c-uso }}$ ) afeta diretamente a computação sendo realizada ou permite que o resultado de uma definição anterior possa ser observado; um uso predicativo (p-uso) afeta diretamente o fluxo de controle de um programa. Uma variável está indefinida quando, ou não se tem acesso ao seu valor, ou esta não tem localização na memória. Os tipos de ocorrência de variáveis são utilizados na caracterização de elementos requeridos por esta classe de critérios e exploram associações entre pontos em que variáveis são definidas e pontos em que essas variáveis são referenciadas.

Os tipos de ocorrência de variáveis são utilizados na caracterização de elementos de fluxo de execução de um programa. Um caminho $\left(\mathbf{i}, \mathbf{n}_{1}, \ldots, \mathbf{n}_{\mathbf{m}}, \mathbf{j}\right), \mathrm{m} \geq 0$, que não contenha definição da variável $\mathbf{x}$ nos nós $\mathbf{n}_{1}$, ..., $\mathbf{n}_{\mathrm{m}}$ é chamado caminho livre de definição com relação a $\mathbf{x}$ do nó $\mathbf{i}$ ao nó $\mathbf{j}$ e do nó i ao arco $\left(\mathbf{n}_{\mathrm{m}}, \mathbf{j}\right)$. Um nó i possui uma definição global de uma variável $\mathbf{x}$ se ocorre uma definição de $\mathbf{x}$ no nó $\mathbf{i}$ e existe um caminho livre de definição de i para algum nó ou para algum arco que contenha um uso da variável $\mathbf{x}$. 
Com o acréscimo de informações sobre definições, c-usos e p-usos de variáveis ao grafo de fluxo de controle, obtem-se o grafo def-uso [RAP85]. Para cada nó do grafo são definidos os seguintes conjuntos: $\underline{\operatorname{def}(\mathbf{i})}=\{$ variáveis com definição global no bloco i $\} ; \underline{\text { c-uso(i) }}=\{$ variáveis com c-uso global no bloco i $\}$ e p-uso(i,j) $=\{$ variáveis com p-uso no arco(i, $\mathbf{j})\}$. Utilizando estes conjuntos, outros dois conjuntos foram definidos: $\underline{\mathbf{d c u}(\mathbf{x}, \mathbf{i})}=\{$ nós $\mathbf{j}$ tal que $\mathbf{x} \in \mathrm{c}$-uso(j) e existe um

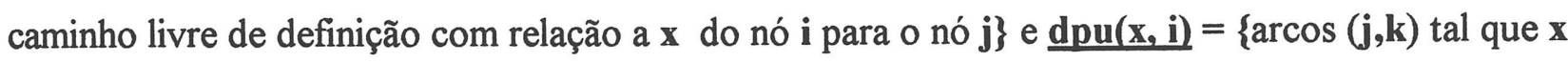
$\in$ p-uso(j,k) e existe um caminho livre de definição com relação a $\mathbf{x}$ do nó i para o $\operatorname{arco}(\mathbf{j}, \mathbf{k})\}$.

Um caminho $\left(\mathbf{n}_{1}, \ldots, \mathbf{n}_{\mathbf{j}}, \mathbf{n}_{\mathbf{k}}\right)$ é um du-caminho com relação à variável $x$ se $\mathbf{n}_{\mathbf{1}}$ tiver uma definição global de x e (1) ou $\mathbf{n}_{\mathbf{k}}$ tem um c-uso de x e $\left(\mathbf{n}_{1}, \ldots, \mathbf{n}_{\mathbf{j}}, \mathbf{n}_{\mathbf{k}}\right)$ é um caminho simples livre de definição com relação a $\mathbf{x}$; (2) ou $\left(\mathbf{n}_{\mathbf{j}}, \mathbf{n}_{\mathbf{k}}\right)$ tem um p-uso de x e $\left(\mathbf{n}_{\mathbf{1}}, \ldots, \mathbf{n}_{\mathbf{j}}, \mathbf{n}_{\mathbf{k}}\right)$ é um caminho livre de definição com relação a x e $\left(\mathbf{n}_{1}, \ldots, \mathbf{n}_{\mathbf{j}}\right)$ é um caminho livre de laço.

Uma associação definição-c-uso [FRA88] é uma tripla (i,j,x) onde i é um nó que contém uma definição global de $\mathrm{x}$ e j $\in$ dcu(x,i). Uma associação definição-p-uso é uma tripla (i,(j,k),x) onde i é um nó que contém uma definição global de $\mathrm{x}$ e $(\mathbf{j}, \mathbf{k}) \in \mathrm{dpu}(\mathrm{x}, \mathbf{i})$. Uma associação é uma associação definição-c-uso ou uma associação definição-p-uso ou um du-caminho.

Rapps e Weyuker [RAP85] introduziram uma família de critérios de fluxo de dados com os critérios centrais: todas-definições, todos-usos e todos-du-caminhos. $\mathrm{O}$ critério todas as definições requer que cada definição de variável seja exercitada pelo menos por um p-uso ou um c-uso. $\mathrm{O}$ critério todos-usos requer que todas as associações entre uma definição de uma variável e subseqüentes c-usos e p-usos desta variável sejam exercitadas pelos casos de teste. $\mathrm{O}$ critério todosdu-caminhos requer que toda associação entre uma definição de variável e subseqüentes c-usos e pusos desta variável seja exercitada por todos os possíveis du-caminhos com relação a esta definição de variável.

Na Figura 3.1. é apresentada uma hierarquia de critérios com critérios de fluxo de controle e de fluxo de dados. Observa-se, por exemplo, na Figura 3.1., que o critério todos os caminhos inclui o critério teste de caminho estruturado e que o critério todos-du-caminhos inclui o critério todos-usos [NTA88]. 


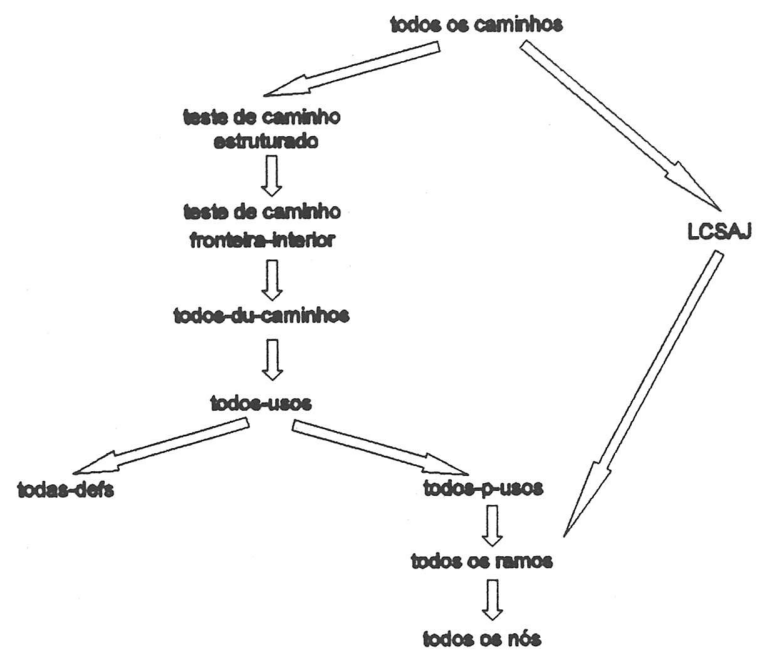

Figura 3.1. Hierarquia de Critérios de Teste

A complexidade de um critério $\mathrm{C}$ é definida como o número máximo de casos de teste requerido pelo critério no pior caso. A complexidade e a relação de inclusão refletem, em geral, as propriedades básicas que devem ser consideradas no processo de definição de um critério $\mathrm{C}$. $\mathrm{O}$ critério deve (1) incluir o critério todos os ramos; (2) incluir o critério todas-definições e (3) requerer um conjunto de casos de teste finito [MAL91].

\subsection{Critérios Potenciais Usos}

Maldonado [MAL88, MAL91] definiu uma família de critérios baseados em fluxo de dados, os Critérios Potenciais Usos, que requerem a execução de caminhos livres de definição a partir de cada nó i contendo definições de variáveis. No caso dos Critérios Potenciais Usos, os elementos são requeridos sem, necessariamente, ocorrer o uso explícito de uma variável; se um uso de uma definição pode ocorrer num dado nó i -- um potencial uso -- a associação entre a definição e o potencial uso deve ser examinada durante as atividades de teste [MAL91]. A seguir, são apresentadas algumas definições necessárias para a apresentação dos Critérios Potenciais Usos.

Um potencial-du-caminho com relação à variável x é um caminho livre de definição $\left(\mathrm{n}_{1}, \ldots, \mathrm{n}_{\mathrm{j}}\right.$, 
$n_{k}$ ) com relação a $x$ do nó $n_{1}$ para o nó $n_{k}$ e para o arco $\left(n_{j}, n_{k}\right)$, onde o caminho $\left(n_{1}, \ldots, n_{j}\right)$ é um caminho livre de laço e no nó $n_{1}$ ocorre uma definição de $x$. $O$ conjunto defg(i) é o conjunto das variáveis definidas no nó i. Uma associação potencial-definição-c-uso é uma tripla (i,j, $x), x \in \operatorname{defg(i)}$ e $\exists$ caminho livre de definição com relação a $x$ do nó i para o nó j. Uma associação potencialdefinição-p-uso é uma tripla (i, $(j, k), x), x \in \operatorname{defg}(i)$ e $\exists$ caminho livre de definição com relação a $x$ do nó i para o arco (j,k). Uma potencial-associação ou é uma associação-potencial-definição-c-uso ou é uma associação-potencial-definição-p-uso ou é um potencial-du-caminho. A extensão do grafo de fluxo de controle para definição dos critérios Potenciais Usos é o grafo def: aos nós do GFC são associados os conjuntos de variáveis definidas nos blocos correspondentes.

Para avaliar o conjunto de casos de teste, verificando se satisfazem os critérios Potenciais Usos para todo nó i tal que defg(i) $\neq \varnothing$ é associado um grafo denominado grafo(i), que contém todos os potenciais-du-caminhos com início no nó i. Um algoritmo para obtenção destes grafos pode ser visto em [MAL88]. Estes grafos e o conceito de arcos primitivos são a base para o modelo de descrição dos elementos requeridos. $\mathrm{Na}$ geração dos grafo(i) definições por referência são consideradas como definições em qualquer outro nó $\mathbf{j} \neq \mathbf{i}$, o que caracteriza um enfoque conservador. Um caminho completo $\pi$ cobre uma associação potencial-definição-c-uso (i, $\mathrm{j}, \mathrm{x}$ ) se incluir um caminho livre de definição com relação a x de i para j.

\section{Critérios Potenciais Usos Básicos}

Critério todos-potenciais-usos: Um conjunto de caminhos II satisfaz o critério todospotenciais-usos se, para todo nó i e para toda variável x para a qual existe uma definição em i, II inclui pelo menos um caminho livre de definição com relação a $\mathbf{x}$ do nó i para todo nó e para todo arco possível de ser alcançado a partir de i.

Critério todos-potenciais-usos/du: Um conjunto de caminhos II satisfaz o critério todospotenciais-usos/du se, para qualquer nó i e para qualquer variável x para a qual existe uma definição em i, II inclui pelo menos um potencial-du-caminho com relação a $\mathbf{x}$ do nó i para todo nó e para todo arco possível de ser alcançado a partir de $\mathbf{i}$.

Critério todos-potenciais-du-caminhos: Um conjunto de caminhos II satisfaz o critério todos-potenciais-du-caminhos se, para qualquer nó i e para qualquer variável x para a qual existe uma 
definição em i, II inclui todos os potenciais-du-caminhos com relação a x em relação ao nó i.

Na Figura 3.2. é ilustrada uma hierarquia de critérios de teste situando a Família de Critérios Potenciais Usos e a Família de Critérios de Fluxo de Dados com relação aos critérios todos os nós, todos os ramos e todos os caminhos, como pode ser vista em [MAL91].

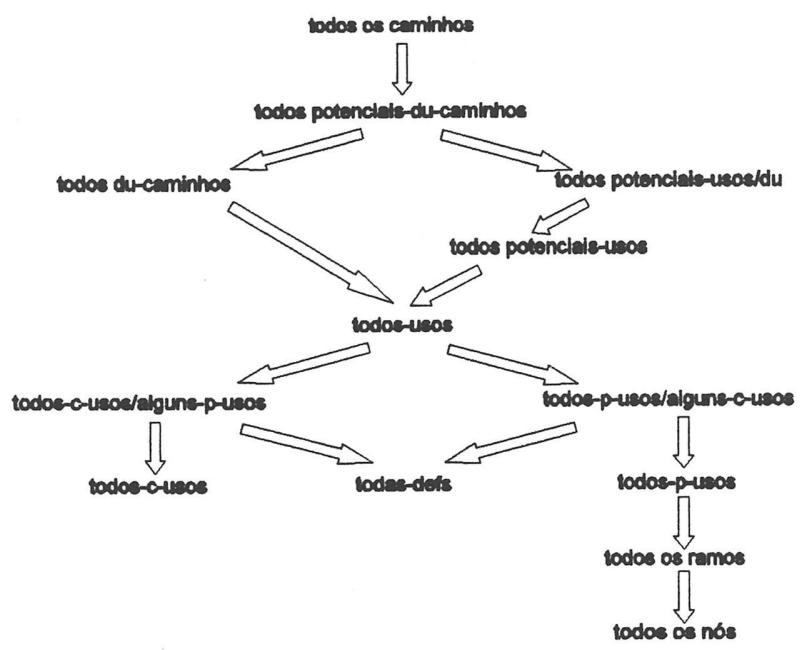

Figura 3.2. Ordem Parcial entre a Família de Critérios Potenciais Usos e a Família de Critérios de Fluxo de Dados

Um problema no teste estrutural é o número de caminhos não executáveis. Um caminho não executável é um caminho que não pode ser exercitado devido à contradição de alguns dos predicados de instruções condicionais [COW88]. A presença de caminhos não executáveis traz dificuldades ao teste estrutural porque, em geral, não se consegue determinar automaticamente se um caminho é executável ou não.

Frankl e Weyuker definiram o conceito de aplicabilidade: um critério de teste satisfaz a propriedade de aplicabilidade se para todo programa P existe um conjunto de casos de testes que é C-adequado para $\mathrm{P}$, isto é, o conjunto $I I$ de caminhos executados por $\mathrm{T}$ inclui todos os elementos exigidos. Com a introdução do conceito de aplicabilidade, definiram a Família de Critérios de Fluxo de Dados Executáveis [FRA88].

Um caminho completo executável é um caminho completo para o qual existe um conjunto 
não vazio de valores que pode ser atribuído às variáveis de entrada do programa que causa a execução desse caminho. Caso contrário, ele é dito não executável. Um caminho executável é subcaminho de um caminho completo executável. Uma potencial associação executável determina somente caminhos executáveis.

Para definição dos critérios Potenciais Usos Executáveis foram introduzidas modificações nos critérios Potenciais Usos Básicos, fazendo seleção de potenciais associações executáveis. Assim, para cada critério Potencial Uso básico C define-se um novo critério Potencial Uso executável C [MAL91].

Maldonado [MAL91] demonstra que os critérios Potenciais Usos satisfazem os requisitos básicos exigidos para um bom critério de teste, mesmo na presença de caminhos não executáveis e que nenhum critério baseado em fluxo de dados inclui os critérios Potenciais Usos. Deste modo, um dos objetivos da presente proposta é viabilizar o uso dos critérios Potenciais Usos no teste estrutural de programas concorrentes.

\subsection{Critérios de Teste para Programas Concorrentes}

Taylor e sua equipe [TAY92] têm trabalhado na definição de critérios de teste para programas concorrentes. Esses critérios são estabelecidos sobre o grafo de concorrência, que representa a estrutura de um programa concorrente.

\subsubsection{Grafo de Concorrência}

A seguir, são colocadas algumas definições importantes na apresentação da proposta. Estados de concorrência mostram a próxima atividade relacionada à sincronização nas tarefas do sistema; uma seqüência legal de estados apresenta uma história de atividades de sincronização. Uma história de concorrência é uma seqüência de estados de concorrência, começando no estado inicial, onde cada elemento $C_{k}$ da seqüência pertence a $\operatorname{succ}\left(C_{k-1}\right), k>1$. Uma história de concorrência própria é uma história de concorrência finita na qual todos os elementos são únicos, salvo, possivelmente, o último. A história de concorrência completa de um programa é o conjunto de todas as histórias de 
concorrência próprias. Pode ser representada como um grafo, o grafo de concorrência, onde cada nó representa um estado de concorrência e cada aresta representa a transição de um estado de concorrência para outro.

Em [TAY92], é dado como exemplo o programa do Jantar dos Filósofos, escrito em Ada. Para cinco filósofos são necessários 5 processos (tarefas) Garfo, 5 processos Filósofo e o processo principal. Para cada processo é construído um grafo de fluxo de processo. $O$ grafo de concorrência representa, então, as possíveis sincronizações na execução do programa. Maiores detalhes sobre a construção do grafo de concorrência podem ser encontrados em [TAY83]. No trabalho de Taylor et al. [TAY92], os autores apresentam a construção do grafo de concorrência do programa Jantar_dos_Filósofos, considerando apenas dois filósofos. Assim, são necessários 5 grafos de fluxo, que poderão ser reduzidos a 4, uma vez que o procedimento principal não realiza processamento aparente. Os 4 grafos de fluxo de processo estão representados na Figura 3.3. A partir desses grafos é construída a Tabela 3.1 que relaciona os estados de concorrência deduzidos. Feito isto, constrói-se o grafo de concorrência correspondente, que está apresentado na Figura 3.4. Examinando este grafo, pode-se detectar a presença de impasse quando cada filósofo pega o garfo esquerdo, bloqueando a chamada de entrada para pegar o garfo direito.

Garfo 1

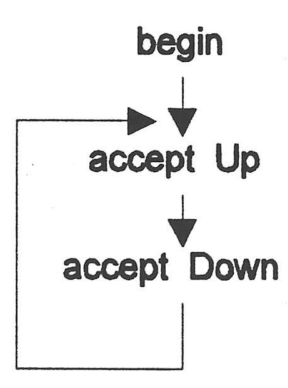

Garfo 2

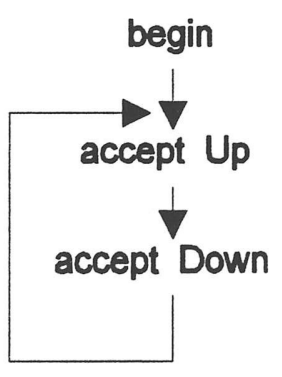

Filósofo 1

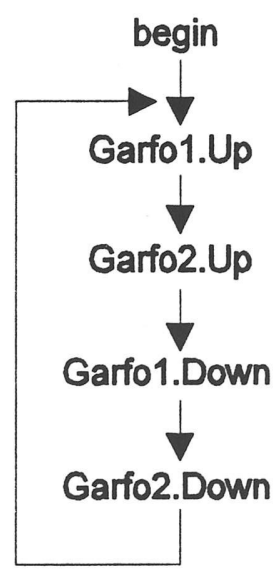

Filósofo 2

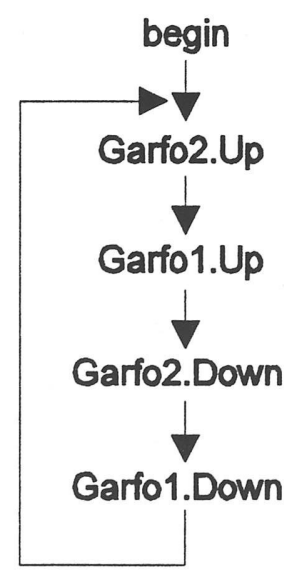

Figura 3.3. Grafos de Sincronização do Programa Jantar_dos_Filósofos 


\begin{tabular}{||c|c|c|c|c||}
\hline \hline $\begin{array}{c}\text { Estado de } \\
\begin{array}{c}\text { Concor- } \\
\text { rência }\end{array}\end{array}$ & Garfo1 & Garfo2 & Filósofo1 & Filósofo2 \\
\hline \hline & & & & \\
\hline 1 & accept Up & accept Up & Garfo1.Up & Garfo2.Up \\
\hline 2 & accept Down & accept Up & Garfo2.Up & Garfo2.Up \\
\hline 3 & accept Down & accept Down & Garfo1.Down & Garfo2.Up \\
\hline 4 & accept Up & accept Down & Garfo2.Down & Garfo2.Up \\
\hline 5 & accept Down & accept Down & Garfo2.Up & Garfo1.Up \\
\hline 6 & accept Up & accept Down & Garfo1.Up & Garfo1.Up \\
\hline 7 & accept Down & accept Down & Garfo1.Up & Garfo2.Down \\
\hline 8 & accept Down & accept Up & Garfo1.Up & Garfo1.Down \\
\hline \hline
\end{tabular}

Tabela 3.1. Estados de Concorrência para o Problema Jantar_dos_Filósofos

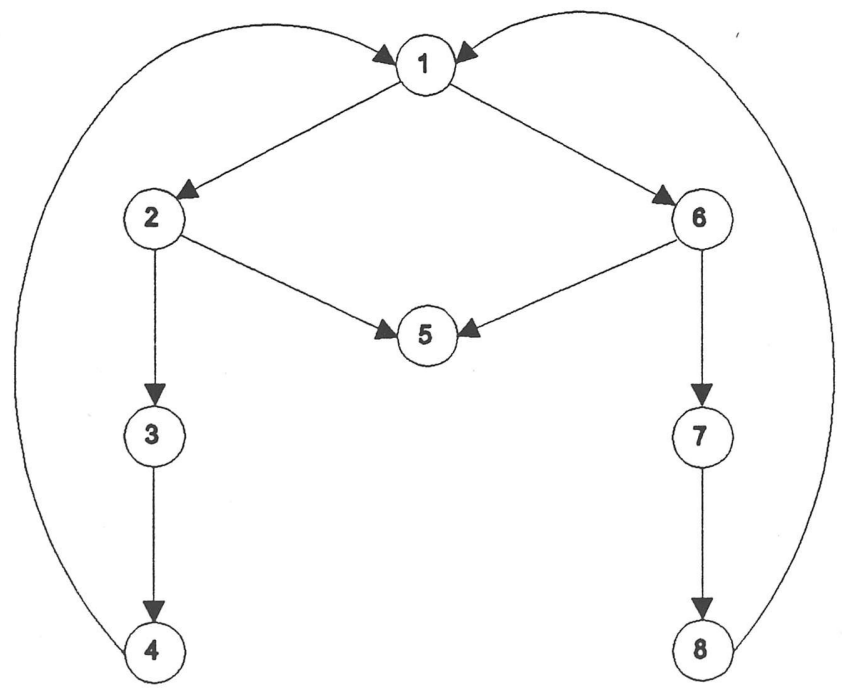

Figura 3.4. Grafo de Concorrência para o Programa Jantar_dos_Filósofos 
O tamanho do grafo de concorrência cresce geometricamente com o número de processos, exigindo muito tempo para a sua construção. Para reduzir o tamanho do grafo de concorrência, procura-se otimizar os grafos de fluxo de tarefa, representando a sincronização como aresta simples e ignorando instruções que não afetem a ordem das interações de processos.

\subsubsection{Critérios de Cobertura de Programas Concorrentes}

Seja $\mathbf{S}$ um programa e $\mathbf{P}$ um conjunto de caminhos determinados pelo critério $\mathbf{C}$ no grafo de $\mathbf{S}$. O par (S,P) satisfaz o critério $\mathbf{C}$ se e só se todos os caminhos de $\mathbf{P}$ são sensibilizados. A seguir, são apresentados os 5 critérios de cobertura contidos em [TAY92] para teste de programas concorrentes.

Critério C1: todos-caminhos-de-concorrência

$\mathbf{P}=$ Conjunto de todos os caminhos através do grafo de concorrência.

Critério C2: todas-histórias-próprias-de-concorrência

$\mathbf{P}=$ História de concorrência completa.

Critério C3: todas-arestas-entre-estados-de-concorrência

Qualquer aresta do grafo de concorrência pertence a algum caminho em $\mathbf{P}$.

Critério C4: todos-estados-de-concorrência

Qualquer nó do grafo de concorrência pertence a algum caminho em $\mathbf{P}$.

Critério C5: todos-possiveis-rendezvous

Qualquer nó do grafo de concorrência que envolve comunicação com outra tarefa pertence a algum caminho em $\mathbf{P}$.

Os cinco critérios listados acima são organizados na seguinte hierarquia (para maiores detalhes, veja a demonstração de Taylor [TAY92]):

$$
\mathrm{C} 1=>\mathrm{C} 2 \Rightarrow \mathrm{C} 3=>\mathrm{C} 4=>\mathrm{C} 5
$$

\subsubsection{Uso dos Critérios de Cobertura}

Para determinar a satisfação de um critério de teste, deve-se escolher um conjunto de casos de teste adequado. Para se ter controle sobre a execução dos casos de teste, uma alternativa é incorporar ao 
programa um processo monitor que gravará as transições de progressão de estado. A inclusão do processo monitor irá provocar sobrecarga (overhead), que é motivada pelo efeito de prova [GAI86].

No grafo de concorrência, podem ser detectados estados que requerem um estudo mais cuidadoso -- aqueles estados que exigem um maior nível de correção. Pode-se aplicar aos caminhos que atingem estes estados uma cobertura mais forte, aplicando aos restantes um critério de cobertura mais fraco. Histórias de concorrência oferecem um bom guia para o desenvolvimento de casos de teste. Para melhorar a praticidade da técnica, é necessário introduzir um escalonador controlável pelo usuário com a finalidade de facilitar a reprodução do comportamento [YAN92].

\subsection{Grafo de Processo e Grafo de Sincronização}

Yang e Chung [YAN92] apresentam uma proposta para teste de programas concorrentes modelando 1) o comportamento de execução de um programa com a representação dos caminhos concorrentes e 2) as sincronizações como rotas concorrentes percorrendo o caminho concorrente usado na execução. Deste modo, o processo de teste verifica a correção de cada rota concorrente ao longo de todos os caminhos concorrentes de um grafo de programa.

\subsubsection{Modelagem de Programas Concorrentes}

Para sensibilização de caminhos, uma grande dificuldade é a garantia de repetição do comportamento [MCD89, KOR92, TAI91, YAN92]. Yang e Chung propõem uma estratégia de teste que leva em consideração este fato [YAN92]. Os autores vêem a execução de um programa concorrente como o percurso dos caminhos concorrentes desse programa obedecendo às sincronizações possíveis para esses caminhos, modeladas por meio de rotas de sincronização concorrentes.

O comportamento de execução de um programa concorrente consiste 1) da saída produzida por cada processo; 2) do caminho de execução de cada processo; 3) da seqüência de sincronização de cada processo e 4) da troca de dados em cada sincronização. Todas as ações interprocesso sensíveis à ordem são controladas direta ou indiretamente pela sincronização e assim, a correção dessas ações é deduzida do comportamento da sincronização. 
A modelagem da execução de um programa concorrente implica em modelar o comportamento de um processo do programa. Cada processo possui o seu próprio fluxo de execução e pode comunicar-se com outros processos em execução; assim, o comportamento de execução de cada um dos processos é determinado pela entrada, pelas seqüências de instruções e pelas seqüências de sincronização dos processos. São propostos dois tipos de grafos para modelar o comportamento de execução dos processos: o grafo de processo, que representa a visão sintática do comportamento de execução do processo, e o grafo de sincronização, representando a visão de tempo de execução.

Seja $\mathbf{S}$ um programa concorrente com os processos $T_{1}, T_{2}, \ldots, T_{n}$. Para o processo $T_{i}$, constrói-se o grafo de processo $\mathrm{G}_{\mathrm{i}}=\left(\mathrm{N}_{\mathrm{i}}, \mathrm{A}_{\mathrm{i}}, \mathrm{s}_{\mathrm{i}}\right)$. Em cada $\mathrm{G}_{\mathrm{i}}, \mathrm{i}=1, \ldots, \mathrm{n}$, define-se, em cada execução de $\mathrm{S}$, um caminho $\mathbf{p}_{\mathrm{i}}$ À tupla de caminhos $\mathrm{P}=\left(\mathbf{p}_{1}, \ldots, \mathbf{p}_{\mathbf{n}}\right)$ dá-se o nome de caminho concorrente ou c-caminho. À união dos $\mathbf{n} \mathrm{G}_{\mathrm{i}}$ dá-se o nome de grafo de programa concorrente.

Para modelar a sincronização dos processos de um programa concorrente, constrói-se o grafo de sincronização para cada processo, constituído de um nó inicial, nós intermediários e um nó final. Os nós intermediários do grafo de sincronização representam os pontos de sincronização requeridos pelo processo. Os pontos de sincronização múltipla são modelados em dois estágios:

1_- estágio: seleção da sincronização que será efetuada;

2. estágio: disparo da sincronização selecionada.

Uma execução de S sensibilizará uma rota de sincronização (ou simplesmente, rota) no grafo de sincronização de processo. A união dos grafos de sincronização é denominada grafo de sincronização de programa. Na execução de $\mathbf{S}$, cada processo percorrerá uma rota no seu grafo de sincronização. A um conjunto de rotas que são percorridas concorrentemente, dá-se o nome de rota

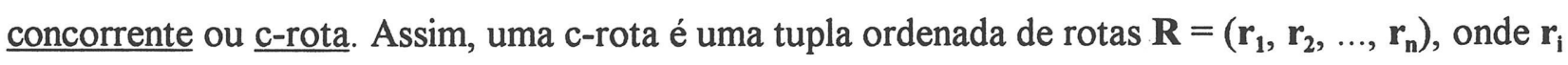
é a rota de sincronização do processo $\mathbf{T}_{\mathbf{i}}$.

Um c-caminho é executável quando há pelo menos uma entrada $\mathbf{X}$ que leva cada tarefa $\mathbf{T}_{\mathbf{i}}$ a percorrer $\mathbf{p}_{\mathbf{i}}$ na execução de $\mathbf{S}$ com $\mathbf{X}$. Caso contrário, o c-caminho é dito não executável. Um ccaminho pode ser não executável devido à dependência de dados ou à dependência de sincronização. Uma c-rota $\mathbf{R}$ é executável quando há pelo menos uma entrada $\mathbf{X}$ que leva cada tarefa $\mathbf{T}_{\mathbf{i}}$ a percorrer $\mathbf{r}_{\mathbf{i}}$ na execução de $\mathbf{S}$ com $\mathbf{X}$. Caso contrário, a c-rota é dita não executável.

A Figura 3.5, mostra uma parte de implementação de um programa Ada -- o Programa 
No grafo de sincronização podem ser observadas quatro c-rotas relacionadas com o ccaminho p:

$$
\begin{aligned}
& \mathbf{r}_{1}=((1,2,3),(1,2,3,4),(1,2,3,4,3,5,6)) \\
& \mathbf{r}_{2}=((1,2,3),(1,2,3,4),(1,2,3,5,3,4,6)) \\
& \mathbf{r}_{3}=((1,2,3),(1,2,3,4),(1,2,3,4,3,4,6)) \\
& \mathbf{r}_{4}=((1,2,3),(1,2,3,4),(1,2,3,5,3,5,6))
\end{aligned}
$$

As c-rotas $\mathbf{r}_{1}$ e $\mathbf{r}_{2}$ são c-rotas executáveis e as c-rotas $\mathbf{r}_{3}$ e $\mathbf{r}_{4}$ são c-rotas não executáveis.

O modelo de caminho concorrente apresentado por Yang e Chung [YAN92] estabelece uma relação muito forte entre c-caminhos e c-rotas, deduzindo-se daí o seguinte teorema:

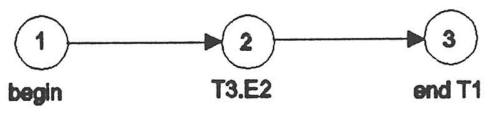

Grafo de Sincronizaçăo de T1

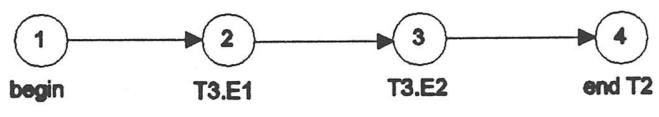

Grafo de sincronizaça de T2

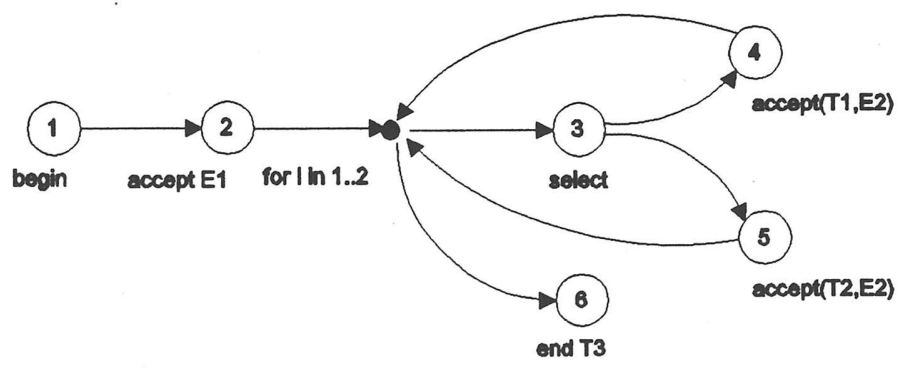

Grafo de Sincronizaçăo de T3

Figura 3.7. Grafo de Sincronização do Programa Exemplo1

Teorema 1: "Se duas execuções de um programa concorrente com a mesma entrada percorrem a mesma c-rota, então estas duas execuções devem produzir o mesmo comportamento" [YAN92].

Do teorema é deduzido o seguinte corolário: 
Corolário: "Em duas execuções de um programa concorrente com a mesma entrada, se as duas execuções percorrem a mesma c-rota, então elas devem percorrer o mesmo c-caminho" [YAN92].

\subsubsection{O Teste de Análise de Caminho}

O terno (X, $\mathbf{P}, \mathbf{R}), \mathbf{X}$ entrada, $\mathbf{P}$ c-caminho, $\mathbf{R}$ c-rota, representa uma computação de um programa concorrente $\mathbf{S}$. Uma c-rota $\mathbf{R}$ define qual c-caminho será percorrido. Assim, o par $(\mathbf{X}, \mathbf{R})$ é suficiente para identificar a computação a ser testada e será denominado teste definido. Daí, deduz-se um outro teorema importante:

Teorema 2: "Os c-caminhos particionam os testes definidos em conjuntos disjuntos" [YAN92].

Seja $\mathbf{S}$ um programa e $\mathbf{P}$ um conjunto de caminhos no grafo de $\mathbf{S}$. O programa $\mathbf{S}$ é composto de um conjunto de c-caminhos e cada c-caminho define um conjunto de c-rotas ao longo dele. Na execução de $\mathbf{S}$ com uma entrada $\mathbf{X}$, cada processo percorrerá seu caminho no grafo de processo, como percorrerá também uma rota no correspondente grafo de sincronização. É importante frisar que a entrada $\mathbf{X}$, sozinha, não é capaz de definir o comportamento de execução do programa $\mathbf{S}$. Para definir o comportamento de execução de $\mathbf{S}$, procura-se fornecer a entrada $\mathbf{X}$, o c-caminho $\mathbf{P}$ e a c-rota $\mathbf{R}$. Sendo assim, define-se o terno $(\mathbf{X}, \mathbf{P}, \mathbf{R})$ como sendo uma computação de $\mathbf{S}$. Percebe-se, facilmente, que alguns ternos $(\mathbf{X}, \mathbf{P}, \mathbf{R})$ representarão computações não executáveis. Para determinar a executabilidade de uma computação $(\mathbf{X}, \mathbf{P}, \mathbf{R})$, há necessidade da existência de um mecanismo para verificar as possíveis condições de execução de $\mathbf{S}$. A presença de um Mecanismo de Controle de Execução ( $\underline{\mathrm{MCE}}$ ) força a execução de $\mathbf{S}$ a percorrer $\mathbf{P}$ e $\mathbf{R}$ com entrada $\mathbf{X}$. A ocorrência de bloqueamento de algum processo indica computação não executável. Se os processos forem bloqueados devido à espera mútua, então ocorre impasse; senão, a computação $(\mathbf{X}, \mathbf{P}, \mathbf{R})$ é verdadeiramente não executável.

Para definir a estratégia de teste de análise de caminho, a interpretação deve partir de dois pontos de vista: 1) visão de partição da função e 2) visão de partição do espaço de entrada. Na visão de partição da função, um programa é um conjunto de funções. Cada uma dessas funções é implementada por um caminho do programa. Então, para demonstrar a correção do programa, é necessário que se demonstre, pelo menos, a correção de cada função.Na visão de partição do espaço 

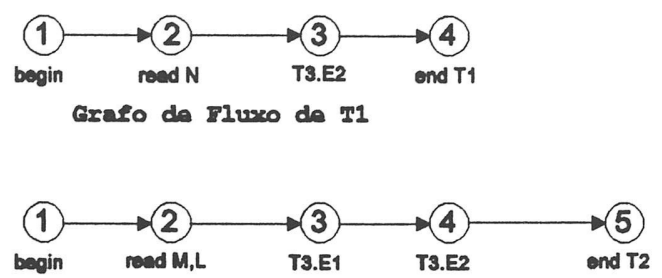

Grafo de Fluse de T2

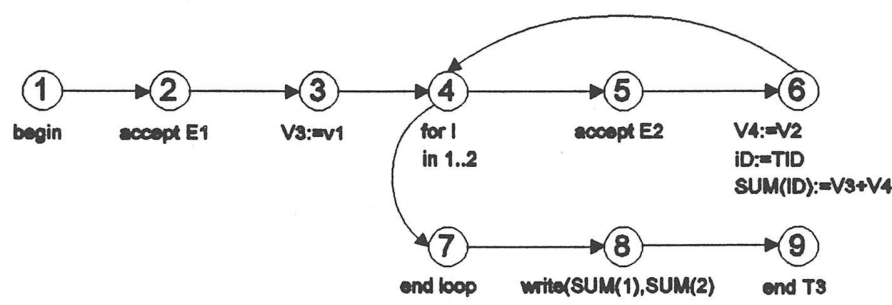

Grafo do Flureo do 53

Figura 3.9. Grafo de Fluxo do Programa Exemplo2

1 - Definição dos c-caminhos

a) Cada processo tem somente um caminho executável.

b) Só um c-caminho será composto:

$$
\mathbf{p}=((1,2,3,4),(1,2,3,4,5),(1,2,3,4,5,6,4,5,6,4,7,8,9))
$$

2 - Geração dos testes definidos

a) As duas c-rotas executáveis são:

$$
\begin{aligned}
& \mathbf{r}_{1}=((1,2,3),(1,2,3,4),(1,2,3,4,3,5,6)) \\
& \mathbf{r}_{2}=((1,2,3),(1,2,3,4),(1,2,3,5,3,4,6))
\end{aligned}
$$

b) Na geração das entradas, trabalhar com entradas do tipo

$$
(\mathbf{N}, \mathbf{M}, \mathbf{L}), \mathbf{N} \neq \mathbf{M} \text {. }
$$

3 - Execução do programa

a) $\mathrm{Na}$ execução sem controle,

a.1) a execução do teste definido ((N, $\left.\mathbf{M}, \mathbf{L}), \mathbf{r}_{1}\right)$

resulta na saída $(\mathbf{L}+\mathbf{N}, \mathbf{L}+\mathbf{M})$;

a.2) a execução do teste definido ((N, $\left.\mathbf{M}, \mathbf{L}), \mathbf{r}_{2}\right)$

resulta na saída $(\mathbf{L}+\mathbf{N}, \mathbf{L}+\mathbf{M})$ também. 


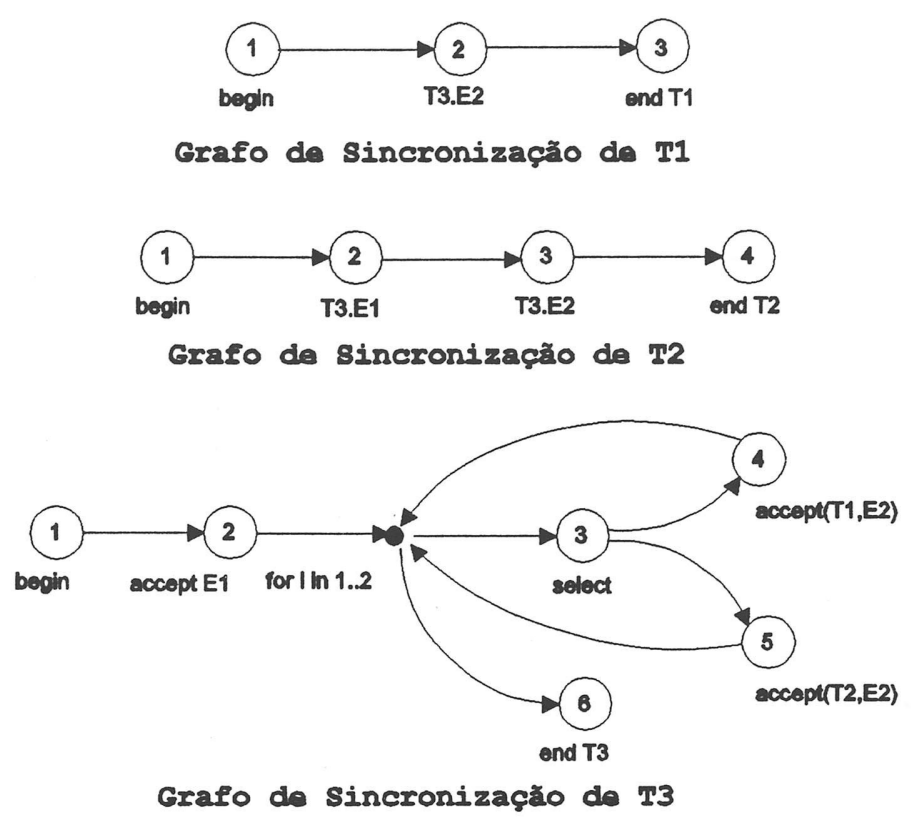

Figura 3.10. Grafo de Sincronização do Programa Exemplo2

Vê-se que o programa Exemplo2 não está em conformidade com a especificação (o programa Exemplo1, apresentado anteriormente, foi construído conforme a especificação).

b) Passando para a execução controlada descobre-se que o parâmetro TID e a variável ID são desnecessários. Basta usar o contador I no lugar de ID em SUM(ID).

Outro exemplo, mais sofisticado, de aplicação da estratégia pode ser visto em [YAN92].

Para usar a estratégia, deve-se colocar algumas questões. Para a seleção de c-caminhos, há a necessidade da definição de critérios de cobertura. Definida uma hierarquia de critérios de cobertura, será necessário desenvolver técnicas para geração de c-caminhos que satisfaçam os critérios de teste desejados. Na definição dos critérios de cobertura, devem ser considerados os pontos de vista local (do processo) e de integração do programa. Do ponto de vista local, não há muito a fazer; basta usar os critérios de teste definidos para programas seqüenciais. Do ponto de vista de integração do programa, devem ser observadas especialmente as condições de sincronização dos processos concorrentes. É importante notar a falta de critérios práticos para programas integrados. Harrold e Soffa [HAR91] apresentam sugestões para o teste de integração de programas seqüenciais, que poderão ser usadas para a integração de programas concorrentes. 
Na geração dos testes definidos, a geração das c-rotas requer técnicas de análise estática para analisar as c-rotas executáveis para cada c-caminho. A geração das entradas requer uso de um avaliador simbólico para computar o domínio das entradas para cada c-caminho [YAN92, YOU89, LUT90]. A seleção dos testes definidos deve ser guiada pela característica de cada tipo de erro.

A questão da execução de teste é projetar um Mecanismo de Controle de Execução (MCE) de teste para rastrear e sensibilizar uma c-rota. Características desejadas de um MCE são reprodutibilidade e simplicidade. Reprodutibilidade, para se fazer análise da cobertura do teste e localização dos erros; simplicidade, para minimizar os esforços de teste e interferência [YAN92].

\subsubsection{Teste de Execução Determinística}

Semelhantemente ao trabalho de Yang e Chung em [YAN92], Tai et al. [TAI91] desenvolveram estudos com relação à execução determinística de programas concorrentes. Observaram que uma execução correta de um programa concorrente com uma entrada não garante a correção do programa com aquela entrada e, também, que a execução de um programa com uma dada entrada pode gerar comportamentos diferentes em dois momentos distintos, sendo a sincronização a responsável por este fato.

Uma das principais preocupações no teste de programas concorrentes é com a sincronização. Para estudar o problema, os autores definem o que é uma seqüência de eventos de sincronização ou, simplesmente, seqüência de sincronização. Para que $\mathbf{X}$ faça uso da execução determinística com sucesso, três questões devem ser resolvidas: 1) como definir o formato de uma seqüência de sincronização, 2) como coletar a seqüência de sincronização de uma execução do programa e 3) como repetir a seqüência de sincronização de uma execução anterior [TAI91, CAR91]. Estando resolvidas estas questões, fica mais fácil desenvolver ferramentas apropriadas.

O programa $\mathbf{P}$ original é ligeiramente modificado para aceitar a sensibilização da seqüência de sincronização escolhida, permitindo que se observe o resultado obtido executando $\mathbf{P}$ com entrada $\mathbf{X}$ e seqüência de sincronização $\mathbf{S}$. A modificação a ser feita no programa vai depender da operação a ser executada. Uma preocupação que não pode ser desprezada é o efeito de prova gerado pela introdução de monitoração na execução do programa. Uma execução do programa $\mathbf{P}$ com entrada $\mathbf{X}$ não garante a correção daquela execução. Por isso, deve-se usar uma técnica de múltiplas 
execuções, para poder exercitar as várias seqüências de sincronização que podem ser formadas com uma mesma entrada na execução de $\mathbf{P}$.

A abordagem de teste de execução determinística [TAI91] consiste em:

1) Selecionar um conjunto de testes, cada um da forma (X,S), $\mathbf{X}$ entrada do programa, $\mathbf{S}$ seqüência de sincronização;

2) Para cada teste $(\mathbf{X}, \mathbf{S})$ selecionado,

2.1) determinar se $\mathbf{S}$ é ou não executável para $\mathbf{P} \operatorname{com} \mathbf{X}$, tentando sensibilizar a execução de $\mathbf{P}$ com $\mathbf{X}$ conforme $\mathbf{S}$;

2.2) se ocorrer a execução determinística, examinar o resultado desta execução.

A técnica de execução determinística traz duas vantagens sobre o teste de execução múltipla: 1) permite a escolha das seqüências de sincronização e 2) após a modificação de $\mathbf{P}, \mathbf{P}$ poderá ser reexecutado com as entradas e seqüências de sincronização de execuções anteriores.

\subsection{Ferramentas de Teste}

Com a crescente complexidade do software, qualquer estratégia de teste sem suporte de ferramenta tende a ser maçante e propensa a erros. Para aplicação efetiva de um critério de teste, faz-se necessário o uso de ferramentas automatizadas que apoiem a aplicação daquele critério; de outro modo, a aplicação do critério será limitada a programas muito simples. As ferramentas de teste estrutural de software fazem, em quase sua totalidade, análise de cobertura segundo algum critério de teste. Chaim [CHA91] e Leitão Jr. [LEI92] apresentam ferramentas de teste existentes para o teste estrutural de programas seqüenciais, sendo, geralmente, voltadas para uma única linguagem. Observam também que não existem ferramentas comerciais que apoiem o teste estrutural baseado em fluxo de dados. As poucas ferramentas para teste de programas concorrentes estão ainda em estágio de protótipo.

Chaim [CHA91] apresenta a arquitetura e os principais aspectos funcionais e de implementação da POKE-TOOL, uma ferramenta para teste de programas seqüenciais que apoia os critérios Potenciais Usos. Nas próximas seções serão feitos comentários sobre ferramentas para teste de programas concorrentes e a descrição da ferramenta de teste POKE-TOOL. 


\subsection{Ferramentas para Teste de Programas Concorrentes}

TDCAda [TAI91, LUT90] é uma das poucas ferramentas para teste de programas concorrentes descritas na literatura. TDCAda suporta depuração de execução determinística e uma nova abordagem de teste chamada teste de execução determinística. TDCAda foi implementada em C usando as ferramentas LEX e YACC do UNIX. Devido ao uso da abordagem baseada em linguagem, este ambiente pode ser executado em qualquer sistema computacional que tenha compiladores $\mathrm{C} \mathrm{e}$ Ada.

Como se pode ver em [TAI91, LUT90], TDCAda é composto por três ferramentas: uma ferramenta de coleta de seqüências de sincronização, uma ferramenta de repetição da execução e uma ferramenta de análise da executabilidade do teste. A ferramenta de coleta transforma o programa $\mathrm{P}$ num programa $\mathrm{P}^{\prime}$ ligeiramente diferente, fazendo coleta das seqüências de sincronização de $\mathrm{P}$ e simplificação da sincronização para uso na reexecução do programa. A ferramenta de repetição da execução transforma P num programa P" -- ligeiramente diferente -- tal que qualquer execução de $\mathrm{P}^{\prime \prime}$ com $(X, S)$ produza o mesmo resultado que P. A ferramenta de executabilidade do teste transforma $P$ num programa $P^{*}$-- ligeiramente diferente -- para determinar se a sincronização $S$ é executável e, sendo executável, se produz o mesmo resultado que P. É bom observar que o problema de determinar a executabilidade de uma seqüência de sincronização é, em geral, indecidível.

O trabalho de Yang e Chung [YAN92] assinala que, do ponto de vista de teste, uma grande preocupação é a correção de uma execução. Mas a correção de um programa é dependente não só do resultado da computação, mas também das condições de sincronização. Todas as ações intertarefas sensiveis à ordem seriam controladas direta ou indiretamente pela sincronização e, assim, a correção dessas ações seria deduzida do comportamento da sincronização [CAR91, KOR92, TAI91, YAN92]. Para esse fim, os autores estão implementando um ambiente de teste para suportar na prática as idéias por eles descritas em seu trabalho. $\mathrm{O}$ ambiente inclui 1) ferramenta para gerar c-caminhos de acordo com critérios de cobertura como cobertura de ramos e cobertura da sincronização; 2) analisador estático para analisar as c-rotas ao longo dos c-caminhos gerados e 3) mecanismo de controle de execução para controlar e monitorar a c-rota selecionada na execução.

Taylor et al. [TAY92] observam que ferramentas de teste e análise devem ser construídas 
de forma bem pensada, para que se possa evitar um excesso de recomputação quando tiver que se gerar uma base de informação de análise estática. Comentam que ferramentas de teste deveriam ser compostas de pequenos componentes modulares e que ferramentas apropriadas para apoiar seus métodos/critérios seriam, principalmente, 1) analisador estático de concorrência; 2) estimador de concorrência e 3) escalonador programável em tempo de execução. Citam o ambiente CATS como um exemplo de um conjunto de ferramentas desenvolvidas para automatizar o processo de construção do grafo de concorrência e as histórias a ele relacionadas, descritos com maior nível de detalhe em [YOU89].

\subsection{A Ferramenta POKE-TOOL}

A ferramenta POKE-TOOL foi desenvolvida pelo grupo de teste da Faculdade de Engenharia Elétrica da UNICAMP para permitir a aplicação dos Critérios Potenciais Usos [CHA91, MAL91]. Um dos requisitos do projeto da ferramenta é que ela deveria se prestar ao teste de programas escritos em várias linguagens, o que levou à distinção entre as funções dependentes do código fonte das demais funções, permitindo que essas tarefas fossem isoladas em módulos distintos daquelas que realizam tarefas independentes da linguagem. Este fato viabiliza a reutilização desses módulos quando da configuração da POKE-TOOL para uma particular linguagem. O processo e as etapas de configuração da POKE-TOOL para uma linguagem de interesse são detalhados em [CHA91]. São utilizados três modelos para implementar as funções dependentes da linguagem em que está escrita a unidade em teste: o modelo de fluxo de controle, o modelo de fluxo de dados e o modelo de implementação; o modelo de elementos requeridos é usado para tratar os aspectos que são independentes de linguagem.

\subsubsection{Modelos de Implementação}

\section{Modelo de fluxo de controle}

Para a obtenção do grafo de fluxo de controle, primeiramente o programa é traduzido para uma linguagem intermediária (LI). A linguagem intermediária visa identificar o fluxo de controle em um programa; é uma linguagem com sintaxe e semântica simples. A partir da LI é que se constrói o grafo de programa. A idéia é isolar o quanto possível a sensibilidade à linguagem ao módulo que traduz o fonte para a LI. 


\section{Modelo de fluxo de dados}

As diretrizes para estender o grafo de programa com informações de fluxo de dados são estabelecidas por este modelo; o principal aspecto é refletir os aspectos semânticos que caracterizam a ocorrência de definições de variáveis no programa e associar essa informação ao grafo de programa, caracterizando o grafo def [MAL91]. A partir do grafo def é que são caracterizados os elementos requeridos.

\section{Modelo de instrumentação}

A instrumentação visa oferecer facilidades para a análise posterior à execução dos casos de teste, como a análise de adequação de um dado conjunto de casos de teste. A instrumentação consiste essencialmente em inserir pontas de prova nos blocos de comandos correspondentes a cada nó do grafo de programa da unidade em teste, possibilitando a identificação do caminho efetivamente executado pelo caso de teste fornecido; ou seja, um trace do caso de teste.

\section{Modelo de descrição dos elementos requeridos}

Para implementar as funções independentes da linguagem utiliza-se o modelo de descrição dos elementos requeridos. Este modelo é fundamentado no conceito de arco primitivo e no conceito de grafo(i), tendo importância para a avaliação do conjunto de casos de teste. Com a utilização destes conceitos, busca-se fornecer um núcleo básico para o suporte à aplicação de critérios de teste estrutural, de um modo geral [MAL91]. O conceito de arco primitivo baseia-se no fato de existirem arcos de um GFC que são sempre executados quando um outro arco é executado. Um arco que sempre é executado quando se executa outro arco é denominado arco herdeiro. Define-se como arco primitivo o arco que não é arco herdeiro.

\subsubsection{Arquitetura da Ferramenta}

A POKE-TOOL é uma ferramenta orientada a sessão de trabalho. Na sessão de trabalho, o usuário realiza todas as tarefas de teste: análise estática da unidade, preparação para o teste, submissão de casos de teste e gerenciamento dos resultados do teste. Tem como entrada o programa a ser testado, a seleção do critério a ser utilizado e um conjunto de casos de teste. Seleciona os elementos que são requeridos pelos critérios Potenciais Usos e avalia os caminhos percorridos pelos casos de teste, informando a cobertura destes caminhos. Adicionalmente, é fornecido o conjunto de 
elementos requeridos e não executados, uma importante ajuda para o projeto de casos de teste. A arquitetura da ferramenta está ilustrada em [CHA91, MAL89, MAL91], apresentando 9 funções, que são descritas sucintamente logo a seguir.

Grafo de Fluxo de Controle: Produz o GFC do programa-fonte a ser testado. Sobre a tabela da sintaxe da linguagem do programa é produzida uma versão em linguagem intermediária que é utilizada para a geração do grafo de fluxo de controle do programa. A correspondência entre os comandos da linguagem fonte e os comandos da linguagem intermediária fazem parte do processo de configuração e é de responsabilidade do usuário configurador.

Cálculo dos Arcos Primitivos: Calcula os arcos primitivos do GFC, que servirão como base para a instrumentação do programa fonte e para a construção dos autômatos utilizados na avaliação de adequação de conjuntos de casos de teste.

Extensão do grafo de fluxo de controle: Produz o grafo def.

Interface Gráfica: Apresenta os GFCs para o usuário.

Instrumentação: Insere comandos de escrita (pontas de prova) no programa fonte para cada um dos nós da unidade em teste, gerando uma nova versão do programa, a versão instrumentada.

Compilador Selecionado: Consiste de um compilador da linguagem fonte na qual o programa em teste foi implementado.

Execução do Programa: Controla a execução da unidade em teste produzindo um conjunto de caminhos executados pelos casos de teste fornecidos.

Construção dos grafo(i): Usando os grafos def e o conjunto de arcos primitivos, fornece o conjunto de caminhos e associações requeridos para satisfazer os critérios Potenciais Usos. Ainda são fornecidos os descritores de caminhos e associações, em termos de arcos primitivos, a serem utilizados na avaliação de um conjunto de casos de teste qualquer. Os descritores são expressões regulares. 
Avaliação: Verifica se o conjunto de caminhos ou associações executados satisfaz o critério selecionado, fazendo um relacionamento da cobertura obtida.

\subsubsection{Implementação da Ferramenta}

A atividade de teste apoiada pela ferramenta POKE-TOOL envolve a definição dos elementos requeridos para a unidade em análise e posterior avaliação dos casos de teste aplicados. A POKETOOL é composta de vários módulos que se comunicam através de arquivos. Esses módulos implementam funções ou parte de funções, as quais foram descritas na seção anterior.

O módulo poketool é o responsável pela comunicação entre a ferramenta e o usuário e pela sequenciação das atividades de teste, através da ativação dos demais módulos. O módulo li realiza a tradução do programa para uma versão escrita na LI. O módulo chanomat gera o grafo de fluxo de controle do programa e uma nova versão do programa em LI (versão numerada). Os módulos li e chanomat implementam a função Grafo de Fluxo de Controle.

O módulo pokernel é responsável pela geração do grafo def da unidade, englobando as funções Extensão do Grafo de Fluxo de Controle e Instrumentação da POKE-TOOL. Implementa, também, as funções Cálculo dos Arcos Primitivos e Construção dos Grafo(i). Esse módulo é chamado repetidamente, onde cada invocação produz informação associada a uma unidade no subdiretório correspondente.

O módulo gera executável fornece as condições para a geração do programa executável da versão instrumentada e engloba a função Compilador Selecionado. O módulo executa casos de teste controla a execução dos casos de teste, salvando as entradas, a saída e o caminho executado para cada caso de teste; implementa a função Execução do Programa. O módulo avaliador verifica quais os caminhos ou associações executados pelo caso de teste e fornece uma análise de cobertura do conjunto de casos de teste fornecidos; implementa a função Avaliação.

Resumidamente, configurar a POKE-TOOL consiste em configurar os módulos que geram o grafo de fluxo de controle estendido com informações de fluxo de dados, o que viabiliza a caracterização dos elementos requeridos pelos critérios disponíveis na ferramenta, e em configurar 
o módulo que realiza a instrumentação do programa fonte, o que viabiliza a posterior análise de cobertura em relação ao critério selecionado pelo usuário. Para configurar a POKE-TOOL é necessário que o usuário configurador especifique o analisador léxico, o analisador sintático e as rotinas necessárias à instrumentação da linguagem alvo.

\subsection{Considerações Finais}

Neste capítulo, foi discutido o tópico teste de software, apresentando o teste funcional, o teste estrutural e o teste baseado em erros, com um destaque maior para o teste estrutural. Foi discutido o teste estrutural baseado em fluxo de dados, com o estudo dos critérios Potenciais Usos, definidos por Maldonado em [MAL88, MAL91].

Foi feito o estudo minucioso de três propostas para teste de programas concorrentes:

1. construção de um grafo de concorrência e estabelecimento de critérios de teste sobre esse grafo [TAY92];

2. definição de um modelo de computação e de um modelo de sincronização que permitem a caracterização de informações necessárias ao teste de programas [YAN92];

3. controle sobre as seqüências de sincronização de uma execução para determinar a reprodutibilidade de um comportamento de execução [TAI91].

Finalmente, foi enfatizada a importância do uso de ferramentas automatizadas para a aplicação de critérios de teste. As ferramentas para teste de programas concorrentes existentes são poucas, estando, ainda, no estágio de protótipo. Apresentou-se, então, a ferramenta POKE-TOOL [MAL89, CHA91], que apóia o teste estrutural baseado em fluxo de dados. A proposta deste trabalho contempla o teste estrutural de programas concorrentes baseado em fluxo de dados. Portanto, ela reúne conceitos estudados sobre programas concorrentes/linguagem Occam e conceitos relacionados a teste estrutural baseado em fluxo de dados com os resultados das três propostas para teste de programas concorrentes [TAI91, TAY92, YAN92].

No próximo capítulo será feita a definição da LIConc e serão apresentadas as diretrizes para aplicação dos modelos de implementação dos critérios Potenciais Usos para Occam, com exceção do modelo de elementos requeridos, que é um modelo independente da linguagem de programação. 


\section{Capítulo 4. A LIConc e Diretrizes para a Aplicação dos Modelos de Implementação dos Critérios Potenciais Usos para a Linguagem Occam}

Neste capítulo é definida uma linguagem intermediária para programas concorrentes, denominada LIConc, que consiste em uma extensão da linguagem LI [CAR91], que viabilizou a implementação da ferramenta POKE-TOOL no contexto do teste de programas seqüenciais. Este é o passo inicial para extensão da ferramenta POKE-TOOL para apoiar o teste de programas concorrentes.

É necessário definir uma linguagem intermediária com base na qual são definidos os modelos de fluxo de controle, fluxo de dados e instrumentação para programas concorrentes. As diretrizes para a aplicação desses modelos para a linguagem Occam consideram aspectos semânticos dos comandos do ponto de vista da influência no fluxo de controle. O relacionamento semântico entre os comandos da LI e de Occam é obtido através do mapeamento de suas construções sintáticas. O modelo de fluxo de dados atém-se ao fato de registrar os tipos de ocorrência de variáveis, permitindo a construção do grafo def.

A instrumentação deve ser tal que reflita a semântica dos comandos da LI e ao mesmo tempo viabilize a correta avaliação dos caminhos efetivamente executados; observa-se também que a instrumentação está fortemente restrita ao modelo de fluxo de controle adotado. A instrumentação será feita adicionando-se ao programa fonte chamadas à função ponta.de.prova(num) nos pontos definidos pelo modelo de instrumentação adotado. Esta função registrará o nó associado -- o valor de num -- ao bloco de comandos que contém o comando.

Neste trabalho não será feita a modelagem da sincronização de programas concorrentes, o que deverá ser tratado em um futuro próximo como evolução do presente trabalho.

Na Seção 4.1. é definida a LIConc - Linguagem Intermediária para Programas Concorrentes. Nas outras seções do capítulo será apresentado o mapeamento dos comandos de Occam para a LIConc. Assim, na Seção 4.2. será exibido o mapeamento dos comandos de seqüência; na Seção 4.3., os comandos de seleção; na Seção 4.4., os comandos de paralelismo; na Seção 4.5., os comandos de 
iteração e, na Seção 4.6., os comandos de bloco. Para cada comando será apresentado um exemplo, representando um trecho de programa Occam, a sintaxe do comando em Occam, o seu mapeamento para a LI, a tabela de equivalência sintática do comando em Occam em relação à LI, o grafo de fluxo de controle correspondente, a versão em LI do exemplo (contendo em cada linha do programa LI átomo, início, comprimento e linha), a versão instrumentada do exemplo e diretrizes para construção do grafo def. As produções da gramática da LI e de Occam serão mostradas de tal forma que se verão os símbolos terminais em formato sublinhado, os símbolos não terminais em itálico entre "<" e ">" e os meta-símbolos em negrito.

\subsection{LIConc - Linguagem Intermediária para Programas Concorrentes}

A tradução de um programa escrito numa linguagem de programação concorrente para uma linguagem intermediária é importante porque se poderá construir ferramentas de teste que não sejam sensíveis à linguagem de programação. Na construção da uma LIConc -- Linguagem Intermediária para Programas Concorrentes -- são consideradas as construções comuns às linguagens de programação concorrente de uma forma geral.

Uma síntese completa da LIConc pode ser vista no Apêndice A da presente dissertação. Esta seção tem o objetivo de apresentar os acréscimos feitos à linguagem intermediária da POKE-TOOL para atender a características exclusivas de programas concorrentes.

Um programa em LIConc é uma seqüência de átomos, onde cada átomo é

$<$ atm_li $>::=<$ atomo $><$ inicio $><$ comprimento $><$ linha $>$

onde

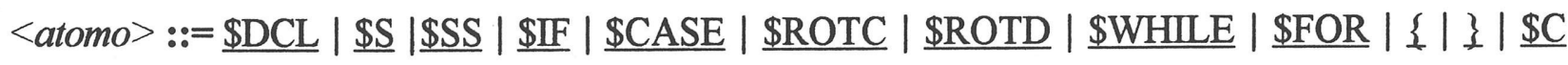
| \$NC | \$REPEAT | \$UNTIL | \$GOTO | \$LABEL | \$BREAK | \$CONTINUE | \$RETURN | \$CC | \$ELSE | \$P | \$I | \$FP | \$PFOR | \$ALT | \$ALTFOR | \$G

e

$<$ inicio $>::=\underline{\text { NUM }}$

$<$ comprimento $>:=\underline{\text { NUM }}$

$<$ linha $>:$ : NUM 
Os terminais anteriormente relacionados representam as seqüências de caracteres indicadas pelos próprios terminais, com exceção dos terminais relacionados na Tabela 4.1., onde os terminais relacionados na coluna esquerda, correspondem às seqüências de caracteres representadas na coluna direita da tabela, onde $n>0, d^{n}$ é uma seqüência de dígitos e $c^{n}$ é uma seqüência de letras e dígitos, começando com letra.

A utilidade desses ponteiros dos átomos é possibilitar o acesso ao código fonte associado ao átomo da LIConc, o que vai ser necessário, por exemplo, para a extensão do grafo de fluxo de controle para a geração do grafo def e para a instrumentação da unidade em teste.

\begin{tabular}{|c|c|}
\hline Terminal & Sequiência de caracteres indicada \\
\hline$\underline{\$ S}$ & $\$ S d^{n}$ \\
\hline$\underline{\$ S S}$ & $\$ \mathrm{SSd}^{\mathrm{n}}$ \\
\hline \$FP & $\$_{\mathrm{FPd}^{\mathrm{n}}}$ \\
\hline$\$ P F O R$ & \$PFORd $^{\text {n }}$ \\
\hline$\underline{\text { \$FPFOR }}$ & $\$_{\text {SFPFORd }}{ }^{\mathrm{n}}$ \\
\hline \$ALT & $\$$ SALTd $^{n}$ \\
\hline \$ALTFOR & \$ALTFORd $^{\mathrm{n}}$ \\
\hline$\underline{\$ C}$ & $\$ C\left(d^{n}\right) d^{n}$ \\
\hline$\$ \mathrm{P}$ & $\$ \mathrm{P}\left(\mathrm{d}^{\mathrm{n}}\right) \mathrm{d}^{\mathrm{n}}$ \\
\hline$\$ \underline{I I}$ & $\$ I\left(d^{n}\right) d^{n}$ \\
\hline$\underline{\$ G}$ & $\$ G\left(d^{n}\right) d^{n}$ \\
\hline$\underline{\text { NUM }}$ & $d^{n}$ \\
\hline$\underline{\underline{L A B E L}}$ & $c^{\mathrm{n}}$ \\
\hline
\end{tabular}


Nas subseções seguintes são abordados os aspectos adicionais que devem ser considerados na formulação de uma linguagem intermediária para programas concorrentes, que são comunicação, sincronização e paralelismo.

\subsubsection{Seqüência}

Foi estabelecido o comando $<s S>$ para modelar os comandos de entrada e de saída, que são comandos relacionados com a comunicação e sincronização. A distinção deste comando em relação aos outros comandos de seqüência prende-se ao fato de que, para esses comandos, precisa-se fazer modelagem da sincronização, para prevenir problemas de impasse e de inanição. Assim, a sintaxe dos comandos de seqüência é dada por:

$<$ sequencia $>::=<$ dcl $>|<s>|<s s>$, onde

$<$ sS $>::=$ \$SS $<$ inicio $><$ comprimento $><$ linha $>$

$\mathrm{e}<\boldsymbol{s S}\rangle$ denota uma comunicação interprocesso.

\subsubsection{Seleção}

Outra característica disponível em linguagens de programação concorrente é a comunicação de forma não determinística, uma vez que vários processos executam concorrentemente; sendo assim, a ordem da comunicação interprocesso vai depender do comportamento da execução dos processos naquele instante. Para tanto, as linguagens de programação concorrente oferecem comandos que permitem escolher alternativas de comunicação. No tocante aos comandos de seleção, a construção nova que surge é a seleção não determinística, que será modelada pelo comando $\langle a l t>$, descrito a seguir.

$<$ alt $>::=<$ alt_atm $>\{\{$ guard_atm $><$ statement $>\}\}$, onde

$<$ alt_atm $>::=\$$ ALT $<$ inicio $><$ comprimento $><$ linha $>\mathrm{e}$

$<$ guard_atm $>::=\$$ G $<$ inicio $><$ comprimento $><$ linha $>$.

O não terminal <alt_atm> representa o átomo que inicia o comando de seleção não determinística, <guard_atm> ( que corresponde a uma entrada, real ou nula, antecedida, opcionalmente, de uma condição ) representa a guarda de $<$ statement $>$. 


\subsubsection{Paralelismo}

O tratamento do paralelismo precisa considerar a ordem em que aquele comando surgiu no programa fonte e o ponto de início de cada ramo de um comando paralelo, devido ao fato que os ramos de um comando paralelo são executados concorrentemente. Com essas informações, pode-se ter, deste modo, o ramo de um comando paralelo que está sendo executado naquele instante, informação esta que é importante para a avaliação de um conjunto de casos de teste. A sintaxe é dada por $<$ parall $>::=<$ par_atm $>\{<b r$ beg_atm $><$ statement $>\}<$ par_end_atm $>$, onde $<$ par_atm $>::=\underline{\$ P}<$ inicio $><$ comprimento $><$ linha $>$, $<$ br_beg_atm $>::=\$$ I $<$ inicio $><$ comprimento $><$ linha $>$, $<$ par_end_atm $>::=\$$ \$FP $<$ inicio $><$ comprimento $><$ linha $>$.

O não terminal <par_atm > representa o átomo que inicia o comando de paralelismo e o não terminal < par_end_atm > representa o átomo que finaliza o comando de paralelismo. O não terminal $<$ br_beg_atm $>$ marca o início de cada um dos comandos representados por <statement $>$, que serão executados paralelamente.

\subsubsection{Repetição}

A LIConc fornece comandos para repetição paralela -- análogo ao for paralelo das linguagens concorrentes -- e para escolha entre uma repetição de alternativas -- o for alternativo das linguagens concorrentes.

O for paralelo da LIConc é definido como

$$
\begin{aligned}
& <\text { parfor }>::=<\text { parfor_atm }>\quad\left\langle s_{1}>\quad<\text { cond_for_atm }>\quad\left\langle s_{2}>\quad<b r \text { beg_atm }>\quad<\text { statement }>\right.\right. \\
& <\text { par_end_atm }>\text { onde } \\
& <\text { parfor_atm }>::=\text { \$PFOR }<\text { inicio }><\text { comprimento }><\text { linha }>\text {, } \\
& <\text { br_beg_atm }>::=\underline{\$ I}<\text { inicio }><\text { comprimento }><\text { linha }>\text {, } \\
& <\text { par_end_atm }>::=\underline{\text { SFP }}<\text { inicio }><\text { comprimento }><\text { linha }>\mathrm{e} \\
& <\text { cond_for_atm }>::=\$ \text { C }<\text { inicio }><\text { comprimento }><\text { linha }>\text {. }
\end{aligned}
$$

O não terminal < parfor_atm> indica o comando for paralelo da LIConc, o não terminal 
$<s_{1}>$ representa a iniciação das variáveis de controle do for através de um comando de seqüência, $<$ cond_for_atm $>$ representa a condição, $<s_{2}>$ representa o comando de paralelismo que altera as variáveis de controle correspondentes a todas as iterações do for e $<$ statement $>$ representa o corpo do comando.

O for alternativo da LIConc é definido como $<$ altfor $>::=<$ altfor_atm $><s_{1}><$ cond_for_atm $><s_{2}><$ guard_atm $><$ statement $>$, onde $<$ altfor_atm $>::=$ \$ALTFOR $<$ inicio $><$ comprimento $><$ linha $>$, $<$ cond_for_atm $>::=\$ \mathbb{C}<$ inicio $><$ comprimento $><$ linha $>\mathrm{e}$ $<$ guard_atm $>::=\underline{\$ G}<$ inicio $><$ comprimento $><$ linha $>$.

O não terminal < altfor_atm > indica o comando for alternativo da LIConc, o não terminal $<s_{1}>$ representa a iniciação das variáveis de controle do for através de um comando de seqüência, $<$ cond_for_atm $>$ representa a condição, $<s_{2}>$ representa o comando de seleção não determinística que altera as variáveis de controle correspondentes a todas as iterações do for, <guard_atm> representa a guarda de $<$ statement $>$, que representa o corpo do comando.

\subsection{Comandos de Seqüência}

São destacados como comandos de seqüência aqueles comandos em que não se altera o fluxo de controle tais como atribuição, entrada e saída. Existe ainda o comando SEQ, usado para agrupar uma lista de comandos que serão executados seqüencialmente.

\subsubsection{Comandos Simples}

Os comandos simples de seqüência consistem dos comandos de atribuição, de entrada, de saída e de chamada de procedimentos, das especificações de programa e de atribuições de processos a processadores. Uma especificação de programa pode ser uma declaração, uma abreviação ou uma definição. Dentre eles, os comandos de entrada e de saída exigem tratamento adicional da sincronização; por esta razão, a LIConc recebeu um novo comando seqüencial, o <ss>, para, a partir de um programa LIConc, se poder modelar a sincronização. 
No Exemplo 1, representado a seguir, mostra-se um trecho de programa contendo comandos simples de seqüência que, por hipótese, são executados seqüencialmente.

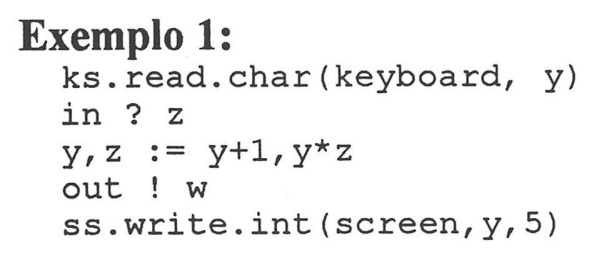

\section{Sintaxe}

São comandos de seqüência os seguintes:

$$
\begin{aligned}
& <\text { allocat }>:=\underline{\text { PLACE }}<\text { name }>\underline{\mathrm{AT}}<\text { expr }> \\
& <\text { specifn }>::=<\text { decl }>\mid<\text { abbrev }>\mid<\text { defin }> \\
& <\text { simpstat }>::=\underline{\text { SKIP }} \mid \underline{\text { STOP } \mid<\text { assign }>} \\
& <\text { syncstat }>::=<\text { input }>\mid<\text { output }> \\
& <\text { instanc }>::=<\text { name }>\left(\left\{\left\{_{2}^{0}<\text { actual }>\right\}\right)\right.
\end{aligned}
$$

\section{Mapeamento para a LIConc}

Os comandos de seqüência de Occam são mapeados diretamente para os comandos de seqüência da LIConc. A sintaxe dos comandos de seqüência da LIConc, apresentada no Apêndice A tem o seguinte formato:

$$
<\text { sequencia }>::=<s>|<s s>|<\text { dcl }>
$$

A equivalência sintática para os comandos de seqüência é mostrada na Tabela 4.2. $\mathrm{O}$ grafo de fluxo de controle é apresentado na Figura 4.1.

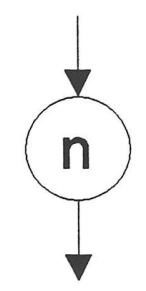

Figura 4.1. Grafo de Fluxo de Controle: Comandos de sequência

\begin{tabular}{lrrr}
\multicolumn{4}{c}{ Versão em LIConc do } \\
\$S1 & 77 & 25 & 6 \\
\$SS1 & 106 & 6 & 7 \\
\$S2 & 116 & 14 & 8 \\
\$SS2 & 134 & 7 & 9 \\
\$S3 & 145 & 24 & 10
\end{tabular}

\section{Diretrizes para a Construção do Grafo Def}

Ao nó n é atribuído o conjunto de variáveis definidas no bloco de comandos associado a esse nó. No Exemplo 1, ao nó n são associadas as variáveis y e z. 


\begin{tabular}{||l|l||}
\hline Occam & LIConc \\
\hline \hline$<$ allocat $>$ & $<d c l>$ \\
\hline$<$ specifn $>$ & $<d c l>$ \\
\hline$<$ instanc $>$ & $<s>$ \\
\hline$<$ simpstat $>$ & $<s>$ \\
\hline$<$ syncstat $>$ & $<s S>$ \\
\hline \hline
\end{tabular}

Tabela 4.2. Mapeamento dos comandos de seqüência para a LIConc

\section{Versão Instrumentada do Exemplo 1:}

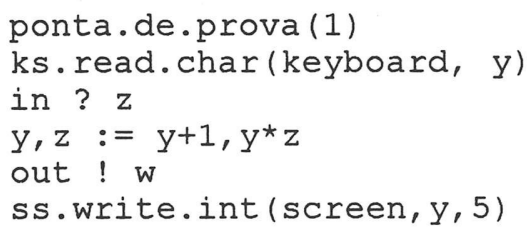

\subsubsection{Comando SEQ}

Os comandos de um programa concorrente podem ser executados de mais de uma forma: seqüencial, paralela ou seletiva. O comando SEQ é usado para agrupar uma lista de comandos que devem ser executados seqüencialmente. O Exemplo 2 mostra um trecho de programa onde é ilustrado o uso do comando SEQ (as duas primeiras linhas são linhas de comentário).

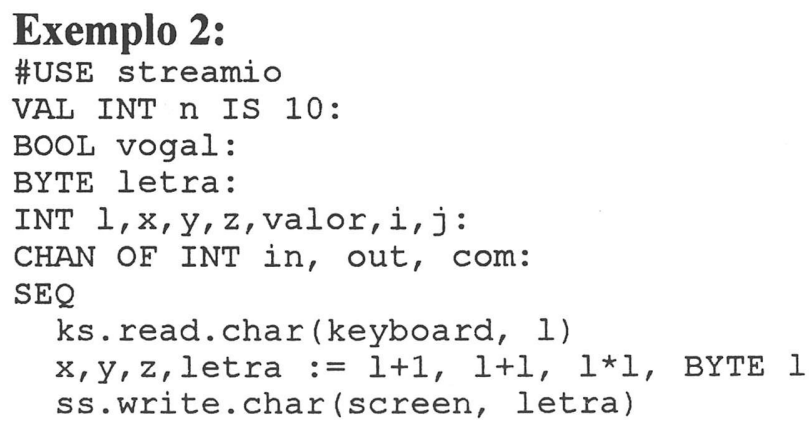




\section{Sintaxe}

O SEQ simples (não associado a uma construção de repetição) tem como sintaxe:

$<$ seqsimp $>::=\underline{\mathrm{SEQ}}<$ at_ind $>\{<$ process $>\}<$ des_ind $>$

\section{Mapeamento para a LIConc}

O comando SEQ de Occam é mapeado para o comando de bloco da LIConc, conforme mostra a Tabela 4.3.

\begin{tabular}{||l|l||}
\hline \multicolumn{1}{|c|}{ Occam } & \multicolumn{1}{c|}{ LIConc } \\
\hline \hline SEQ $<$ at ind $>$ & 1 \\
\hline$<$ process $>$ & $<$ statement $>$ \\
\hline$<$ des ind $>$ & 3 \\
\hline \hline
\end{tabular}

Tabela 4.3. Mapeamento do comando SEQ para a LIConc

\section{Grafo de Fluxo de Controle}

O grafo de fluxo de controle para o comando SEQ simples, apresentado na Figura 4.2., é representado pelo subgrafo $\mathbf{S}$. $\mathrm{O}$ aspecto desse subgrafo dependerá dos comandos relacionados pelo SEQ.

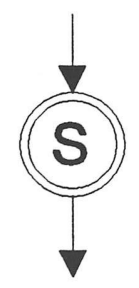

Figura 4.2. Grafo de Fluxo de Controle: Comando SEQ

\section{Diretrizes para a Construção do Grafo Def}

A extensão do subgrafo $\mathbf{S}$ depende dos comandos associados ao comando SEQ. No Exemplo 2, ao comando SEQ foram associados apenas comandos seqüenciais simples. Sendo assim, o subgrafo $\mathbf{S}$ corresponderá a um único nó $\mathbf{n}$. A esse nó são associadas as variáveis $\mathbf{l}, \mathbf{x}, \mathbf{y}, \mathbf{z}$ e letra. 
Versão em LIConc do Exemplo 2:

$\begin{array}{lrrr}\text { \$DCL } & 35 & 13 & 3 \\ \text { \$DCL } & 50 & 16 & 4 \\ \text { \$DCL } & 68 & 11 & 5 \\ \text { \$DCL } & 81 & 11 & 6 \\ \text { \$DCL } & 94 & 22 & 7 \\ \text { \$DCL } & 118 & 26 & 8 \\ \{ & 146 & 3 & 9 \\ \text { \$S1 } & 153 & 25 & 10 \\ \text { \$S2 } & 182 & 36 & 11 \\ \text { \$S3 } & 222 & 28 & 12\end{array}$

\section{Versão Instrumentada do Exemplo 2:}

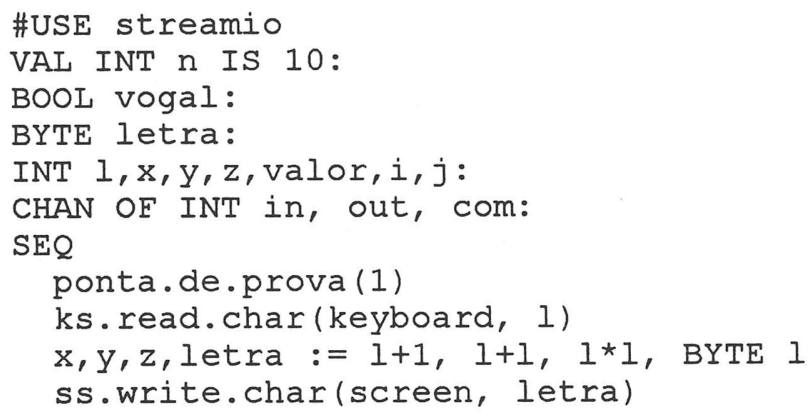

\subsection{Comandos de Seleção}

As estruturas de seleção da linguagem Occam estão presentes nos comandos IF, CASE e ALT. Os comandos IF e CASE têm similares nas linguagens de programação seqüenciais, enquanto que o comando ALT é um comando que representa construções que são exclusivas de uma linguagem de programação concorrente.

\subsubsection{Comando IF}

Um comando condicional é formado por um IF acompanhado de uma seqüência de escolhas onde cada escolha corresponde a uma condição seguida de uma lista de ações. O comando IF de Occam 
tem uma sintaxe mais abrangente quando comparada com a sintaxe do comando if de uma linguagem seqüencial estilo ALGOL.

\section{Exemplo 3:}

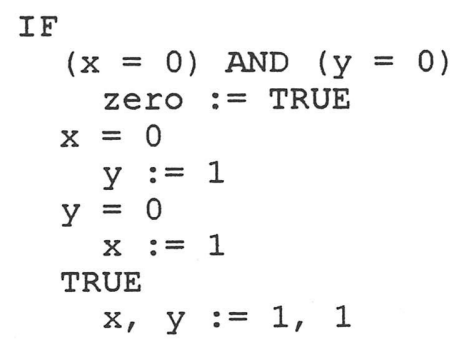

\section{Sintaxe}

A sintaxe do comando IF é dada por:

$<$ if $>::=\underline{\text { IF }}<$ at_ind $>\{<$ boolean $><$ at_ind $><$ process $><$ des_ind $>\}$ [ TRUE $<$ at_ind $><$ process $><$ des_ind $>]<$ des_ind $>$

\section{Mapeamento para a LIConc}

Por ser mais geral que o comando if da LIConc, o comando IF de Occam será mapeado para o comando case da LIConc. A equivalência sintática para o comando IF de Occam é mostrada na Tabela 4.4. O grafo de fluxo de controle correspondente ao Exemplo 3 é mostrado na Figura 4.3.

\begin{tabular}{||l|l||}
\hline \multicolumn{1}{|c|}{ Occam } & \multicolumn{1}{c|}{ LIConc } \\
\hline \hline$\underline{\underline{\mathrm{IF}}<\text { at } \text { ind }>}$ & $<$ case atm $><$ cond case atm $>$ \\
\hline$<$ boolean $><$ at ind $>$ & $<$ rotc atm $>$ \\
\hline$<$ process $><$ des ind $>$ & $\{<$ statement $><$ break $>\}$ \\
\hline TRUE $<$ at ind $>$ & $<$ rotd atm $>$ \\
\hline$<$ des ind $>$ & \{ \\
\hline \hline
\end{tabular}

Tabela 4.4. Mapeamento do comando IF para a LIConc 


\section{Diretrizes para a Construçã̉o do Grafo Def}

Com relação à Figura 4.3., que é o grafo de fluxo de controle do Exemplo 3, aos nós 1 e 6 são associadas as variáveis definidas nos respectivos blocos; neste caso não há nenhuma variável associada ao comando IF. Agora, com relação aos comandos associados às escolhas do IF, são associadas as variáveis definidas nas condições e nos comandos correspondentes. Assim, no nó 2 temse definição da variável zero; no nó 3 , da variável y; no nó 4 , da variável x e, no nó 5 , das variáveis x e y.

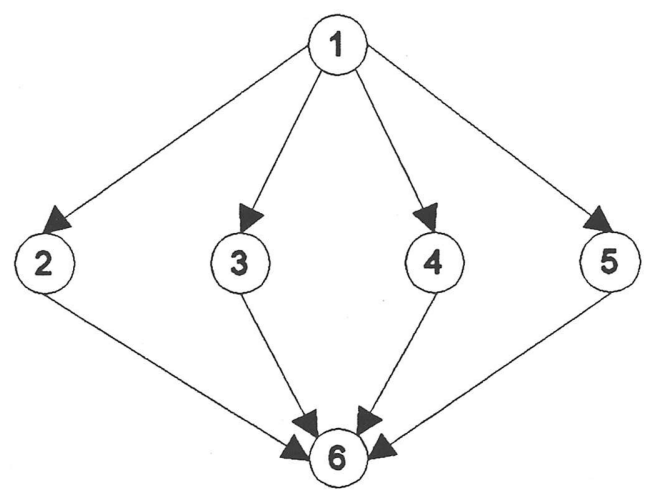

Figura 4.3. Grafo de Fluxo de Controle: Comando IF

\section{Versão em LIConc do Exemplo 3:}

$\begin{array}{lrrr}\text { \$CASE } & 182 & 2 & 9 \\ \text { \$CC } & 184 & 0 & 9 \\ \text { \{ } & 190 & 0 & 10 \\ \text { \$ROTC } & 190 & 19 & 10 \\ \text { \$S4 } & 217 & 11 & 11 \\ \text { \$BREAK } & 234 & 0 & 0 \\ \text { \$ROTC } & 234 & 5 & 12 \\ \text { \$S5 } & 247 & 6 & 13 \\ \text { \$BREAK } & 259 & 0 & 0 \\ \text { \$ROTC } & 259 & 5 & 14 \\ \text { \$S6 } & 272 & 6 & 15 \\ \text { \$BREAK } & 284 & 0 & 0 \\ \text { \$ROTD } & 284 & 4 & 16 \\ \text { \$S7 } & 296 & 12 & 17 \\ \text { \} } & 312 & 0 & 18\end{array}$




\section{Versão Instrumentada do Exemplo 3:}

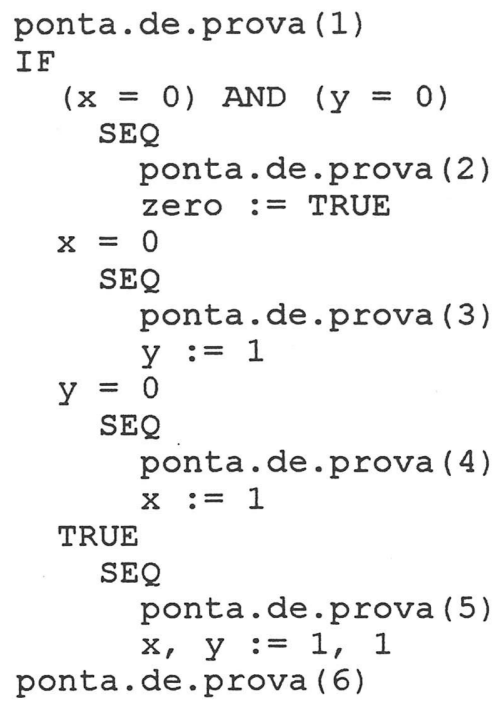

\subsubsection{Comando CASE}

Em situações específicas IF pode ser substituído por CASE; quando a condição de um IF puder ser fatorada, este poderá ser transformado num CASE. Este comando tem sintaxe e semântica semelhante ao comando case das linguagens estilo ALGOL.

\section{Exemplo 4:}

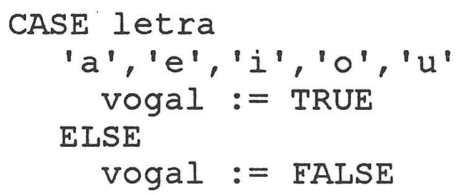

\section{Sintaxe}

A seguir, apresenta-se a sintaxe do comando CASE:

$<$ selectn $>::=\underline{\text { CASE }}<$ selectr $><$ at_ind $>\left\{\left\{<\right.\right.$ casexpr $\left.>{ }_{2}\right\}<$ casexpr $><a$ at_ind $><$ process $>$

$<$ des_ind $>\}[\underline{\text { ELSE }}<$ at_ind $><$ process $><$ des_ind $>$ ] $<$ des_ind $>$ 


\section{Mapeamento para a LIConc}

O comando CASE de Occam é mapeado para o comando case da LIConc, conforme se pode observar na Tabela 4.5 .

\section{Versão em LIConc do Exemplo 4:}

$\begin{array}{llrr}\text { \$CASE } & 627 & 4 & 29 \\ \text { \$CC } & 631 & 5 & 29 \\ \{ & 646 & 0 & 0 \\ \text { \$ROTC } & 646 & 4 & 30 \\ \text { \$ROTC } & 650 & 4 & 30 \\ \text { \$ROTC } & 654 & 4 & 30 \\ \text { \$ROTC } & 658 & 4 & 30 \\ \text { \$ROTC } & 662 & 3 & 30 \\ \text { \$S11 } & 677 & 13 & 31 \\ \text { \$BREAK } & 700 & 0 & 0 \\ \text { \$ROTD } & 700 & 4 & 0 \\ \text { \$S12 } & 716 & 14 & 33 \\ \text { \} } & 736 & 0 & 0\end{array}$

\section{Grafo de Fluxo de Controle}

O grafo de fluxo de controle para o comando CASE apresenta nós correspondentes ao início e ao fim do comando e nós intermediários correspondentes às opções do CASE. Na Figura 4.4. apresenta-se o grafo de fluxo de controle para o Exemplo 4.

\begin{tabular}{||l|l||}
\hline \multicolumn{1}{|c|}{ Occam } & \multicolumn{1}{c|}{ LIConc } \\
\hline \hline CASE $<$ selectr $><$ at ind $>$ & $<$ case atm $><$ cond case atm $>1$ \\
\hline$<$ casexpr $>2$ & $<$ rotc atm $>$ \\
\hline$<$ casexpr $><$ at ind $>$ & $<$ rotc atm $>$ \\
\hline$<$ process $><$ des ind $>$ & $\{<$ statement $><$ break $>\}$ \\
\hline ELSE & $<$ rotd atm $>$ \\
\hline$<$ des ind $>$ & \{ \\
\hline
\end{tabular}

Tabela 4.5. Mapeamento do comando CASE para a LIConc 


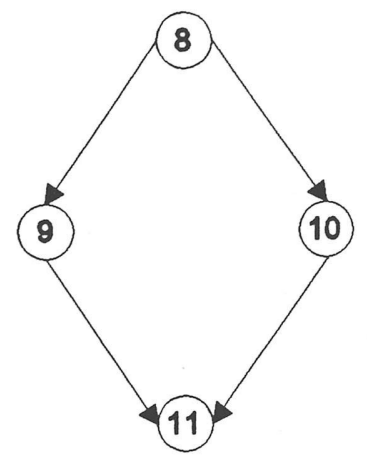

Figura 4.4. Grafo de Fluxo de Controle: Comando CASE

\section{Versão Instrumentada do Exemplo 4:}

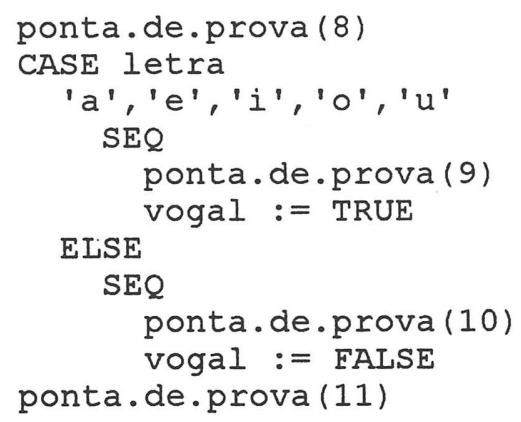

\section{Diretrizes para a Construção do Grafo Def}

Aos nós 8 e 11 são associadas as variáveis definidas nos respectivos blocos; neste caso, não há nenhuma que seja relacionada ao comando CASE. Com relação aos blocos de programa associados aos nós 9 e 10 do GFC, vê-se definida em ambos a variável vogal.

\subsubsection{Comando ALT}

Para expressar o não determinismo, existe o comando ALT. O comando de alternativa reune um número de processos guardados por entradas, executando o comando que está associado à guarda; se mais de uma guarda estiver pronta, uma delas é escolhida não deterministicamente e o processo correspondente é executado; se nenhuma guarda estiver pronta, o ALT espera alguma guarda tornarse pronta para, daí, passar à execução do processo sob guarda. O comando ALT corresponde a uma 
distribuição de decisões ao longo de vários processos, sendo muito importante no processo de comunicação/sincronização.

Alguns aspectos do comando ALT serão estudados com maior profundidade quando do tratamento da sincronização em linguagens de programação concorrente/paralela, em trabalho futuro com a determinação do grafo de sincronização [YAN92]. No aspecto de fluxo de controle, o comando ALT tem tratamento semelhante ao do comando CASE, ficando, contudo, informações necessárias para o tratamento da sincronização.

\section{Exemplo 5:}

ALT

in ? j

out ! z+y

com ? j

$x:=x+j$

\section{Sintaxe}

A sintaxe do comando ALT é dada por

$<$ altrtn $>::=\underline{\text { ALT }}<$ at_ind $>\{[<$ specifn $>$ ] $(<$ guard $><$ at_ind $><$ process $><$ des_ind $>1$ $<$ altrtn $>\mid<$ altfor $>$ ) $\}<$ des_ind $>$

\section{Mapeamento para a LIConc}

A Tabela 4.6. mostra o mapeamento do comando ALT para a LIConc.

\section{Grafo de Fluxo de Controle}

Semelhante ao que foi feito para o comando IF, o grafo de fluxo de controle para o comando ALT apresenta nós correspondentes ao início e ao fim do comando e nós intermediários correspondentes às alternativas do ALT. Na Figura 4.6. apresenta-se o grafo de fluxo de controle para o Exemplo 5. 


\begin{tabular}{||l|l||}
\hline \multicolumn{1}{|c|}{ Occam } & \multicolumn{1}{c|}{ LIConc } \\
\hline \hline ALT $<$ at ind $>$ & $<$ alt atm $>\{$ \\
\hline$<$ guard $><$ at ind $>$ & $<$ guard $>$ \\
\hline$<$ process $><$ des ind $>$ & $<$ statement $>$ \\
\hline$<$ des ind $>$ & \} \\
\hline
\end{tabular}

Tabela 4.6. Mapeamento do comando ALT para a LIConc

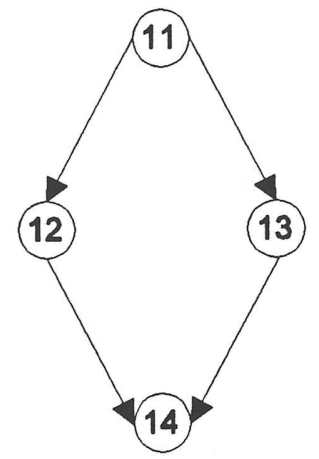

Figura 4.5. Grafo de Fluxo de Controle: Comando ALT

Versão em LIConc do Exemplo 5:

$\begin{array}{lrrr}\text { \$ALT1 } & 736 & 3 & 34 \\ \{ & 747 & 0 & 0 \\ \text { \$G(1)1 } & 747 & 6 & 35 \\ \text { \$SS } 4 & 763 & 9 & 36 \\ \text { \$G(2)1 } & 780 & 7 & 37 \\ \text { \$S14 } & 797 & 10 & 38 \\ \text { \} } & 811 & 0 & 0\end{array}$

\section{Diretrizes para a Construção do Grafo Def}

Nos nós correspondentes à abertura e ao fechamento do comando são associadas as variáveis definidas nos respectivos blocos. Nos nós intermediários correspondentes às diversas guardas são 
associadas a cada nó a variável definida na guarda e as variáveis definidas nos comandos associados à guarda. No caso do grafo def do Exemplo 5, não existem variáveis associadas aos nós 11 e 14 relativas ao comando ALT; só ao nó 12 se associa a variável $\mathbf{j}$ e ao nó 13 , as variáveis $\mathbf{j}$ e $\mathbf{x}$.

\section{Versão Instrumentada do Exemplo 5:}

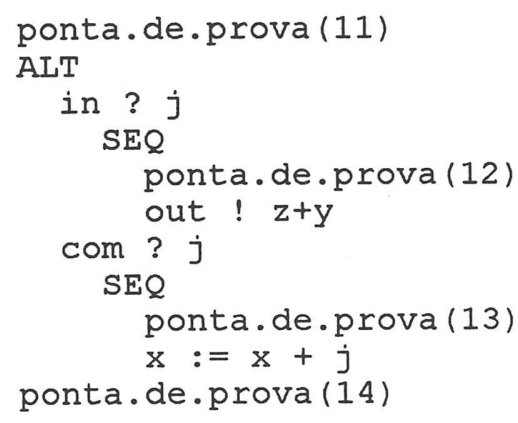

\subsection{Comandos de Paralelismo}

Os comandos de paralelismo exigem um cuidado especial porque vários processos são ativados simultaneamente. Além disso, Occam permite o aninhamento de comandos de paralelismo. Sendo assim, é necessário o registro do nível do comando paralelo sendo tratado, bem como o ramo paralelo que está sendo executado. Occam possui dois comandos de paralelismo: o comando PAR -- que será apresentado logo a seguir -- e o comando PAR ... FOR, apresentado na Subseção 4.4.5.

\subsubsection{Comando PAR}

Um comando paralelo é definido pela palavra-chave PAR seguida de uma lista de comandos mais simples que serão executados em paralelo. Uma vez que não pode ocorrer interferência mútua, processos concorrentes só podem comunicar-se por entradas e saídas por meio de canais.

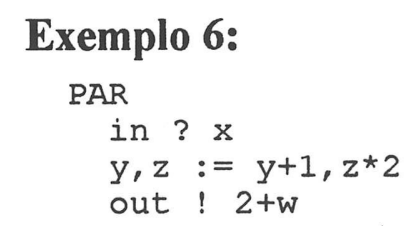




\section{Sintaxe}

A sintaxe do comando PAR é dada por

$<$ parsimp $>::=\underline{\mathrm{PAR}}<$ at_ind $>\{<$ process $>\}<$ des_ind $>$

\section{Mapeamento para a LIConc}

O mapeamento do comando PAR para a LIConc é feito de acordo com a Tabela 4.7. Os tokens relativos a início e a fim de paralelismo e a início e a fim de ramo são importantes para permitir a serialização da execução de um programa Occam.

\begin{tabular}{||l|l||}
\hline \multicolumn{1}{|c|}{ Occam } & \multicolumn{1}{c|}{ LIConc } \\
\hline \hline$\underline{\text { PAR }<\text { at } \text { ind }>}$ & $<$ par atm $>$ \\
\hline$<$ process $>$ & $<$ br beg atm $><$ statement $>$ \\
\hline$<$ des ind $>$ & $<$ par end atm $>$ \\
\hline
\end{tabular}

Tabela 4.7. Mapeamento do comando PAR para a LIConc

\section{Grafo de Fluxo de Controle}

O grafo de fluxo de controle para o comando PAR deve externar um visual de paralelismo, deve apresentar nós correspondentes ao início e ao fim do comando e, para cada ramo do comando, o subgrafo correspondente àquele ramo. Na Figura 4.6., em (a), mostra-se o aspecto do grafo de fluxo de controle para o comando PAR simples, em geral, e, em (b) mostra-se o grafo de fluxo de controle relativo ao Exemplo 6. 


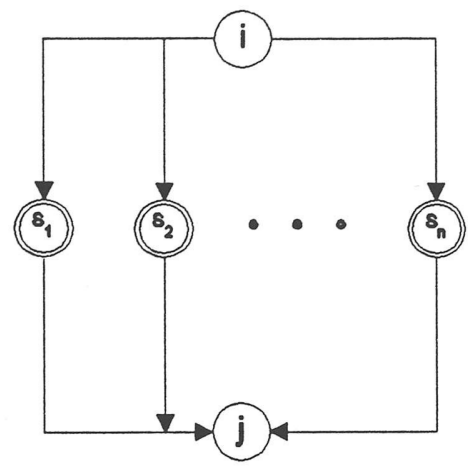

(a)

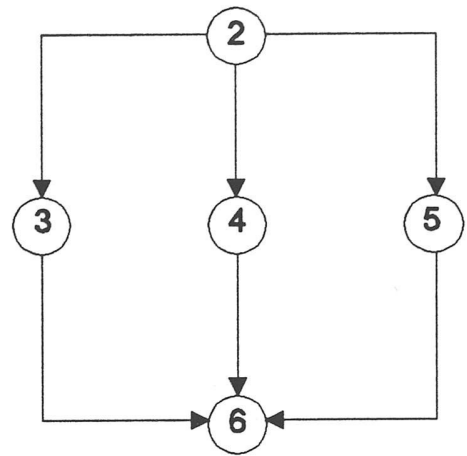

(b)

Figura 4.6. Grafo de Fluxo de Controle: Comando PAR

\section{Versão em LIConc do Exemplo 6:}

$\begin{array}{lrrr}\text { \$P (3) } 1 & 173 & 3 & 11 \\ \text { \$I (1) } 1 & 182 & 0 & 12 \\ \text { \$SS3 } & 182 & 6 & 12 \\ \text { \$I (2) 1 } & 194 & 0 & 13 \\ \text { \$S7 } & 194 & 14 & 13 \\ \text { \$I (3) } 1 & 214 & 0 & 14 \\ \text { \$SS4 } & 214 & 0 & 14 \\ \text { \$FP1 } & 227 & 0 & 15\end{array}$

\section{Versão Instrumentada do Exemplo 6:}

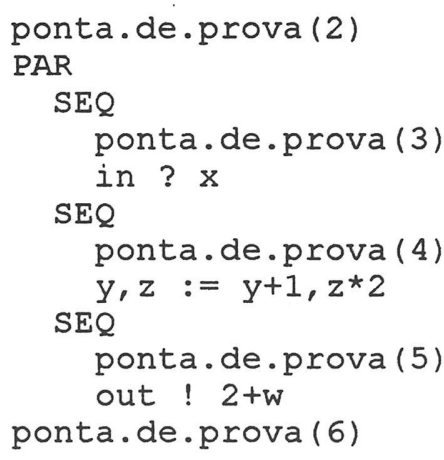

\section{Diretrizes para a Construção do Grafo Def}

Aos nós do GFC correspondentes ao início e ao fim do paralelo não se define variáveis relativas a esse comando, mas sim as relativas a outros comandos dos respectivos blocos. Aos nós correspondentes aos subgrafos dos ramos do paralelo são associadas as variáveis definidas nos respectivos blocos. Com relação ao GFC da Figura 4.6, não são associadas variáveis aos nós 2 e 6; ao nó 3 é associada a variável $\mathbf{x}$; ao nó 4 , as variáveis y e $\mathbf{z}$ e, ao nó 5 , nenhuma variável. 


\subsection{Comandos de Iteração}

Comandos de iteração são usados com muita freqüência em qualquer linguagem de programação. Occam usa o comando WHILE quando o número de iterações não é determinado, sendo, assim, uma construção seqüencial. Os comandos SEQ, IF, PAR e ALT podem estar associados à construção de repetição

vvel.de.controle = val.inicial $F O R$ num.vezes

expressando uma iteração seqüencial, condicional, paralela e alternativa, respectivamente.

\subsubsection{Comando WHILE}

O comando WHILE de Occam corresponde ao comando while das linguagens seqüenciais estilo ALGOL.

\section{Exemplo 7:}

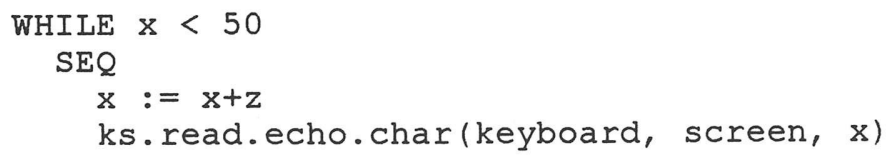

\section{Sintaxe}

A sintaxe do comando WHILE é dada por

$<$ loop $>\quad::=\underline{\text { WHILE }}<$ boolean $><$ at_ind $><$ process $><$ des_ind $>$

\section{Mapeamento para a LIConc}

A Tabela 4.8. mostra que o mapeamento do comando WHILE para a LIConc é direto. 


\begin{tabular}{||l|l||}
\hline \multicolumn{1}{|c|}{ Occam } & \multicolumn{1}{c|}{ LIConc } \\
\hline \hline WHILE & $<$ while atm $>$ \\
\hline$<$ boolean $>$ & $<$ cond while atm $>$ \\
\hline$<$ at ind $><$ process $><$ des ind $>$ & $<$ statement $>$ \\
\hline
\end{tabular}

Tabela 4.8. Mapeamento do comando WHILE para a LIConc

\section{Grafo de Fluxo de Controle}

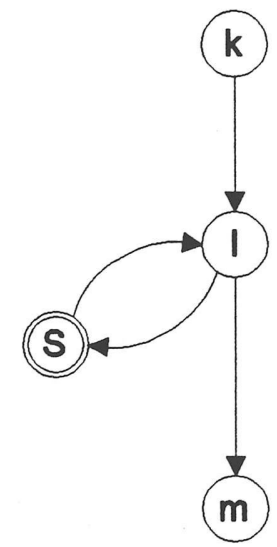

(a)

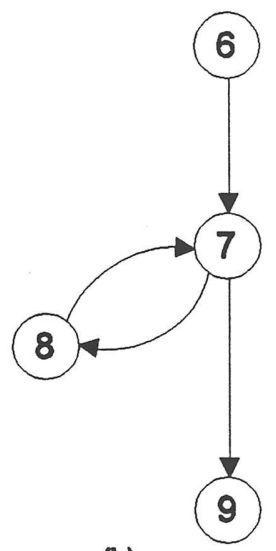

(b)

Figura 4.7. Grafo de Fluxo de Controle: Comando WHILE

Versão em LIConc do Exemplo 7:

$\begin{array}{llrl}\text { \$WHILE } & 227 & 5 & 15 \\ \text { \$C (1) 1 } & 232 & 7 & 15 \\ \{ & 245 & 3 & 16 \\ \text { \$S9 } & 256 & 8 & 17 \\ \text { \$S10 } & 272 & 39 & 18 \\ \} & 313 & 0 & 19\end{array}$




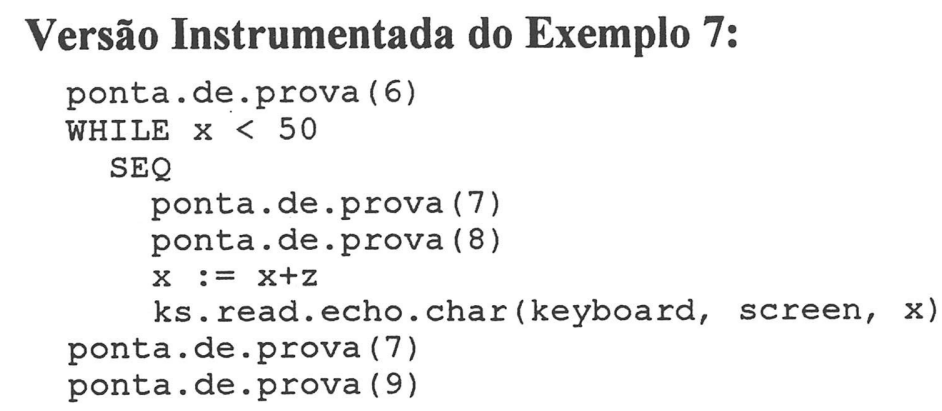

\section{Diretrizes para a Construção do Grafo Def}

Com relação ao grafo da Figura 4.7.b. ao nó 7 não é associada nenhuma definição de variável por não haver definições de variáveis na condição e ao nó 8 é associada a variável x. Aos nós 6 e 9 não são associadas variáveis relativas ao WHILE.

\subsubsection{Comando SEQ ... FOR}

O comando SEQ ... FOR tem sintaxe e semântica semelhante ao comando for das linguagens seqüenciais estilo ALGOL.

\section{Exemplo 8:}

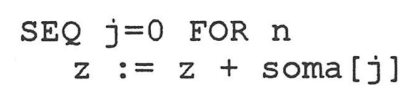

\section{Sintaxe}

A sintaxe do comando SEQ ... FOR é dada por

$<$ seqfor $>::=\underline{\mathrm{SEQ}}<$ base $>\equiv<$ name $>\underline{\mathrm{FOR}}<$ count $><$ at_ind $><$ process $><$ des_ind $>$

\section{Mapeamento para a LIConc}

A Tabela 4.9. mostra como fazer o mapeamento do comando SEQ ... FOR para a LIConc. 


\begin{tabular}{||l|l||}
\hline \multicolumn{1}{|c|}{ Occam } & \multicolumn{1}{c|}{ LIConc } \\
\hline \hline$\underline{\mathrm{SEQ}}<$ base $>\equiv<$ name $>$ & $<$ for atm $><s_{1}>$ \\
\hline$\underline{\mathrm{FOR}}<$ count $>$ & $<$ cond for atm $><s_{2}>$ \\
\hline$<$ at ind $><$ process $><$ des ind $>$ & $\{<$ statement $>$ \} \\
\hline
\end{tabular}

Tabela 4.9. Mapeamento do comando SEQ ... FOR para a LIConc

\section{Grafo de Fluxo de Controle}

Conforme se vê na Figura 4.8., o nó $\mathbf{k}$ é associado aos comandos de iniciação da variável de controle do for; o nó $\mathbf{j}$, aos comandos que alteram variável de controle (o nó j é o nó de saída do subgrafo S); o nó $\mathrm{l}$, a <cond_for_atm> e o nó $\mathrm{m}$, ao encerramento do for. $\mathrm{O}$ aspecto do subgrafo $\mathrm{S}$ vai depender dos comandos que o compõem.

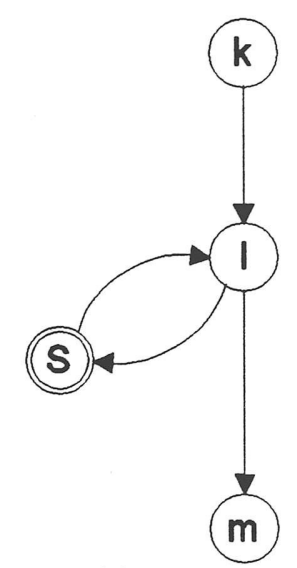

(a)

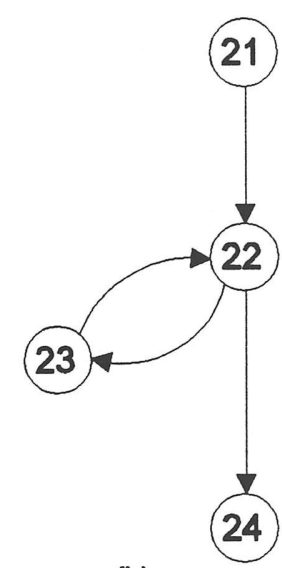

(b)

Figura 4.8. Grafo de Fluxo de Controle: Comando SEQ ... FOR

\section{Versão em LIConc do Exemplo 8:}

$\begin{array}{llrl}\text { \$FOR } & 666 & 4 & 38 \\ \text { \$S28 } & 670 & 5 & 38 \\ \text { \$C (1) } 9 & 675 & 0 & 38 \\ \text { \$S29 } & 675 & 0 & 38 \\ \{ & 681 & 0 & 39 \\ \text { \$S30 } & 681 & 16 & 39 \\ \} & 701 & 0 & 40\end{array}$




\section{Versão Instrumentada do Exemplo 8:}

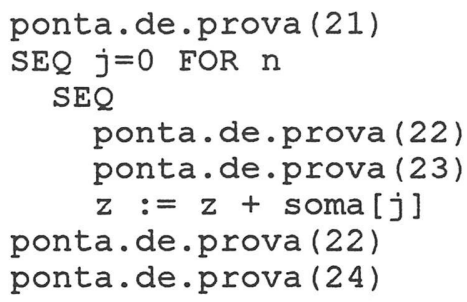

\section{Diretrizes para a Construção do Grafo Def}

Ao nó 21 associa-se a definição da variável j (variável de controle); ao nó 23, as variáveis $\mathbf{z}$ e j, não havendo associação de variáveis aos nós 22 e 24 .

\subsubsection{Comando IF ... FOR}

IF ... FOR é um comando sem correspondente em linguagens estilo ALGOL por ter sintaxe e semântica mais abrangentes.

\section{Sintaxe}

A sintaxe do comando é dada por

$<$ iffor $>::=\underline{\text { IF }}<$ base $>\equiv<$ name $>\underline{\text { FOR }}<$ count $><$ at_ind $><$ boolean $><$ at_ind $><$ process $>$ $<$ des_ind $><$ des_ind $>$

Todo programa que tenha este tipo de comando deve passar por uma fase de préprocessamento, em que será transformado para

$<$ iffor $>::=\underline{\mathrm{SEQ}}<$ base $>\equiv<$ name $>\underline{\mathrm{FOR}}<$ count $><$ at_ind $>\underline{\mathrm{IF}}<$ at_ind $><$ boolean $><$ at_ind $>$ $<$ process $><$ des_ind $><$ des_ind $><$ des_ind $>$

Após esse pré-processamento vê-se no lugar do IF ... FOR, um comando SEQ ... FOR com um IF nele aninhado.

\section{Exemplo 9:}

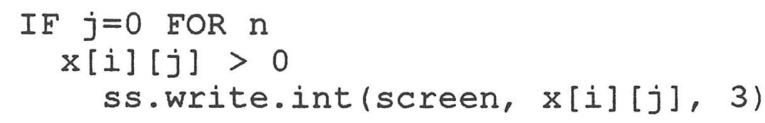


Após o pré-processamento, resulta

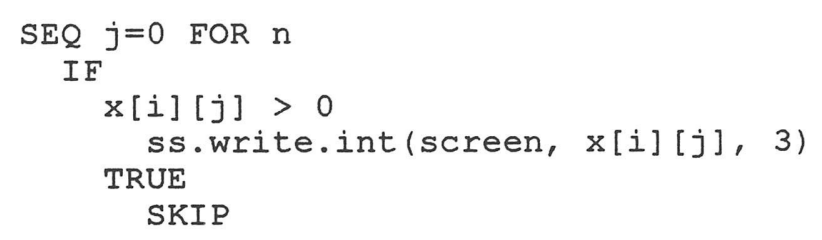

\section{Versão em LIConc do Exemplo 9:}

$\begin{array}{llrr}\text { \$FOR } & 270 & 4 & 15 \\ \text { \$S9 } & 274 & 5 & 15 \\ \text { \$C (1) } 4 & 279 & 0 & 15 \\ \text { \$S10 } & 279 & 0 & 15 \\ \{ & 289 & 0 & 0 \\ \text { \$CASE } & 289 & 2 & 16 \\ \text { \$CC } & 291 & 0 & 16 \\ \{ & 303 & 0 & 17 \\ \text { \$ROTC } & 303 & 11 & 17 \\ \text { \$S11 } & 328 & 32 & 18 \\ \text { \$BREAK } & 372 & 0 & 19 \\ \text { \$ROTD } & 372 & 4 & 19 \\ \text { \$S12 } & 390 & 4 & 20 \\ \text { \} } & 398 & 0 & 21 \\ \text { \} } & 398 & 0 & 21\end{array}$

\section{Versão Instrumentada do Exemplo 9:}

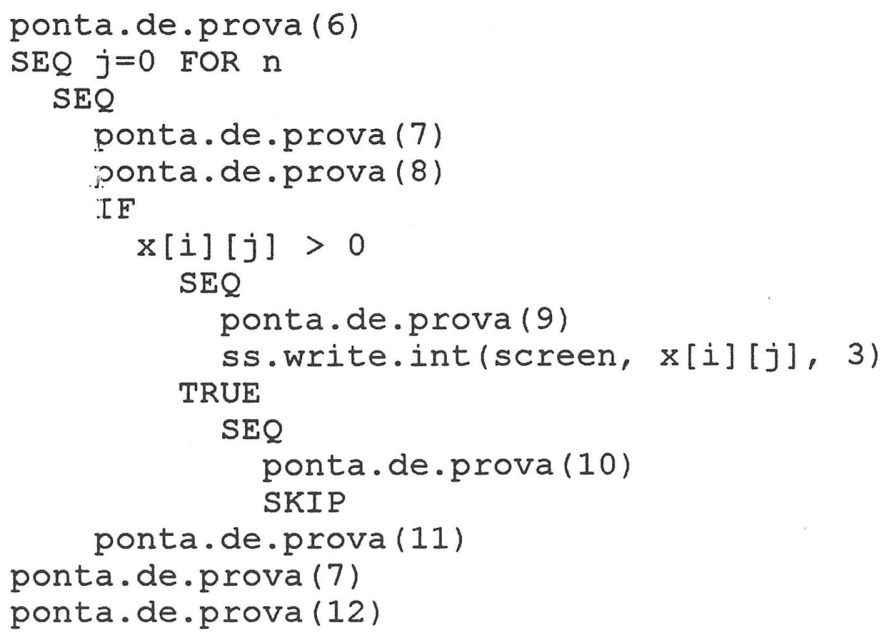




\subsubsection{Comando ALT ... FOR}

O comando ALT ... FOR tem por finalidade tornar disponíveis uma série de guardas. Uma dessas guardas é escolhida não deterministicamente, com execução dos comandos associados a ela.

\section{Exemplo 10:}

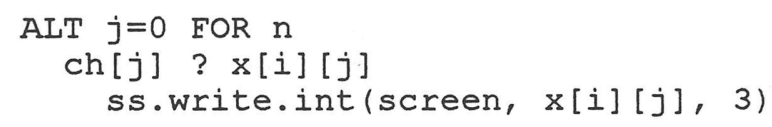

\section{Sintaxe}

A sintaxe do comando ALT ... FOR é dada por

$$
\begin{gathered}
<\text { altfor }>::=\underline{\mathrm{ALT}}<\text { base }>\equiv<\text { name }>\underline{\mathrm{FOR}}<\text { count }><\text { at_ind }>[<\text { specifn }>](<\text { guard }><\text { at_ind }> \\
<\text { process }><\text { des_ind }>\mid<\text { altrtn }>\mid<\text { altfor }>)<\text { des_ind }>
\end{gathered}
$$

\section{Mapeamento para a LIConc}

O comando ALT ... FOR é mapeado para a LIConc conforme consta da Tabela 4.10.

\begin{tabular}{||l|l||}
\hline \multicolumn{1}{|c|}{ Occam } & \multicolumn{1}{c|}{ LIConc } \\
\hline \hline$\underline{\text { ALT }<\text { base }>=<\text { name }>}$ & $<$ alt atm $><s_{1}>$ \\
\hline$\underline{\text { FOR }<\text { count }><\text { at ind }>}$ & $<$ cond for atm $><s_{2}>1$ \\
\hline$<$ specifn $>$ & $<$ dcl $>$ \\
\hline$<$ guard $><$ at ind $>$ & $<$ guard $>$ \\
\hline$<$ process $><$ des ind $>$ & $<$ statement $>$ \\
\hline$<$ des ind $>$ & $?$ \\
\hline \hline
\end{tabular}

Tabela 4.10. Mapeamento do comando ALT ... FOR para a LIConc

\section{Grafo de Fluxo de Controle}

Para a construção do grafo de fluxo de controle para o comando ALT ... FOR tem-se um nó i relativo ao início do comando, um nó $\mathbf{j}$ relativo ao término e um subgrafo intermediário $\mathbf{S}$ relativo à guarda e comandos sob guarda, como se vê na Figura 4.9. A linha pontilhada em forma de ângulo ligando os nós i e j indica a representação de um comando ALT ... FOR. 


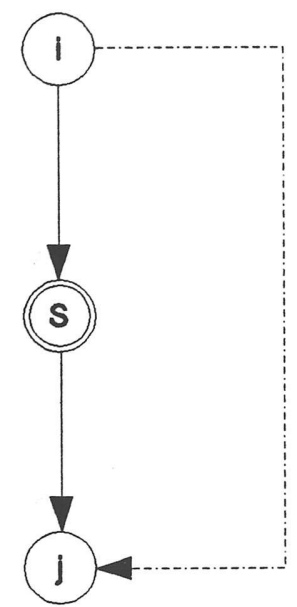

Figura 4.9. Grafo de Fluxo de Controle: Comando ALT ... FOR

\section{Versão em LIConc do Exemplo 10:}

$\begin{array}{llrl}\text { \$ALTFOR1 } & 440 & 4 & 24 \\ \text { \$S16 } & 445 & 5 & 24 \\ \text { \$C (1)6 } & 445 & 0 & 24 \\ \text { \$S17 } & 445 & 0 & 24 \\ \{ & 453 & 0 & 25 \\ \text { \$G(1)1 } & 453 & 15 & 25 \\ \text { \$S18 } & 478 & 32 & 26 \\ \} & 514 & 0 & 27\end{array}$

\section{Versão Instrumentada do Exemplo 10:}

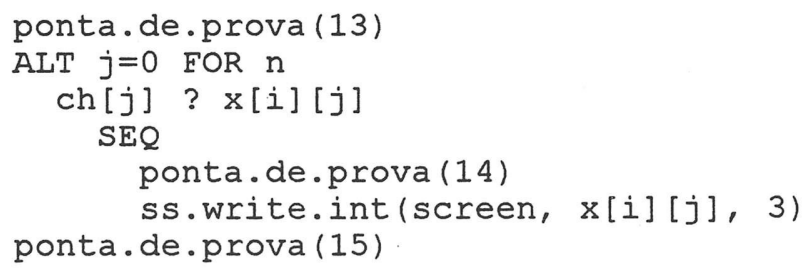

\section{Diretrizes para a Construção do Grafo Def}

Ao nó i do GFC associa-se a variável de controle; ao nó inicial do subgrafo $\mathbf{S}$ associa-se a variável definida na guarda (quando for o caso); a ele e a outros nós do subgrafo $\mathbf{S}$ associam-se as variáveis definidas nos comandos sob guarda; ao nó de encerramento do ALT ... FOR nenhuma variável se associa relativa ao comando. 


\subsubsection{Comando PAR ... FOR}

O comando PAR ... FOR destina-se à execução em paralelo de comandos homogêneos, isto é, comandos que diferem entre si apenas em valores de índices.

\section{Exemplo 11:}

PAR $j=0$ FOR $n$ soma $[j]:=x[0][j] * x[1][j]$

\section{Sintaxe}

A sintaxe do comando PAR ... FOR é dada por

$<$ parfor $>::=\underline{\text { PAR }}<$ base $>\equiv<$ name $>\underline{\text { FOR }}<$ count $><$ at_ind $><$ process $><$ des_ind $>$

\section{Mapeamento para a LIConc}

A Tabela 4.11. mostra o mapeamento do comando PAR ... FOR para a LIConc.

\section{Grafo de Fluxo de Controle}

O grafo de fluxo de controle para o comando PAR ... FOR apresenta nós para início e fim de paralelismo (nós $\mathbf{k}$ e l) e, no seu único ramo paralelo, será representado o subgrafo $\mathbf{S}$ do processo paralelo. A linha tracejada paralela ao ramo indica multiplicidade. Na Figura 4.10. vê-se o grafo de fluxo de controle para o comando PAR ... FOR.

\begin{tabular}{|c|c|}
\hline Occam & LICone \\
\hline$\underline{\mathrm{PAR}}<$ base $>\equiv<$ name $>$ & $<$ par atm $\left.><s_{1}\right\rangle$ \\
\hline$\underline{\mathrm{FOR}}<$ count $><$ at ind $>$ & $<$ cond for $\mathrm{atm}><s_{2}>$ \\
\hline$<$ process $>$ & $<$ br beg atm $><$ statement $>$ \\
\hline$<$ des ind $>$ & $<$ par end atm> \\
\hline
\end{tabular}

Tabela 4.11. Mapeamento do comando PAR ... FOR para a LIConc 
Versão em LIConc do Exemplo 11:

$\begin{array}{llrl}\text { \$PFOR3 } & 537 & 4 & 29 \\ \text { \$S20 } & 541 & 5 & 30 \\ \text { \$C (1)7 } & 546 & 0 & 30 \\ \text { \$S21 } & 546 & 0 & 30 \\ \text { \$I(1) 3 } & 552 & 0 & 31 \\ \text { \$S22 } & 552 & 26 & 31 \\ \text { \$FP3 } & 582 & 0 & 32\end{array}$

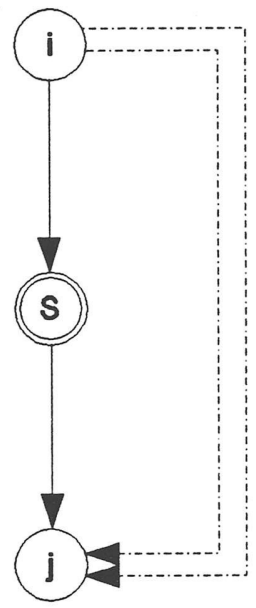

Figura 4.10. Grafo de Fluxo de Controle: Comando PAR ... FOR

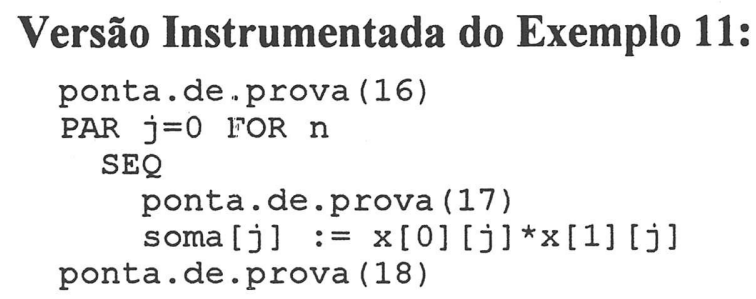

\section{Diretrizes para a Construção do Grafo Def}

No nó k serão definidas as variáveis correspondentes ao bloco de instruções representadas pelo nó e a variável de controle do PAR ... FOR; no nó l, somente as variáveis correspondentes ao bloco. A extensão do subgrafo $\mathbf{S}$ depende do comando que ele representa. 


\subsection{Comandos de Bloco}

Existem vários modos de definição de bloco em Occam tais como os construtores SEQ, PAR, ALT e IF. A definição de processo em Occam corresponde a uma definição de bloco. Deste modo, devemos agir conforme foi indicado para os respectivos comandos em itens anteriores, desde o mapeamento para a LIConc, passando pela construção do grafo de fluxo de controle, criação do programa fonte instrumentado e estabelecimento de diretrizes para definição do grafo de fluxo de controle.

\subsection{Considerações Finais}

Neste capítulo definiram-se a Linguagem Intermediária para Programas Concorrentes -- LIConc -e os modelos de implementação da POKE-TOOL/Occam com base na LIConc visando a apoiar a aplicação dos critérios Potenciais Usos no teste de programas Occam.

Na configuração da POKE-TOOL para Occam, fez-se o mapeamento dos comandos de seqüência, seleção, paralelismo e iteração para a LIConc. Adicionalmente, descreveu-se a construção do grafo de fluxo de controle e fluxo de dados, além da produção do programa instrumentado.

No próximo capítulo será feita a descrição da implementação do mapeamento de Occam para a LIConc. 


\section{Capítulo 5. Aspectos do Mapeamento de Occam para a LIConc}

Este capítulo descreve o exercício de implementação desenvolvido no presente trabalho, que foi fazer o mapeamento de Occam para a LIConc. Remetendo ao projeto da ferramenta, descrito no Capítulo 3, três módulos da POKE-TOOL implementam as funções que são dependentes da linguagem: os módulos li, chanomat e pokernel.

No trabalho de extensão da POKE-TOOL para programas concorrentes a primeira atividade a ser desenvolvida é a configuração do módulo li. Essa atividade deve ser cumprida em duas etapas:

1. desenvolvimento do analisador léxico da linguagem alvo e

2. construção das tabelas sintáticas da linguagem para o analisador sintático da POKETOOL.

Mudanças foram introduzidas nos analisadores léxico e sintático da ferramenta para poderem incorporar características específicas de programas concorrentes, com a produção de rotinas semânticas especiais. Adicionalmente foram construídas as tabelas dos analisadores e rotinas e ações semânticas relacionadas com a configuração de Occam para a LIConc.

\subsection{O Analisador Léxico de Occam}

Em 5.1.1. apresenta-se a análise léxica usando autômatos finitos. Na configuração da POKETOOL para Occam, foi desenvolvido o autômato finito que realiza a análise léxica da linguagem. $\mathrm{O}$ autômato foi armazenado na Tabela de Transições Léxicas que é mostrada em 5.1.2. A Tabela de Palavras Reservadas armazena as palavras reservadas da linguagem e é apresentada em 5.1.3. O trabalho é complementado com a descrição das ações semânticas que foram introduzidas, que são mostradas no Apêndice B. $\mathrm{O}$ analisador léxico foi depurado juntamente com as ações semânticas desenvolvidas. 


\subsubsection{Análise Léxica Usando Autômatos Finitos}

O passo inicial na compilação de programas e mesmo na análise de código fonte é o processo de análise léxica. A análise léxica separa os itens constituintes de uma linguagem -- itens léxicos -- e determina suas classes. Como exemplos de classes de itens léxicos têm-se identificadores, palavras reservadas, símbolos especiais e constantes.

Como a POKE-TOOL faz análise do código fonte para determinar os caminhos requeridos pelos critérios Potenciais Usos, foi necessário dessenvolver um algoritmo que fizesse análise léxica da unidade em teste. Entretanto, era também desejado que a POKE-TOOL pudesse ser configurada para uma determinada classe de linguagens. Por isso, foi escolhido um algoritmo genérico de análise léxica para a POKE-TOOL.

Uma forma de apresentar um algoritmo genérico [SET81] para a análise léxica é utilizando autômatos finitos.

A esse analisador léxico foi acrescida a facilidade de executar em paralelo com o analisador sintático. A comunicação entre os dois analisadores é feita por meio de um buffer que recebe os itens produzidos pelo analisador léxico, servindo de entrada para o analisador sintático à medida que este necessita dos itens.

\subsubsection{Tabela de Transições do Autômato}

$\mathrm{O}$ algoritmo de análise interpreta um autômato finito cujas transições foram organizadas numa estrutura de dados criada a partir de uma entrada do usuário. A interpretação do autômato é baseada na pela estrutura de dados que representa as transições e por caracteres lidos do programa fonte. Associadas às transições do autômato estão as ações semânticas, isto é, rotinas que são executadas quando uma determinada transição ocorre.

Na Tabela 5.1. é apresentada a tabela de transições e os estados finais do autômato finito do analisador léxico de Occam. A tabela é organizada por linhas, onde o primeiro elemento identifica o símbolo lido, o segundo elemento identifica o estado atual, o terceiro elemento define o próximo 
estado, o quarto elemento indica a ação semântica a ser executada e o quinto elemento fornece a próxima transição. A primeira linha da tabela é a linha número 0 . Como exemplo, observe-se a linha número 6: corresponde à leitura do símbolo '-', estando no estado inicial (estado 0), vai para o estado número 60 , executa a ação semântica 1 e passa para a transição descrita na linha número 46 . $O$ estado de número 1000 corresponde ao estado final do autômato. A tabela está armazenada num arquivo em formato ASCII, o arquivo TABTRANS.TSR.
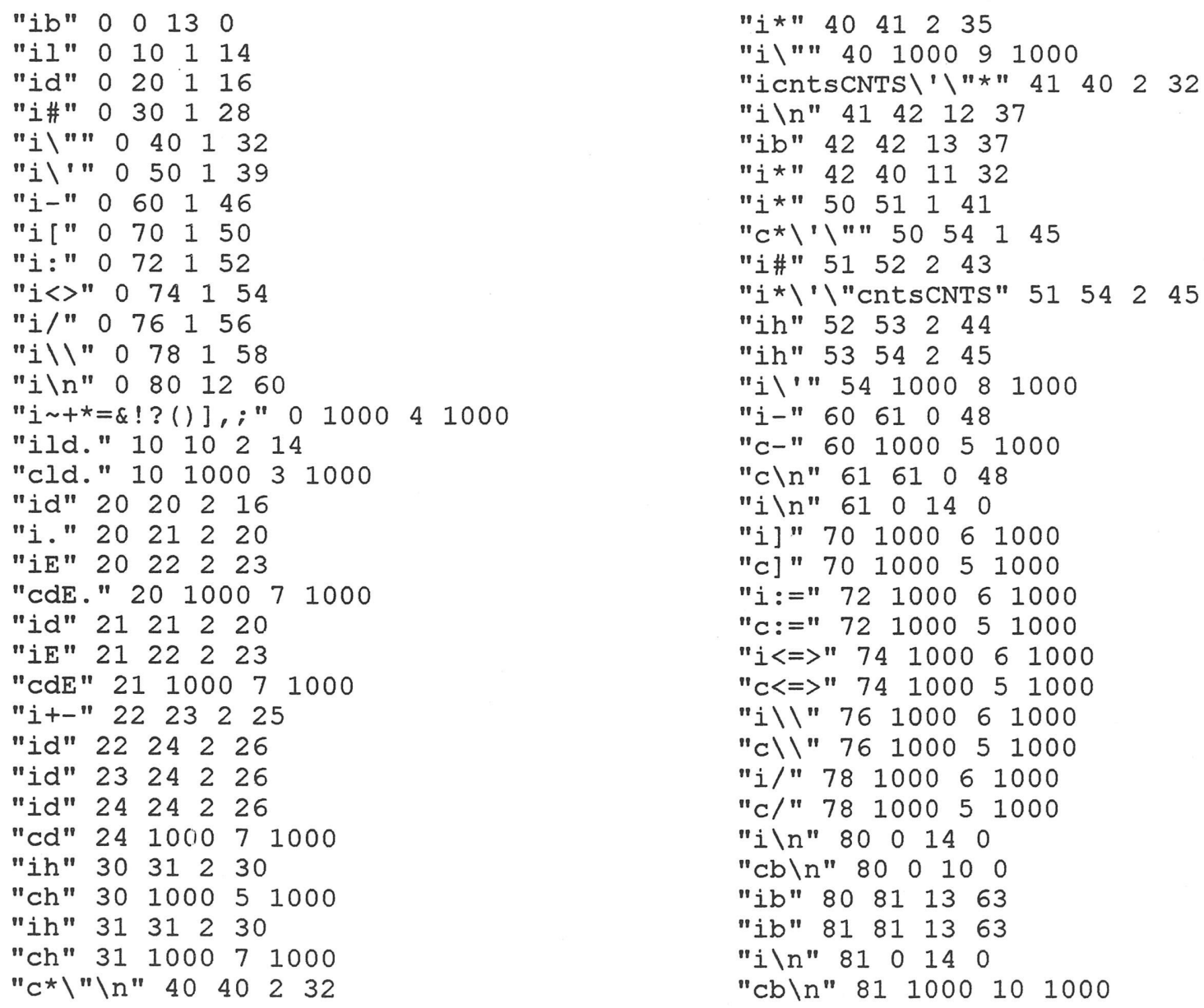

Tabela 5.1. Tabela de Transições do Autômato de Occam

\subsubsection{Tabela de Palavras Reservadas da Linguagem Occam}

A Tabela 5.2. apresenta a tabela de palavras reservadas de Occam, que fica armazenada no arquivo 


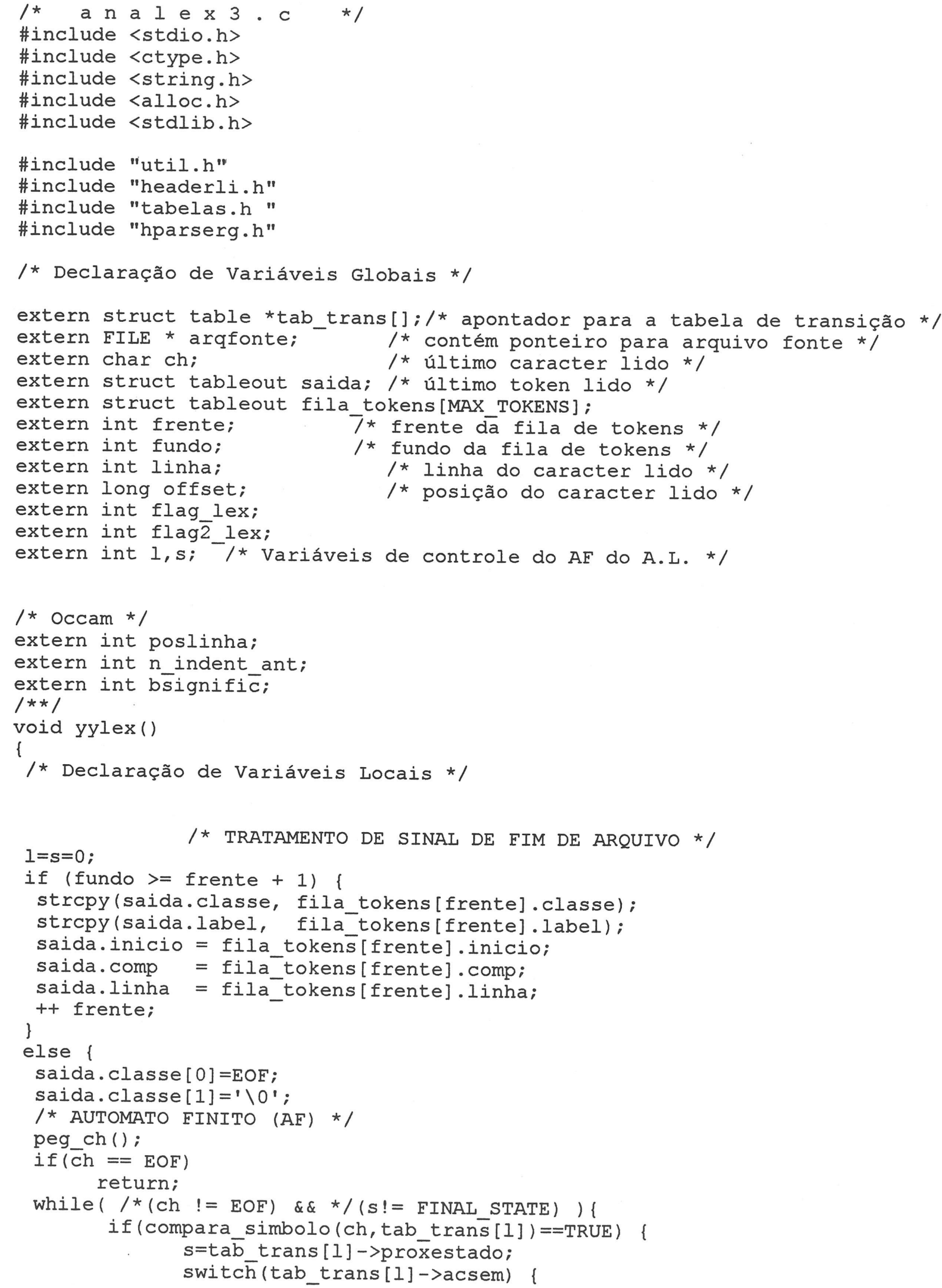




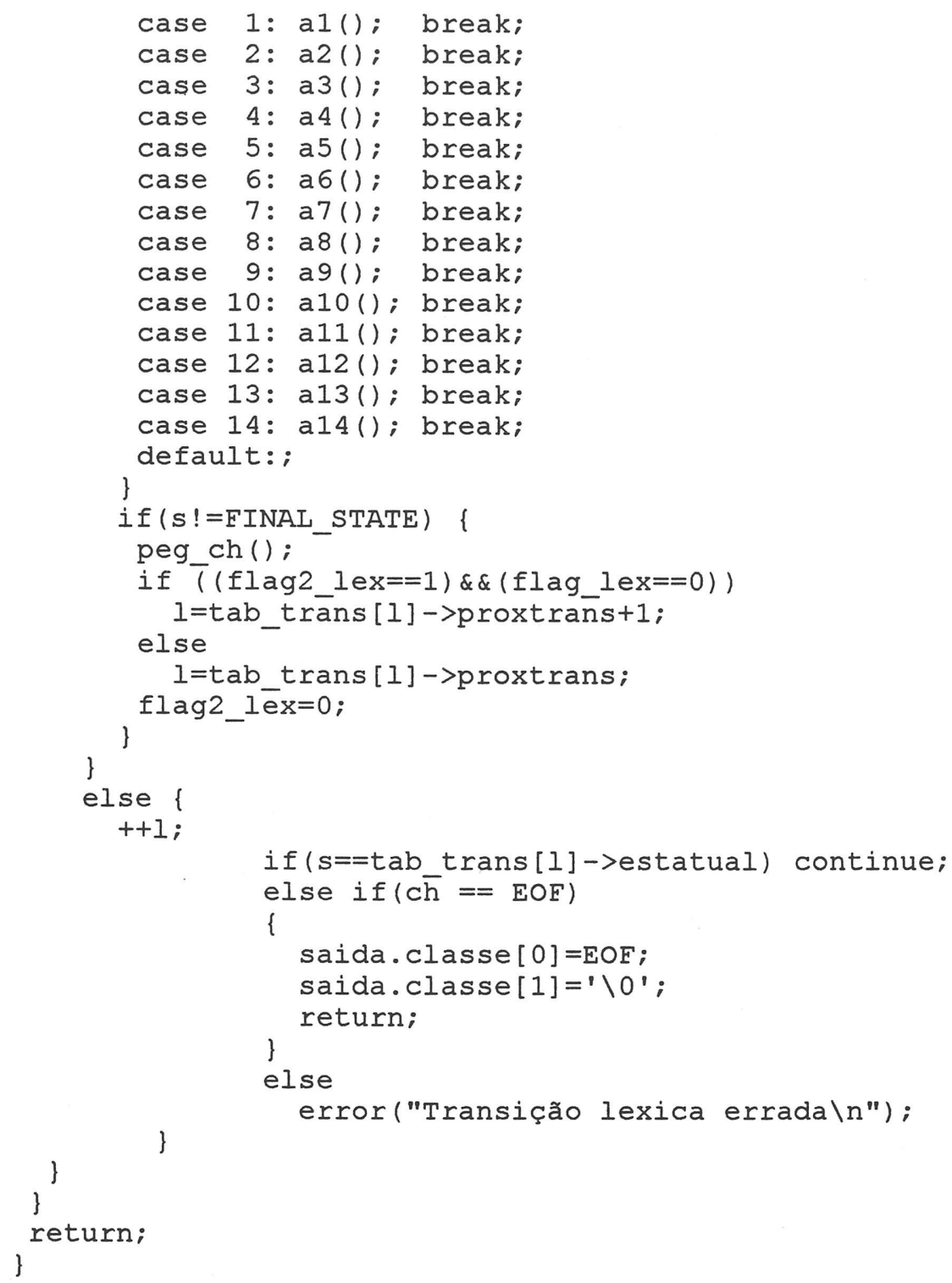

\subsection{Análise Sintática}

A segunda etapa do mapeamento de Occam para a LIConc compreende a configuração do analisador sintático da POKE-TOOL para a nova linguagem. Inicialmente, em 5.2.1., observam-se as restrições apresentadas pelo algoritmo de análise sintática da POKE-TOOL. Em 5.2.2. é feita a descrição da gramática de Occam para uma gramática aceita pela POKE-TOOL. No Apêndice C são mostradas as rotinas semânticas do analisador sintático, onde novas rotinas foram criadas para atender as novas situações consideradas pela LIConc. 


\subsubsection{O Algoritmo de Análise Sintática}

Wirth propõe um algoritmo de análise sintática descendente, isto é, a partir do símbolo inicial reconstroem-se os passos de geração da sentença final. Na POKE-TOOL o algoritmo foi implementado de maneira ligeiramente diferente porque a POKE-TOOL não só reconhece sentenças mas também obtém informações para obtenção do grafo def [CHA91].

A intenção foi produzir um algoritmo genérico e eficiente. Durante o processo de análise sintática deseja-se que todo passo da análise dependa unicamente do estado atual da computação e do próximo símbolo a ser lido. Passo já executado não precisa ser recuperado. É um algoritmo com um lookahead e sem backtracking.

Gramáticas para este algoritmo têm limitações. A seguir, são colocadas duas restrições impostas a gramáticas escritas de forma que sejam entrada para esse algoritmo [CHA91].

$\mathbf{1}^{\mathrm{a}}: \mathbf{A}::=\mathbf{e}_{1}\left|\mathbf{e}_{2}\right| \ldots \mid \mathbf{e}_{\mathrm{n}}$ : os conjuntos de símbolos iniciais de todas as sentenças que podem ser geradas a partir dos símbolos $\mathbf{e}_{\mathbf{i}}$ devem ser disjuntos.

$2^{a}$ : Não terminal A que gera a seqüência nula $\lambda$ : o conjunto de símbolos iniciais deve ser diferente do conjunto de símbolos que podem seguir seqüências geradas por $\mathbf{A}$.

Atendendo a essas restrições tomou-se a gramática original de Occam [INM88] e fez-se a sua transformação para o padrão aceito pela POKE-TOOL. É o que se vê a seguir.

\subsubsection{Descrição Sintática de Occam}

A gramática da linguagem Occam a ser analisada pela POKE-TOOL deve ser descrita em um arquivo chamado TABSIN.TSR, em formato ASCII. Como o algoritmo de análise sintática faz análise descendente (top-down), é necessário começar a descrição do arquivo pela primeira produção que deve ser reconhecida. A forma de descrever uma produção da gramática é baseada na notação estendida de Backus-Naur. A Tabela 5.3. mostra a equivalência dos símbolos. 


\begin{tabular}{|c|c|}
\hline BNF Estendida & POKE-TOOL \\
\hline \hline$::=$ & $=$ \\
\hline 1 &, \\
\hline\{ & {[} \\
\hline$\}$ & ] \\
\hline$\in$ & $\star$ \\
\hline
\end{tabular}

Tabela 5.3. Equivalência de Símbolos entre a BNF e a POKE-TOOL

Ainda, a notação aceita pela POKE-TOOL exige que cada produção seja terminada por um ponto ('.'). Os símbolos terminais são precedidos e terminados com apóstrofo (' ' '). Dessa maneira, a produção

formal = formaux specifr 'IDENT' [ ',' 'IDENT' $]$.

indica a definição do não terminal formal como sendo a concatenação dos não terminais formaux, specifr e de um ou mais terminais IDENT separados por vírgula.

O arquivo TABSIN.TSR presta-se tabém a indicar as rotinas semânticas a serem executadas quando um dado item de uma produção é reconhecido. Faz-se isto colocando o número da rotina semântica a ser executada ao lado do símbolo da produção sendo reconhecido. Considere, por exemplo, a seguinte produção :

procaux $1=$ '!' element 54 ,'?' element 54 .

Nesta produção, quando se fizer o reconhecimento de element, será ativada a rotina semântica 54.

A seguir, apresenta-se a gramática de Occam transformada para uma forma aceita pela POKE-TOOL. 


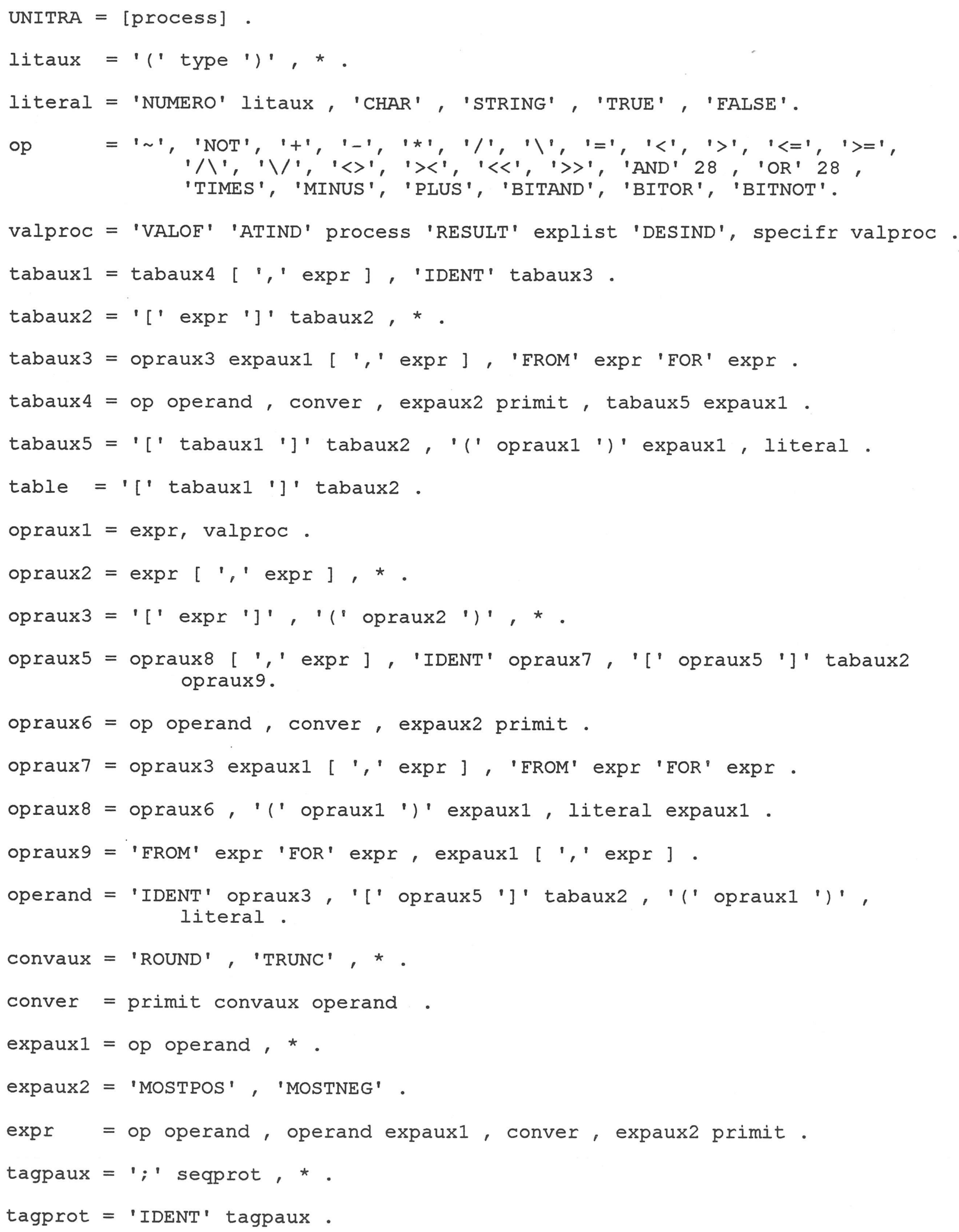




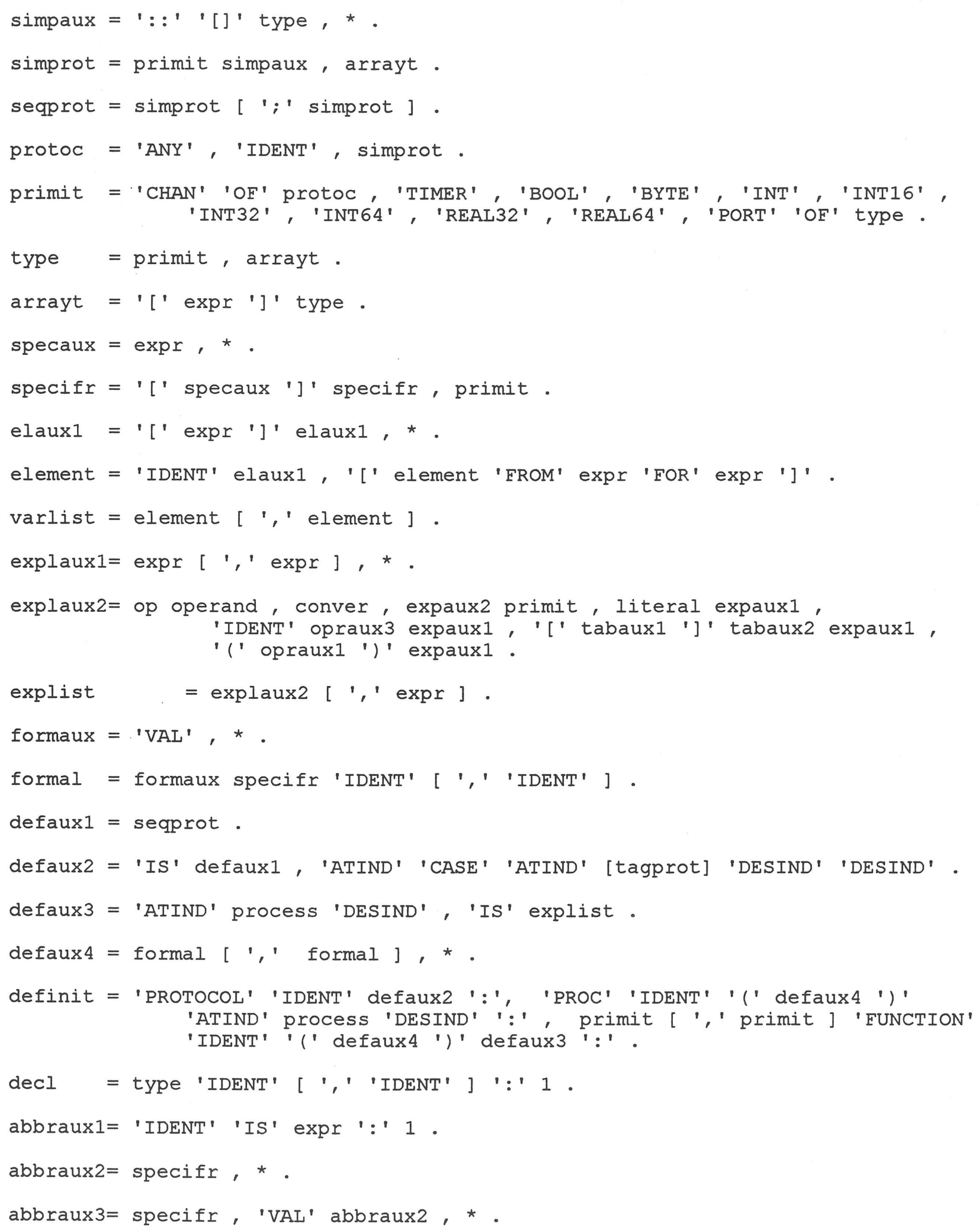




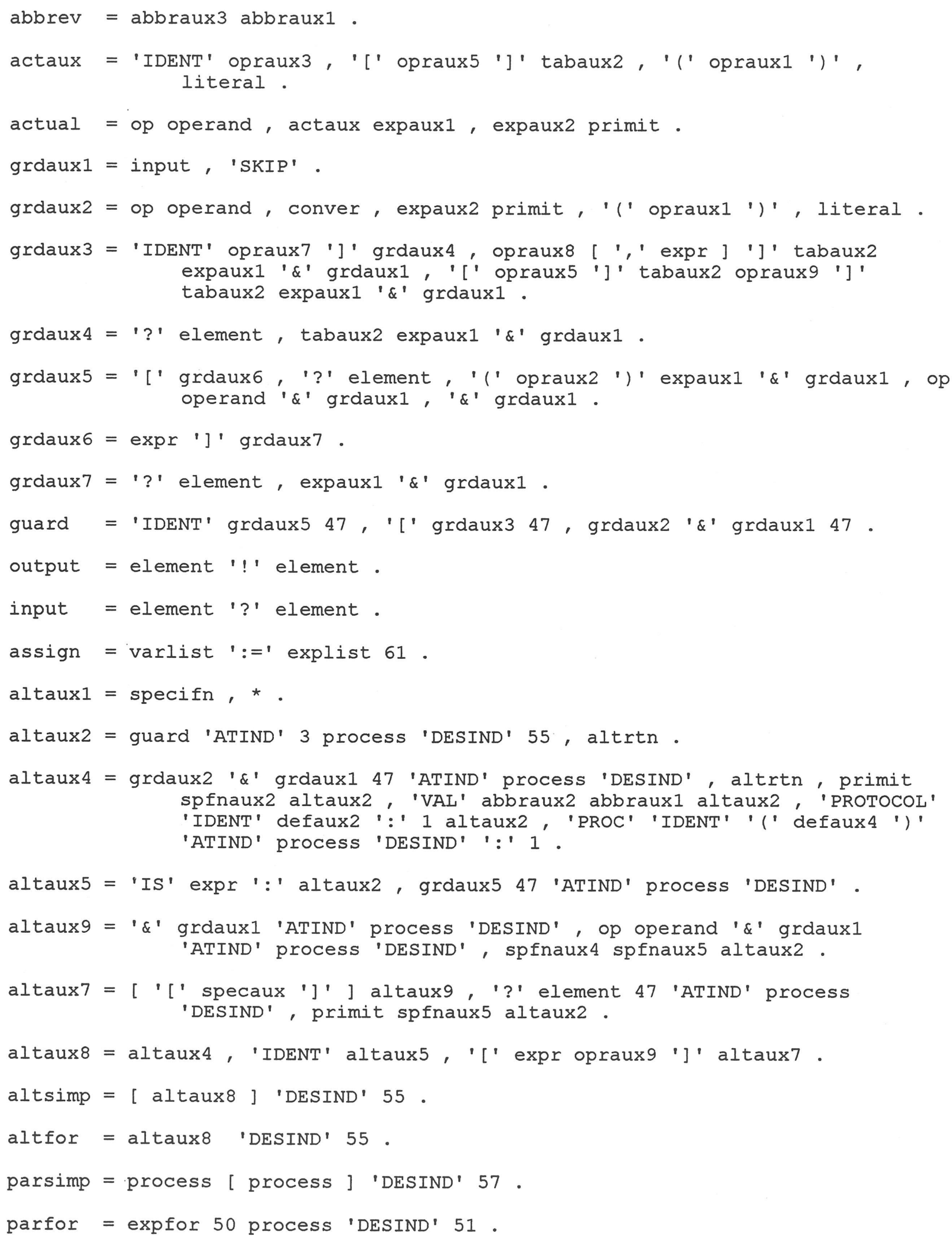




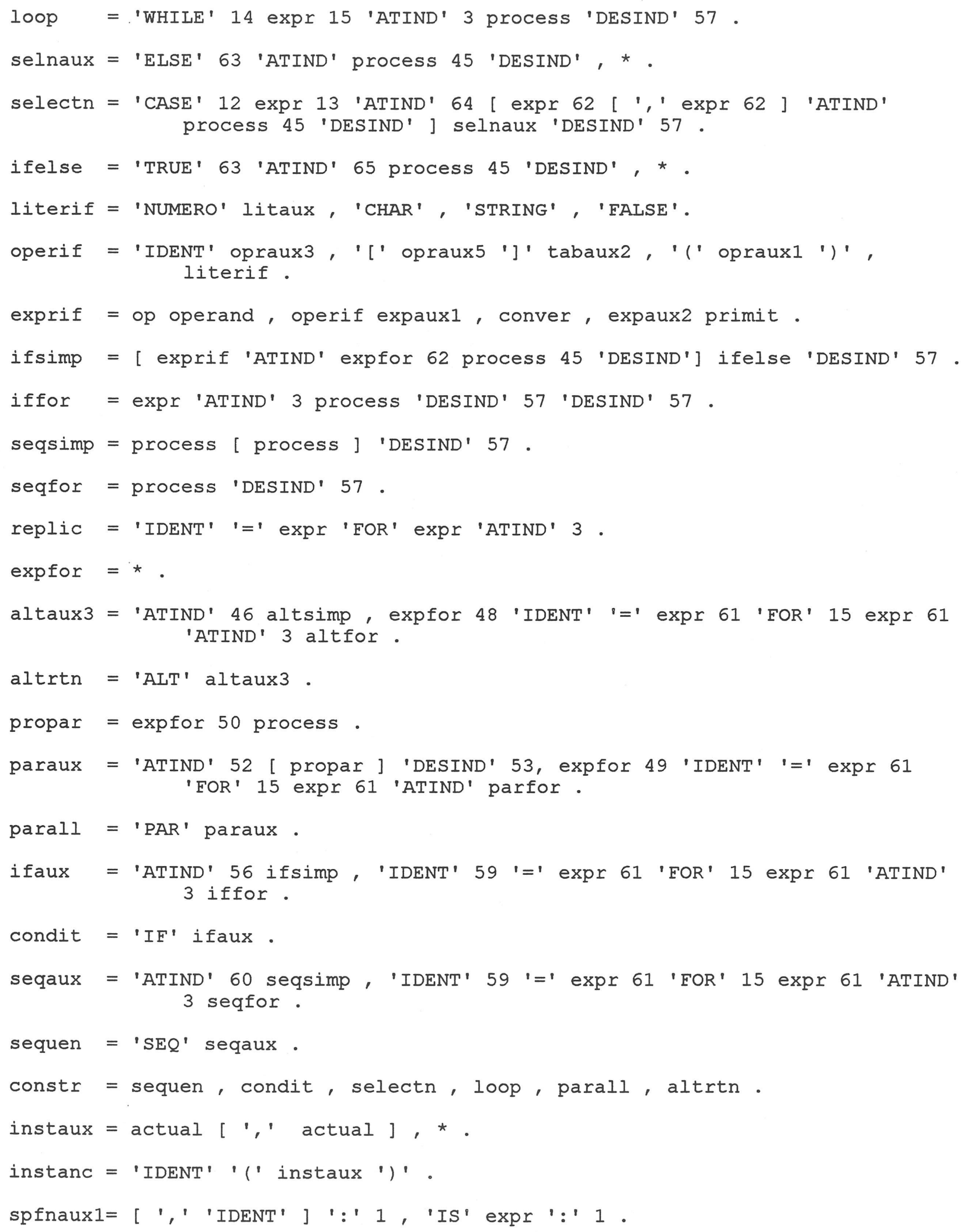




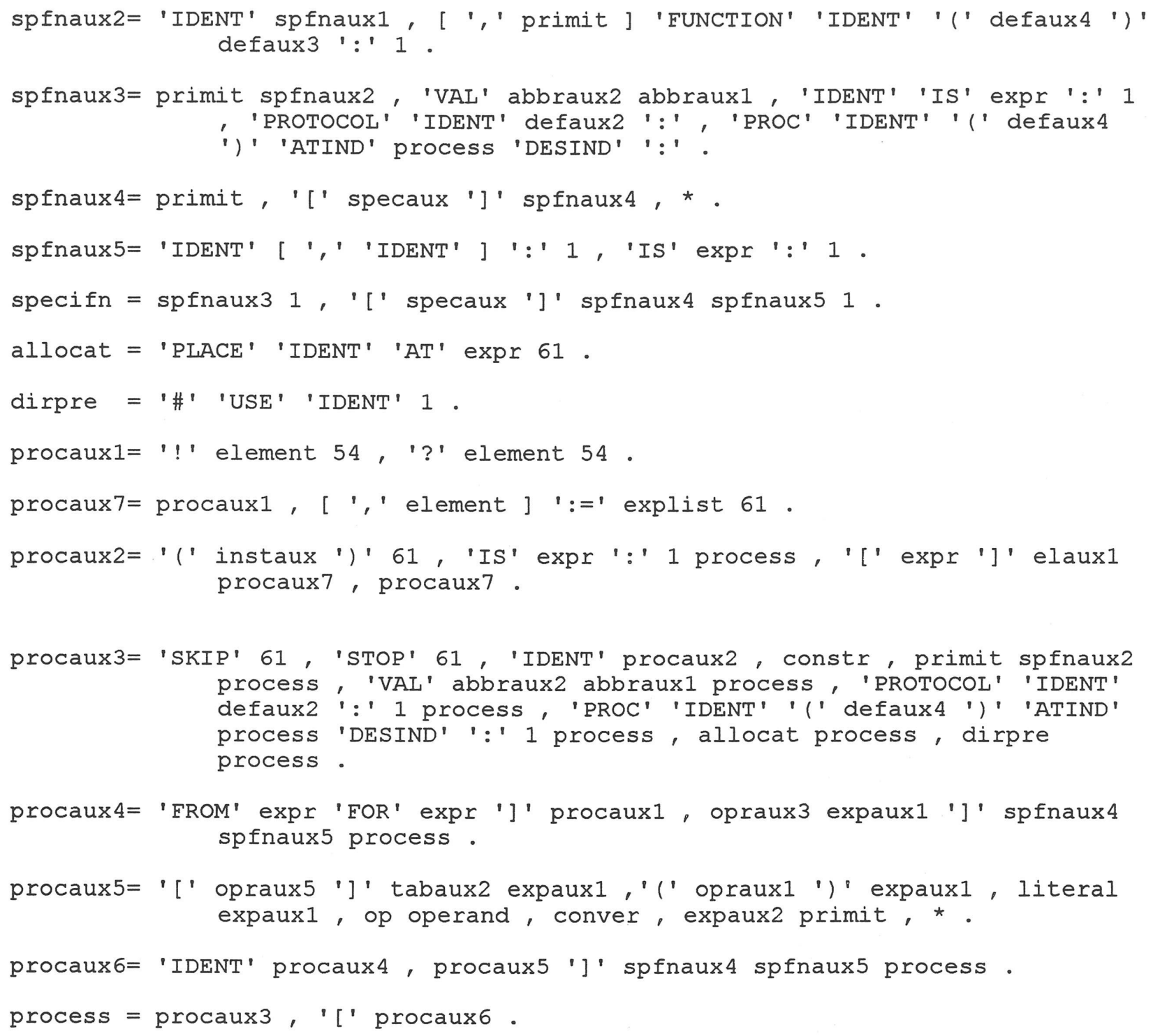

\subsection{Um Exemplo}

Seja o programa exemplo listado na Figura 2.2., Capítulo 2. O seu mapeamento para a LIConc resultou no programa EXEMPLO.LI, apresentado a seguir. 


\begin{tabular}{|c|c|c|c|}
\hline$\$ D C L$ & 32 & 13 & 2 \\
\hline$\$ D C L$ & 84 & 16 & 4 \\
\hline$\$ D C L$ & 102 & 11 & 5 \\
\hline \$DCL & 115 & 26 & 6 \\
\hline \$DCL & 143 & 25 & 7 \\
\hline\{ & 217 & 3 & 9 \\
\hline$\$ S 01$ & 224 & 25 & 10 \\
\hline \$SO2 & 281 & 36 & 11 \\
\hline \$SO3 & 346 & 28 & 12 \\
\hline$\$ P(02) 01$ & 451 & 3 & 14 \\
\hline SI (01) 01 & 507 & 0 & 16 \\
\hline\{ & 507 & 3 & 16 \\
\hline \$CASE & 587 & 2 & 18 \\
\hline$\$ C C$ & 589 & 0 & 18 \\
\hline\{ & 599 & 0 & 19 \\
\hline \$ROTC & 599 & 33 & 19 \\
\hline \$SO4 & 645 & 17 & 20 \\
\hline \$BREAK & 670 & 0 & 0 \\
\hline \$ROTC & 671 & 33 & 21 \\
\hline\{ & 716 & 3 & 22 \\
\hline \$SO5 & 733 & 11 & 23 \\
\hline$\$ S 06$ & 759 & 15 & 24 \\
\hline$\}$ & 774 & 0 & 24 \\
\hline \$BREAK & 782 & 0 & 0 \\
\hline \$ROTC & 783 & 33 & 25 \\
\hline$\$ \$ 07$ & 829 & 11 & 26 \\
\hline \$BREAK & 848 & 0 & 0 \\
\hline \$ROTD & 849 & 4 & 27 \\
\hline\{ & 865 & 3 & 28 \\
\hline \$S08 & 882 & 11 & 29 \\
\hline \$S09 & 908 & 11 & 30 \\
\hline$\}$ & 919 & 0 & 30 \\
\hline \$BREAK & 925 & 0 & 0 \\
\hline$\}$ & 925 & 0 & 31 \\
\hline \$CASE & 970 & 4 & 32 \\
\hline$\$ C C$ & 975 & 5 & 32 \\
\hline\{ & 989 & 0 & 0 \\
\hline \$ROTC & 991 & 3 & 33 \\
\hline \$ROTC & 995 & 3 & 33 \\
\hline \$ROTC & 999 & 3 & 33 \\
\hline \$ROTC & 1003 & 3 & 33 \\
\hline \$ROTC & 1007 & 3 & 33 \\
\hline \$S10 & 1021 & 13 & 34 \\
\hline \$BREAK & 1043 & 0 & 0 \\
\hline \$ROTD & 1044 & 4 & 35 \\
\hline \$S11 & 1060 & 15 & 36 \\
\hline \$BREAK & 1079 & 0 & 0 \\
\hline$\}$ & 1079 & 0 & 36 \\
\hline$\}$ & 1079 & 0 & 36 \\
\hline SI (02) 01 & 1172 & 0 & 39 \\
\hline \$ALT01 & 1172 & 3 & 39 \\
\hline\{ & 1182 & 0 & 0 \\
\hline$\$ G(01) 01$ & 1183 & 6 & 40 \\
\hline \$SS01 & 1199 & 7 & 41 \\
\hline$\$ G(02) 01$ & 1214 & 7 & 42 \\
\hline \$S12 & 1231 & 11 & 43 \\
\hline$\}$ & 1242 & 0 & 0 \\
\hline
\end{tabular}




$\begin{array}{lrrr}\text { \$FP01 } & 1244 & 0 & 44 \\ \text { \$S13 } & 1321 & 28 & 46 \\ \text { \$S14 } & 1353 & 30 & 47 \\ \text { \$S15 } & 1387 & 26 & 48 \\ \} & 1413 & 0 & 48\end{array}$

\subsection{Considerações Finais}

Foi descrito, neste capítulo, o trabalho de implementação que consistiu em produzir o mapeamento de programas Occam para a LIConc. Alterações foram introduzidas no analisador léxico da POKETOOL, com a inclusão de novas ações semânticas e construção das tabelas do analisador. No trabalho de desenvolvimento do analisador sintático pequenas alterações foram feitas nas funções do analisador, novas rotinas semânticas foram criadas e se fez o mapeamento da gramática original de Occam para uma gramática aceita pela POKE-TOOL. Com a apresentação de um exemplo pode-se observar a funcionalidade do programa de mapeamento. No próximo capítulo são apresentadas as conclusões deste trabalho. 


\section{Capítulo 6. Conclusões e Trabalhos Futuros}

\subsection{Conclusões}

A Engenharia de Software tem como objetivo o desenvolvimento de software com custo adequado e qualidade controlada. Para controlar a qualidade do processo de construção e do produto que está sendo construído devem ser executadas atividades de garantia de qualidade de software. $\mathrm{O}$ desenvolvimento dessas atividades implica no uso de métodos, técnicas e ferramentas para desenvolvimento do software, na aplicação de revisões e inspeções durante a construção do software e no emprego de atividades de teste.

Considerando esse contexto, foram definidos os objetivos do presente trabalho que consistiram em levantar características de programas concorrentes, definir uma linguagem intermediária para programas concorrentes -- a LIConc -- e construir o módulo de mapeamento de Occam para a LIConc.

Neste trabalho estudou-se com maior ênfase os critérios de fluxo de dados para o teste estrutural de programas seqüenciais, com uma atenção maior para os critérios Potenciais Usos e para a ferramenta POKE-TOOL, que foi construída para a sua aplicação. Essa escolha deveu-se, fundamentalmente, à experiência consolidada dos grupos de Engenharia de Software do ICMSC-USP e do DCA/FEE/UNICAMP que cooperam nesta linha de pesquisa. Foram estudadas também algumas propostas para o teste de programas concorrentes. Como muito do teste de programas concorrentes pode basear-se no teste de programas seqüenciais, buscou-se reunir idéias no sentido de estender e configurar a ferramenta POKE-TOOL para alguma linguagem de programação concorrente. 
Algumas linguagens de programação concorrente foram estudadas. Dentre elas, Occam foi tratada com maior atenção. Em suma, viu-se que uma linguagem de programação concorrente possui as construções de uma linguagem de programação seqüencial acrescida das construções de paralelismo e cooperação. Daí, observou-se a possibilidade de extensão e configuração da POKETOOL para a linguagem Occam. Nesse trabalho procurou-se construir os modelos de implementação da POKE-TOOL para Occam considerando também a configuração da ferramenta para outras linguagens de programação concorrentes.

A solução encontrada consistiu em definir uma linguagem intermediária para programas concorrentes, a LIConc, procurando manter na extensão da POKE-TOOL para programas concorrentes a característica multilinguagem.

A tarefa seguinte consistiu em implementar o módulo que permite o mapeamento de programas Occam para a LIConc, buscando reaproveitar ao máximo o código do módulo li da POKE-TOOL para programas seqüenciais. Nessa atividade algumas rotinas da ferramenta foram reformuladas e no mapeamento de Occam para a LIConc foram construídas as tabelas dos analisadores léxico e sintático. O módulo de mapeamento de Occam para a LIConc foi codificado em C, estando disponível para PC sob DOS.

\subsection{Trabalhos Futuros}

Como continuidade do presente trabalho, destaca-se, a curto prazo, a programação de todos os modelos de implementação para critérios de fluxo de dados, visto que as diretrizes para a implementação dos modelos de fluxo de controle, de fluxo de dados e de instrumentação já estão estabelecidas e o modelo de elementos requeridos é um modelo que não depende da linguagem. Uma vez concluída essa atividade, a elaboração e aplicação de um benchmark visando a avaliação do custo e eficácia de aplicação de critérios de teste estruturais seria uma continuidade natural deste trabalho. 
No teste de programas concorrentes, adicionalmente, deve-se considerar a sincronização. Assim, outra atividade a desenvolver seria acrescentar à POKE-TOOL para Occam um modelo de sincronização, para tratar os aspectos relacionados com a sincronização. Para tanto, no projeto da LIConc previu-se a introdução futura desse modelo na POKE-TOOL para Occam, ao se criar instruções específicas na LIConc para instruções da linguagem de programação relacionadas com a sincronização.

Uma outra atividade para ser desenvolvida a curto prazo seria o desenvolvimento dos aspectos de visualização do grafo de programa concorrente, uma vez que se levou em consideração esse aspecto no projeto da LIConc.

Finalmente, um outro trabalho relevante para o aprimoramento da LIConc será conduzir o mapeamento de outras linguagens concorrentes ou paralelas como CPAR ou, mesmo, LOTOS, no sentido de validar e concretizar as construções básicas da LIConc. 


\section{Referências Bibliográficas}

[ALM94] Almasi, G. S., Gottlieb, A., Highly Parallel Computing, $2^{\mathrm{a}}$ ed., Benjamin/Cummings, 1994.

[BAL89] Bal, H. E., Steiner, J. G., Tanenbaum, A. S., Programming Languages for Distributed Computing Systems, Comput. Surveys, 21(3), setembro 1989, pp 261-322.

[BAR89] Barnes, J. G. P., Programming in Ada, Addison-Wesley, 1989.

[CAR91] Carver, R. H., Tai, K. C., Replay and Testing for Concurrent Programs, IEEE Software, 8(2), março 1991, pp 66-74.

[CHA91] Chaim, M. L., POKE-TOOL - Uma Ferramenta para Suporte ao Teste Estrutural de Programas Baseado em Análise de Fluxo de Dados, Tese de Mestrado, DCA / FEE / UNICAMP, abril 1991.

[COW88] Coward, P. D., A Review of Software Testing, Info. Soft. Tech., 30(3), abril 1988, pp 189-198.

[DEL93] Delamaro, M. E., Proteum - Um Ambiente de Teste Baseado na Análise de Mutantes, Dissertação de Mestrado, SCE / ICMSC / USP, outubro 1993.

[FID89] Fidge, C. J., Partials Orders for Parallel Debugging, Sigplan Notices, 24(1), janeiro 1989, pp 183-194.

[FRA88] Frankl, P. G., Weyuker, E. J., An Applicable Family of Data Flow Testing Criteria, IEEE Trans. Soft. Eng., 14(10), outubro 1988, pp 1483-1498.

[GAI86] Gait, J., A Probe Effect in Concurrent Programs, Soft. Pract. Exp., 16(3), março 1986, pp 225-233. 
[GEH89] Gehani, N. H., Roome, W. D., The Concurrent C Programming Language, Silicon Press, Summit, N.J., 1989.

[HAR91] Harrold, B., Soffa, M. L., Selecting and Using Data for Integration Testing, IEEE Software, 8(2), março 1991, pp 58-65.

[HOA85] Hoare, C. A. R., Communicating Sequential Processes, Prentice Hall, 1985.

[HOW89] Howden, W. E., Validating Programs without Specifications in Proc. $3^{\text {rd }}$ Symp. on Soft. Testing, Analysis, and Verification, Soft. Eng. Notes, 14(8), pp 2-9, dezembro 1989.

[INM88] INMOS Limited, Occam 2 Reference Manual, Prentice Hall, 1988.

[INM90] INMOS Limited, Transputer Development System, Prentice Hall, $2^{\mathrm{a}}$ ed., 1990.

[JON88] Jones, G., Goldsmith, M., Programming in Occam 2, Prentice Hall, 1988.

[KOR92] Korel, B., Wedde, H., Ferguson. R., Dynamic Method of Test Data Generation for Distributed Software, Info Soft. Tech., 34(8), agosto 1992, pp 523-531.

[LEI92] Leitão Jr., P. S., Suporte ao Teste de Programas COBOL no Ambiente POKE-TOOL, Dissertação de Mestrado, FEE/UNICAMP, Campinas, SP, agosto 1992.

[LUT90] Lutz, M., Testing Tools, IEEE Software, 7(3), maio 1990, pp 53-57.

[MAL88] Maldonado, J. C., Chaim, M. L., Jino, M., Seleção de Casos de Teste Baseada nos Critérios Potenciais Usos, in Proc. II Simpósio Brasileiro de Engenharia de Software, Canela, RS, outubro 1988, pp 24-35.

[MAL89] Maldonado, J. C., Chaim, M. L., Jino, M., Arquitetura de uma Ferramenta de Teste de Apoio aos Critérios Potenciais Usos, in Proc. XXII Congresso Nacional de Informática, São Paulo, SP, setembro 1989. 
[MAL91] Maldonado, J. C., Critérios Potenciais Usos: Uma Contribuição ao Teste Estrutural de Software, Tese de Doutorado, FEE/UNICAMP, Campinas, SP, 1991.

[MCD89] McDowell, C. E., Helmbold, D. P., Debugging Concurrent Programs, Comput. Surveys, 21(4), dezembro 1989, pp 593-622.

[MIL80] Milner, A. J. R. G., A Calculus of Communicating Systems, Lec. Notes Comp. Sci., Vol 92, Springer-Verlag, 1980.

[MIL89] Milner, R., Communication and Concurrency, Prentice Hall, Englewood Cliffs, NJ, 1989, $260 \mathrm{pp}$.

[MIT88] Mitchell, H. J. (coordenador), 32 Bits - Microprocessador, Mc Graw Hill, 1988.

[MYE79] Myers, G. J., The Art of Software Testing, John Wiley \& Sons, 1979, 177 pp.

[NTA88] Ntafos, S. C., A Comparison of Some Structural Testing Strategies, IEEE Trans. Soft. Eng., 14(6), junho 1988, pp 868-873.

[PRE92] Pressman, R. S., Software Engineering - A practitioner's approach, $3^{\mathrm{a}} \mathrm{ed} ., \mathrm{Mc}$ Graw Hill, 1992.

[RAP85] Rapps, S., Weyuker, E. J., Selecting Software Test Data Using Data Flow Information, IEEE Trans. Soft. Eng., 11(4), abril 1985, pp 367-375.

[SA T93] Sato, L. M.,Programação Paralela e Compiladores, Anais do Workshop sobre Computação de Alto Desempenho, agosto-setembro 1993, São Carlos, SP, pp 74-85.

[SET81] Setzer, V. W., Melo, I. S. H., A Construção de um Compilador, $3^{\text {a }}$ ed., Editora Campus, Rio de Janeiro, RJ, 1981. 
[TA191] Tai. K. C., Carver, R. H., Obaid, E. E., Debugging Concurrent Ada Programs by Deterministic Execution, IEEE Trans. Soft. Eng., 17(1), janeiro 1991, pp 45-63.

[TAY83] Taylor, R. N., A General-Purpose Algorithm for Analyzing Concurrent Programs, Comm.ACM, 26(5), maio 1983, pp 362-376.

[VIL94a] Vilela, P. R. S., Uma Ferramenta para Auxílio Visual ao Teste e Depuração de Programas, Dissertação de Mestrado, DCA/FEE/UNICAMP, Campinas, SP, março 1994.

[VIL94b] Vilela, P. R. S., Maldonado, J. C., Jino, M., Chaim, M. L., Visualização de Grafos de Programa: Uma Abordagem sem Reposicionamento, VII SIBGRAPI, novembro 1994, pp. 189-196.

[TAY92] Taylor, R. N., Levine, D. L., Kelly, C. D., Structural Testing of Concurrent Programs, IEEE Trans. Soft. Eng., 18(3), março 1992, pp 206-215.

[WIR77] Wirth, N., Modula: A Language for Modular Multiprogramming, Soft. Pract. Exp, 7(1), janeiro-fevereiro 1977, pp 3-35.

[YAN92] Yang, R. D., Chung, C. G., Path Analysis Testing of Concurrent Programs, Info. Soft. Tech., 34(1), janeiro 1992.

[YOU89] Young, M., Taylor, R. N., Forester. K., Brodbeck, D., Integrated Concurrency Analysis in a Software Development Environment, in Proc. $3^{\text {rd }}$ Symp. Soft. Test., Analysis and Verif., Soft. Eng. Notes, 14(8), dezembro 1989, pp 200-209.

[YOU90] Yourdon, E., Análise Estruturada Moderna, Editora Campus, Rio de Janeiro, RJ, 1990. 


\section{Apêndice A. A 니Conc - Linguagem Intermediária para Programas Concorrentes}

Este apêndice apresenta uma síntese da descrição da Linguagem Intermediária para programas seqüenciais [CHA91] com o acréscimo de construções para a análise de programas concorrentes. A LI visa a identificar o fluxo de execução em um programa. Basicamente, a LI tem dois tipos de comandos: os comandos de seqüência e os comandos de controle de fluxo. Os comandos de seqüência da LI indicam os comandos das linguagens procedimentais que representam uma declaração de variável ou uma computação (comandos de atribuição, de entrada e de saída ou de chamadas de procedimentos) e que, portanto, não alteram o fluxo de execução. Os comandos de controle de fluxo da LI são equivalentes aos comandos das linguagens procedimentais que causam seleção, iteração e desvio incondicional.

Uma característica própria da LI é que todos os átomos da linguagem são seguidos por números que identificam, respectivamente, o início do átomo no arquivo fonte da unidade em teste , o comprimento do átomo e a linha onde está o átomo.

Este apêndice mostrará as construções da LI em BNF, de tal forma que os símbolos não terminais serão representados em itálico entre "<" e ">", os símbolos terminais em formato sublinhado e os meta-símbolos em negrito. Dessa maneira, em BNF, o átomo terá a seguinte estrutura:

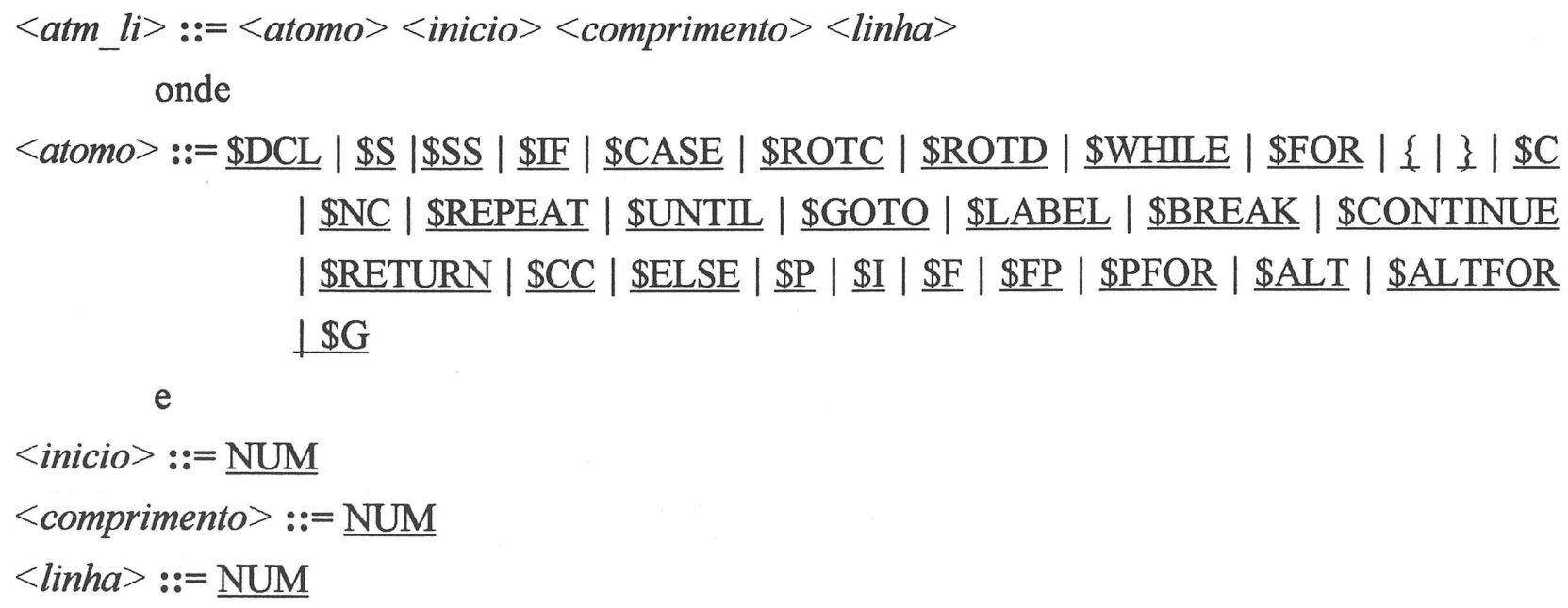


Os terminais anteriormente relacionados representam a seqüência de caracteres indicadas pelos próprios terminais, com execeção dos terminais relacionados na Tabela A.1. Na coluna da esquerda, que indicam a seqüência de caracteres representada na coluna direita da tabela, onde $n>0$, $\mathrm{d}^{\mathrm{n}}$ é uma seqüência de dígitos e $\mathrm{c}^{\mathrm{n}}$ é uma seqüência de letras e dígitos, começando com letra.

\begin{tabular}{|c|c|}
\hline Terminal & Sequência de caracteres indicada \\
\hline$\underline{\$ S}$ & $\$ \mathrm{Sd}^{\mathrm{n}}$ \\
\hline$\underline{\$ S S}$ & $\$ S S S d^{n}$ \\
\hline$\$$ \$FP & $\$ \mathrm{FPd}^{\mathrm{n}}$ \\
\hline \$PFOR & ${\underline{\$ P F O R d^{n}}}^{\mathrm{N}}$ \\
\hline \$FPFOR & \$FPFORd $^{\mathrm{n}}$ \\
\hline$\$$ \$ALT & \$ALTd $^{\mathrm{n}}$ \\
\hline \$ALTFOR & \$ALTFORd ${ }^{\mathrm{n}}$ \\
\hline$\underline{\$ \mathrm{C}}$ & $\$ C\left(d^{n}\right) d^{n}$ \\
\hline$\underline{\$ P}$ & $\$ P\left(d^{n}\right) d^{n}$ \\
\hline$\underline{\$ I}$ & $\$ \mathrm{I}\left(\mathrm{d}^{\mathrm{n}}\right) \mathrm{d}^{\mathrm{n}}$ \\
\hline$\underline{\$ G}$ & $\$ G\left(d^{n}\right) d^{n}$ \\
\hline$\underline{\underline{N U M}}$ & $d^{n}$ \\
\hline$\underline{\underline{L A B E L}}$ & $c^{n}$ \\
\hline
\end{tabular}

Tabela A. 1. Extensões de terminais da LI

A utilidade desses ponteiros dos átomos é possibilitar o acesso ao código fonte associado ao átomo da LI, o que vai ser necessário, por exemplo, para a extensão do grafo de fluxo de controle 
para a geração do grafo def e para a instrumentação da unidade em teste.

\section{A.1. Comandos de Seqüência}

A sintaxe dos comandos de seqüência é dada por:

$<$ sequencia $>::=<$ dcl $>|<s>|<s s>$,

onde

$<$ dcl $>::=$ \$DCL $<$ inicio $><$ comprimento $><$ linha $>$,

$<s>::=\$$ S $<$ inicio $><$ comprimento $><$ linha $>\mathrm{e}$

$<$ sS $>::=$ \$SS $<$ inicio $><$ comprimento $><$ linha $>$

onde $\langle d c l>$ denota uma declaração de variável; $\langle s\rangle$, uma computação; sendo que uma computação pode ser uma atribuição de valor a uma variável ou uma chamada de procedimento e $<s s>$, uma comunicação interprocesso.

Observe que $\underline{\$ S 1}$ representa o primeiro comando de seqüência do programa em LI, ou seja, o número que segue os caracteres $\underline{\$ S}$ indica a ordem em que aparece o comando seqüencial no programa.

\section{A.2. Comandos de Seleção}

\section{A.2.1. Seleção Simples}

$$
\begin{aligned}
& \begin{aligned}
&<\text { if }>::=<\text { if_atm }><\text { cond_atm }><\text { statement }_{1}>\mid<\text { if_atm }><\text { cond_atm }><\text { statement }_{1}><\text { else_atm }> \\
&<\text { statement }{ }_{2}> \\
& \text { onde }
\end{aligned} \\
& <\text { if_atm }>::=\underline{\$ I F}<\text { inicio }><\text { comprimento }><\text { linha }>, \\
& <\text { cond_atm }>::=\underline{\$ C}<\text { inicio }><\text { comprimento }><\text { linha }>, \\
& <\text { else_atm }>::=\underline{\$ E L S E}<\text { inicio }><\text { comprimento }><\text { linha }>\text { e } \\
& <\text { statement } t_{i}>\text { é o não terminal que denota todos os possíveis comandos da LI, agrupados ou não; }
\end{aligned}
$$


$<$ statement $>$ será definido formalmente mais adiante. Este comando corresponde ao if das linguagens estilo ALGOL.

A solução para a ambigüidade que poderia ser gerada pelo encadeamento de \$IF e \$ELSE sem delimitadores de bloco $\{$ e $\}$ foi tomada inspirada na maioria das linguagens estilo ALGOL.

Os números que aparecem em $\underline{\$ C(1) 1}$ indicam, respectivamente, o número de predicados que a condição possui e a ordem de aparição no programa fonte.

\section{A.2.2. Seleção Múltipla}

$$
\begin{aligned}
& <\text { case }>::=<\text { case_atm }><\text { case_cond_atm }>\{\{(<\text { rotc_atm }>\mid<\text { rotd_atm }>)<\text { statement }>\}\} \\
& \text { onde } \\
& <\text { case_atm }>::=\underline{\text { \$CASE }<\text { inicio }><\text { comprimento }><\text { linha }>,} \\
& <\text { case_cond_atm }>::=\underline{\$ C C}<\text { inicio }><\text { comprimento }><\text { linha }>, \\
& <\text { rotc_atm }>::=\underline{\text { \$ROTC }<\text { inicio }><\text { comprimento }><\text { linha }>\mathrm{e}} \\
& <\text { rotd_atm }>::=\underline{\text { \$ROTD }}<\text { inicio }><\text { comprimento }><\text { linha }>.
\end{aligned}
$$

O não terminal <case_atm $>$ representa o átomo que inicia o comando de seleção múltipla, $<$ case_cond_atm $>$ representa a condição de comando e $<$ rotc_atm $>$ representa os possíveis rótulos para as seqüências de comandos indicadas por $<$ statement $>$. O não terminal $<$ rotd_atm $>$ representa o rótulo para a seqüência de comandos a ser executada quando a condição não combina com nenhum rótulo $<$ rotc_atm $>$.

A semântica do comando <case $>$ é equivalente à do comando switch da linguagem $\mathbf{C}$.

\section{A.2.3. Seleção Não Determinística}

$$
\begin{gathered}
<\text { alt }>::=<\text { alt_atm }>\{\{<\text { guard_atm }><\text { statement }>\}\} \\
\text { onde }
\end{gathered}
$$


$<$ alt_atm $>::=$ \$ALT $<$ inicio $><$ comprimento $><$ linha $>\mathrm{e}$

$<$ guard_atm $>::=\underline{\$ G}<$ inicio $><$ comprimento $><$ linha $>$.

O não terminal <alt_atm $>$ representa o átomo que inicia o comando de seleção não determinística, <guard_atm> ( que corresponde a uma entrada, real ou nula, antecedida, opcionalmente, de uma condição ) representa a guarda de $<$ statement $>$. A semântica do comando alt é equivalente ao comando de seleção não determinística de Occam.

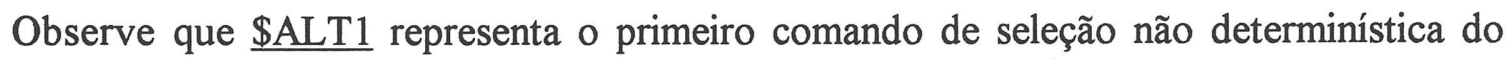
programa em LI, ou seja, o número que segue os caracteres \$ALT indica a ordem em que aparece o comando de alternativa no programa. Os números que aparecem em $\$$ G(1)1 indicam, respectivamente, o número de ordem da guarda no comando alt e a ordem de aparição no programa fonte.

\section{A.3. Paralelismo}

$$
\begin{aligned}
& <\text { parall }>::=<\text { par_atm }>\{<b r \text { beg_atm }><\text { statement }>\}<\text { par_end_atm }> \\
& \text { onde } \\
& <\text { par_atm }>::=\$ \mathbb{\mathrm { P }}<\text { inicio }><\text { comprimento }><\text { linha }>, \\
& <b r \text { beg_atm }>::=\underline{\$ I}<\text { inicio }><\text { comprimento }><\text { linha }>, \\
& <\text { par_end_atm }>::=\underline{\$ F P}<\text { inicio }><\text { comprimento }><\text { linha }>.
\end{aligned}
$$

O não terminal < par_atm> representa o átomo que inicia o comando de paralelismo e o não terminal <par_end_atm > representa o átomo que finaliza o comando de paralelismo. O não terminal $<$ br_beg_atm $>$ marca o início de cada um dos comandos representados por $<$ statement $>$, que serão executados paralelamente.

Os números que aparecem em $\underline{\$ P(2) 1}$ indicam, respectivamente, o número de ramos paralelos do comando e a ordem de aparição no programa fonte. Os números que aparecem em $\$$ I(2)1 e $\underline{\$ F(2) 1}$ indicam, respectivamente, o número do ramo do comando paralelo sendo tratado e a ordem de aparição do comando paralelo no programa fonte. Observe que \$FP1 representa o fim do primeiro comando de paralelismo do programa em LI, ou seja, o número que segue os caracteres \$FP indica 
o término do primeiro comando de paralelismo que foi aberto no programa fonte.

\section{A.4. Iteração}

A LI fornece comandos para iteração tanto para um número fixo de repetições quanto para um número de repetições que depende de uma condição. No caso de um número fixo de repetições, essas repetições podem ser executadas seqüencialmente, paralelamente ou alternadamente. Tratandose do número fixo de repetições seqüenciais tem-se um comando semelhante ao comando for das linguagens seqüenciais estilo ALGOL. No caso das repetições paralelas tem-se um comando análogo ao for paralelo das linguagens concorrentes; no caso de uma escolha entre uma repetição de alternativas, tem-se o for alternativo.

Os comandos de iteração cujo número de repetições é dirigido por uma condição são equivalentes aos tradicionais while e repeat-until das linguagens estilo ALGOL.

O for seqüencial da LI é definido como

$$
<\text { for }>::=<\text { for_atm }><s_{1}><\text { cond_for_atm }><s_{2}><\text { statement }>
$$

onde

$<$ for_atm $>::=\underline{\$ F O R}<$ inicio $><$ comprimento $><$ linha $>\mathrm{e}$

$<$ cond_for_atm $>::=\underline{\$ C}<$ inicio $><$ comprimento $><$ linha $>$.

O não terminal $<$ for_atm $>$ indica o comando for da LI, o não terminal $<s_{1}>$ representa os comandos de iniciação das variáveis de controle do for; <cond_for_atm> representa a condição; $<s_{2}>$ representa o comando de seqüência que altera as variáveis de controle a cada iteração do for e $<$ statement $>$ representa o corpo do comando. O comando for da LI é inspirado no comando equivalente da linguagem $\mathbf{C}$, possuindo a mesma semântica.

O for paralelo da LI é definido como

$$
\begin{aligned}
<\text { parfor }>::= & <\text { parfor_atm }><s_{1}><\text { cond_for_atm }><s_{2}><b r \text { beg_atm }><\text { statement }> \\
& <\text { par_end_atm }>
\end{aligned}
$$


$<$ br_beg_atm $>::=\$$ I $<$ inicio $><$ comprimento $><$ linha $>$,

$<$ par_end_atm $>::=\$$ FP $<$ inicio $><$ comprimento $><$ linha $>\mathrm{e}$

$<$ cond_for_atm $>::=\$$ C $<$ inicio $><$ comprimento $><$ linha $>$.

O não terminal $<$ parfor_atm $>$ indica o comando for paralelo da LI, o não terminal $<s_{1}>$ representa a iniciação das variáveis de controle do for através de um comando de seqüência, $<$ cond_for_atm $>$ representa a condição, $\left\langle s_{2}>\right.$ representa o comando de paralelismo que altera as variáveis de controle correspondentes a todas as iterações do for e $<$ statement $>$ representa o corpo do comando.

O for alternativo da LI é definido como

$<$ altfor $>::=<$ altfor_atm $><s_{1}><$ cond_for_atm $><s_{2}><$ guard_atm $><$ statement $>$

onde

$<$ altfor_atm $>::=\$$ \$ALTFOR $<$ inicio $><$ comprimento $><$ linha $>\mathrm{e}$

$<$ cond_for_atm $>::=\$$ C $<$ inicio $><$ comprimento $><$ linha $>$.

$<$ guard_atm $>::=\$$ G $<$ inicio $><$ comprimento $><$ linha $>$.

O não terminal $<$ altfor_atm $>$ indica o comando for alternativo da LI, o não terminal $\left\langle s_{1}\right\rangle$ representa a iniciação das variáveis de controle do for através de um comando de seqüência, $<$ cond_for_atm $>$ representa a condição, $<s_{2}>$ representa o comando de seleção não determinística que altera as variáveis de controle correspondentes a todas as iterações do for, <guard_atm> representa a guarda de $<$ statement $>$, que representa o corpo do comando.

Observe que \$ALTFOR1 representa o primeiro comando de seleção não determinística do programa em LI, ou seja, o número que segue os caracteres \$ALT indica a ordem em que aparece o comando de alternativa no programa. Os números que aparecem em $\$ \mathrm{G(1)1}$ indicam, respectivamente, o número de ordem da guarda no comando alt e a ordem de aparição no programa fonte.

O while da LI é definido como

$<$ while $>::=<$ while_atm $><$ cond_while_atm $><$ statement $>$

onde 
$<$ for_atm $>::=$ \$WHILE $<$ inicio $><$ comprimento $><$ linha $>\mathrm{e}$

$<$ cond_for_atm $>::=\$$ C $<$ inicio $><$ comprimento $><$ linha $>$.

$<$ while_atm $>$ indica o comando while, $<$ cond_while_atm $>$, a condição e <statement $>$, o corpo do while. $\mathrm{O}$ corpo será executado enquanto a condição em $<$ cond_while_atm $>$ permanecer verdadeira.

$O$ repeat-until da $\mathrm{LI}$ é definido como

$<$ repeat-until $>::=<$ repeat_atm $><$ statement $><$ until_atm $><$ cond_until_atm $>$

onde

$<$ repeat_atm $>::=\underline{\text { \$REPEAT }}<$ inicio $><$ comprimento $><$ linha $>$,

$<$ until_atm $>::=$ \$UNTIL $<$ inicio $><$ comprimento $><$ linha $>\mathrm{e}$

$<$ cond until atm $>::=(\underline{\$ C} \mid \underline{\$ N C})<$ inicio $><$ comprimento $><$ linha $>$.

$<$ repeat_atm $>$ indica o início do comando repeat-until, <statement $>$ o corpo do comando, $<$ until_atm $>$ indica o fim do comando e $<$ cond_until_atm $>$ representa a condição de término. A semântica desse comando da LI é igual ao comando equivalente das linguagens seqüenciais estilo ALGOL.

\section{A.5. Desvio Incondicional}

Os comandos de desvio incondicional provocam a mudança do fluxo de execução em um programa. A LI possui um comando de transferência incondicional irrestrito do tipo goto e comandos de transferência incondicional controlada; estes últimos têm sua utilização limitada a algumas situações e seu efeito bem previsível.

O comando goto da LI é definido como

$<$ goto $>::=<$ goto_atm $><$ label_atm $>$

onde

$<$ goto_atm $>::=$ \$GOTO $<$ inicio $><$ comprimento $><$ linha $>\mathrm{e}$ 
$<$ label_atm $>::=\underline{\text { LABEL }}<$ inicio $><$ comprimento $><$ linha $>$.

$<$ goto_atm> representa o comando goto da LI e <label_atm> representa o rótulo para onde deve ser dirigido o fluxo de execução quando é encontrado o comando goto.

Existem mais três comandos de desvio incondicional na LI, que são:

$<$ break $>::=$ \$BREAK $<$ inicio $><$ comprimento $><$ linha $>$,

$<$ continue $>::=$ \$CONTINUE $<$ inicio $><$ comprimento $><$ linha $>$ e

$<$ return $>::=$ \$RETURN $<$ inicio $><$ comprimento $><$ linha $>$.

Estes comandos de transferência incondicional foram inspirados nos seus homônimos da linguagem $\mathbf{C}$ e, por isso, possuem efeitos idênticos.

\section{A.6. Comandos de Bloco}

Até aqui foram descritos os comandos individuais da LI, ainda falta definir como se agrupam comandos na LI e como esses comandos são organizados em um programa. O não terminal $<$ statement $>$, muito utilizado acima, representa um único comando da LI ou um agrupamento deles e é definido como

$<$ statement $>::=\{\{$ statement $>\}\} \mid<$ dcl $>|<s>|<$ ss $>\mid<$ if $>\mid<$ case $>\mid<$ alt $>\mid<$ parall $>$
$\mid<$ for $\mid><$ parfor $>\mid<$ altfor $>\mid<$ while $>\mid<$ repeat-until $>\mid \underline{\text { LABEL }}<$ statement $>\mid$
$<$ goto $>\mid<$ break $>\mid<$ continue $>\mid<$ return $>$.

Os programas em LI são definidos da seguinte maneira:

$<$ program $>::=\{<$ dcl $>\}\{<$ statement $>\}$. 


\title{
Apêndice B. Ações Semânticas do Analisador Léxico de Occam
}

\begin{abstract}
A seguir, é listado o código fonte do arquivo que contém as ações semânticas do analisador léxico de Occam para o seu mapeamento para a LIConc. Novas ações semânticas foram introduzidas tendo como principal objetivo o tratamento da indentação em Occam, uma vez que programas Occam são sensíveis à indentação. As novas ações semânticas criadas foram as ações semânticas $10,11,12$ e 13. Modificações foram feitas em outras ações semânticas já existentes.
\end{abstract}

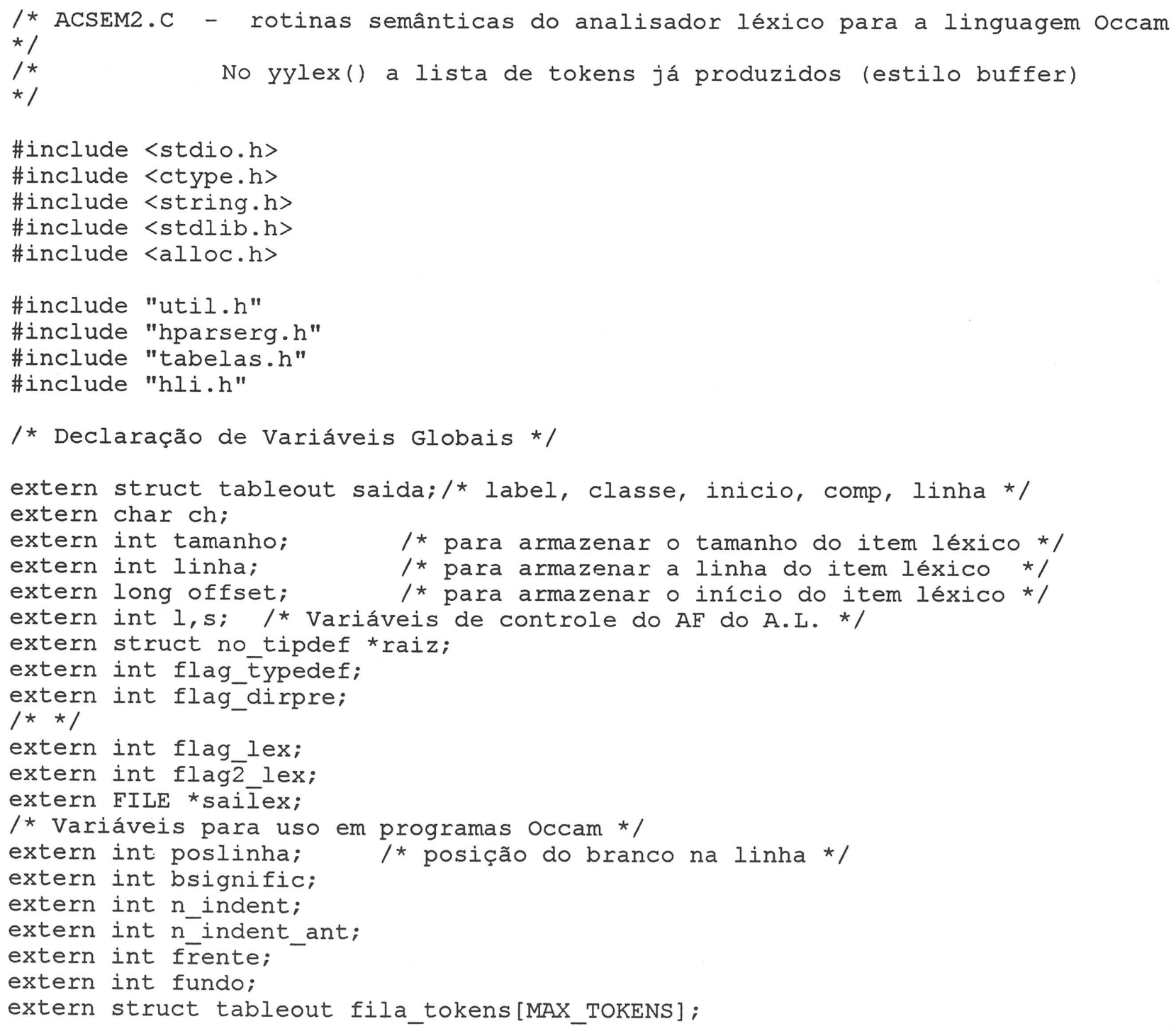




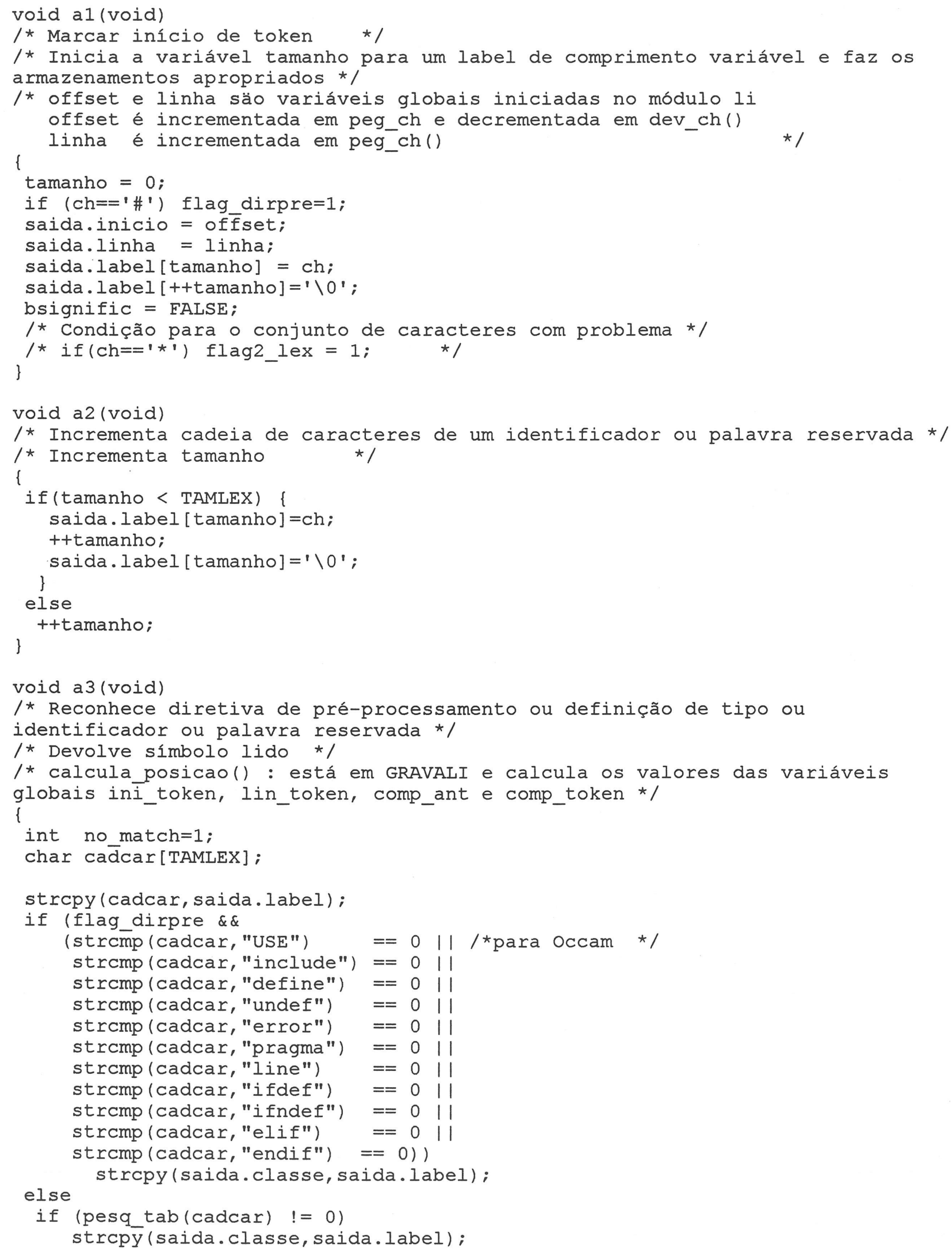









\section{Apêndice C. Rotinas Semânticas do Analisador Sintático de Occam}

Neste apêndice exibe-se a listagem de ROTSEM.C, que contém as rotinas semânticas do analisador sintático que faz a tradução de Occam para a LIConc. Algumas rotinas novas foram criadas para o tratamento de Occam. É o caso das rotinas semânticas que têm números entre 45 e 56. ROTSEM.C é apresentado em C.1.

Muitas chamadas são feitas à função grava_li(), que também sofreu modificações. O código dessa função está no arquivo GRAVALI.C e será listado em C.2.

\section{C.1. Listagem do arquivo ROTSEM.C}

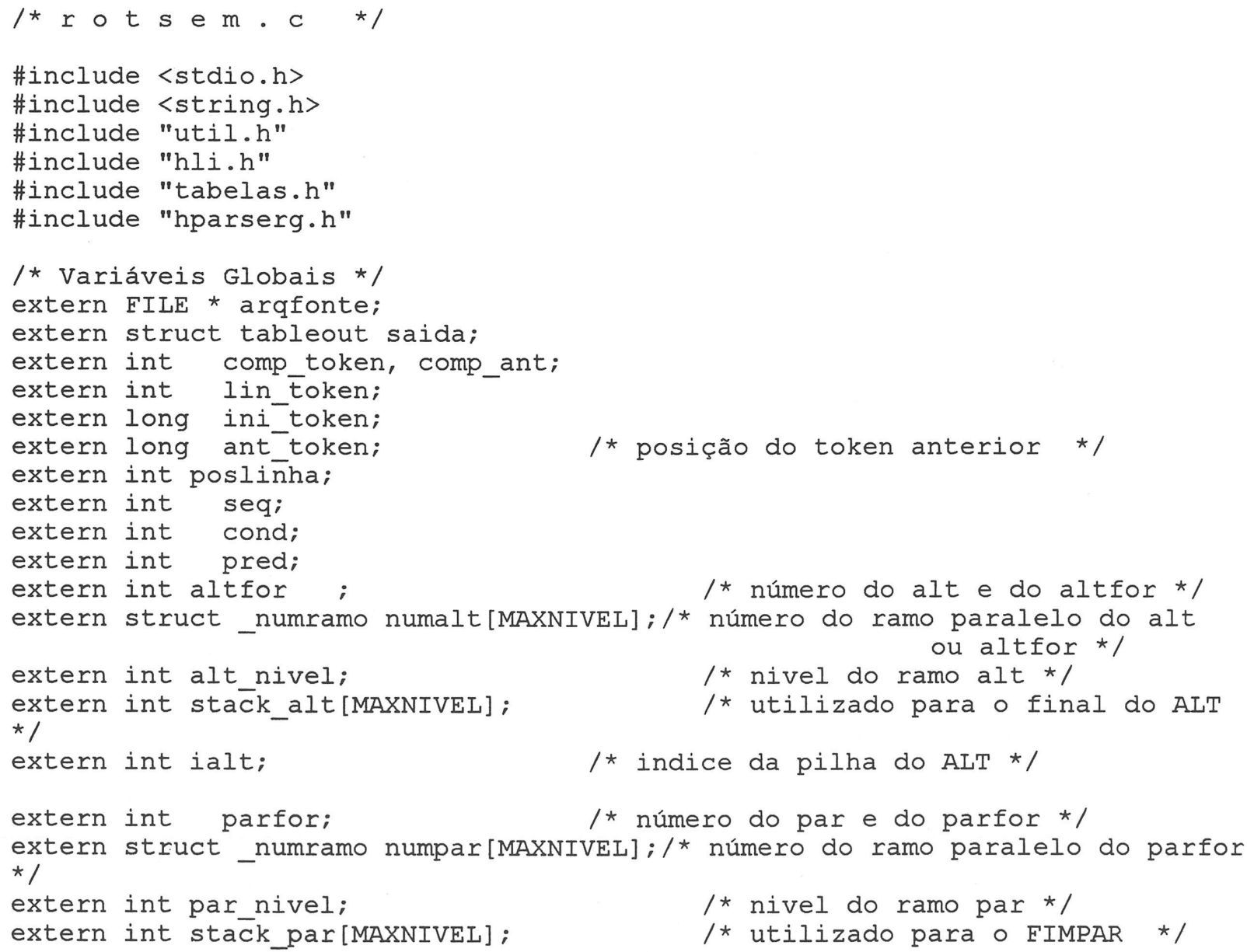




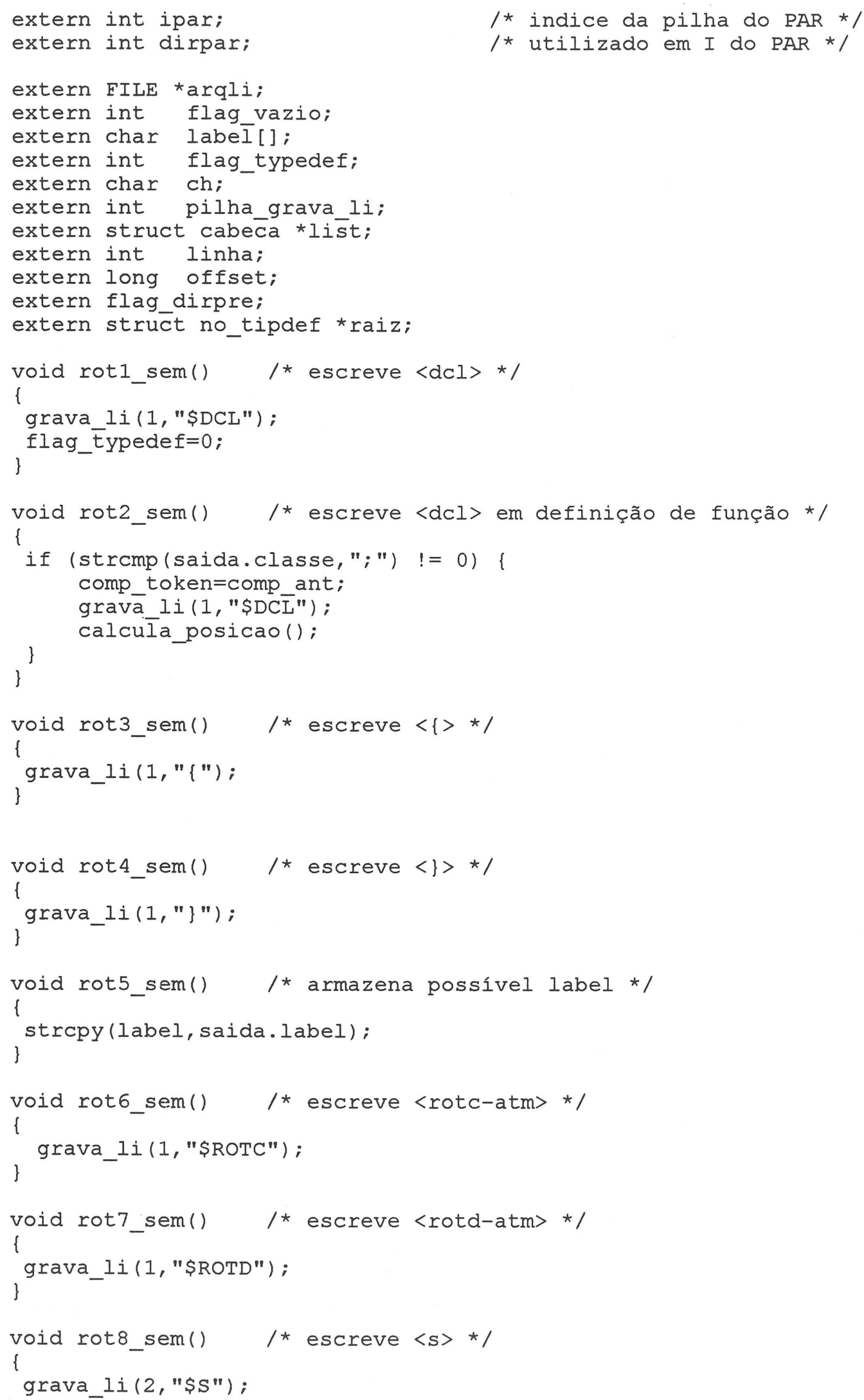




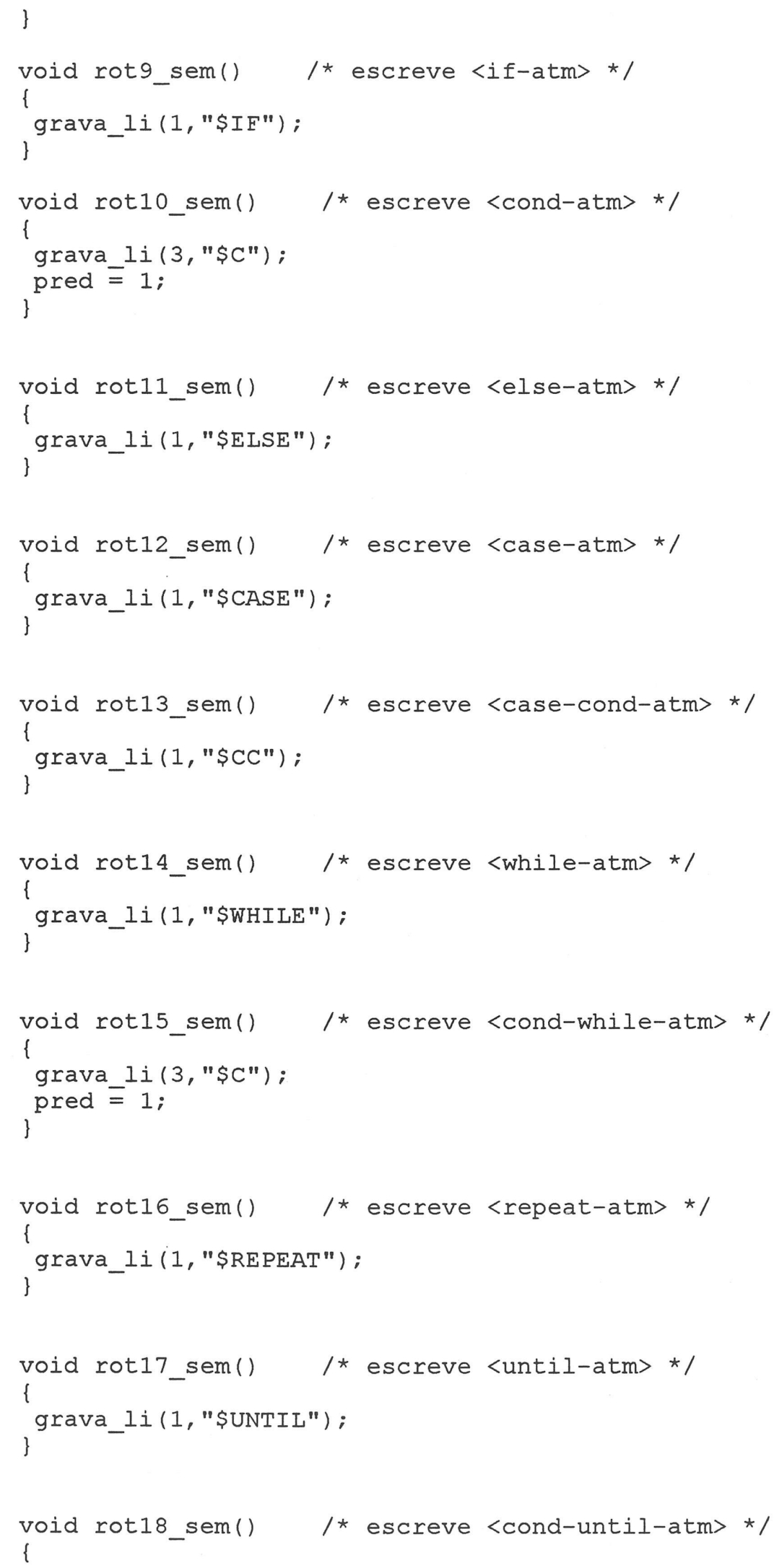




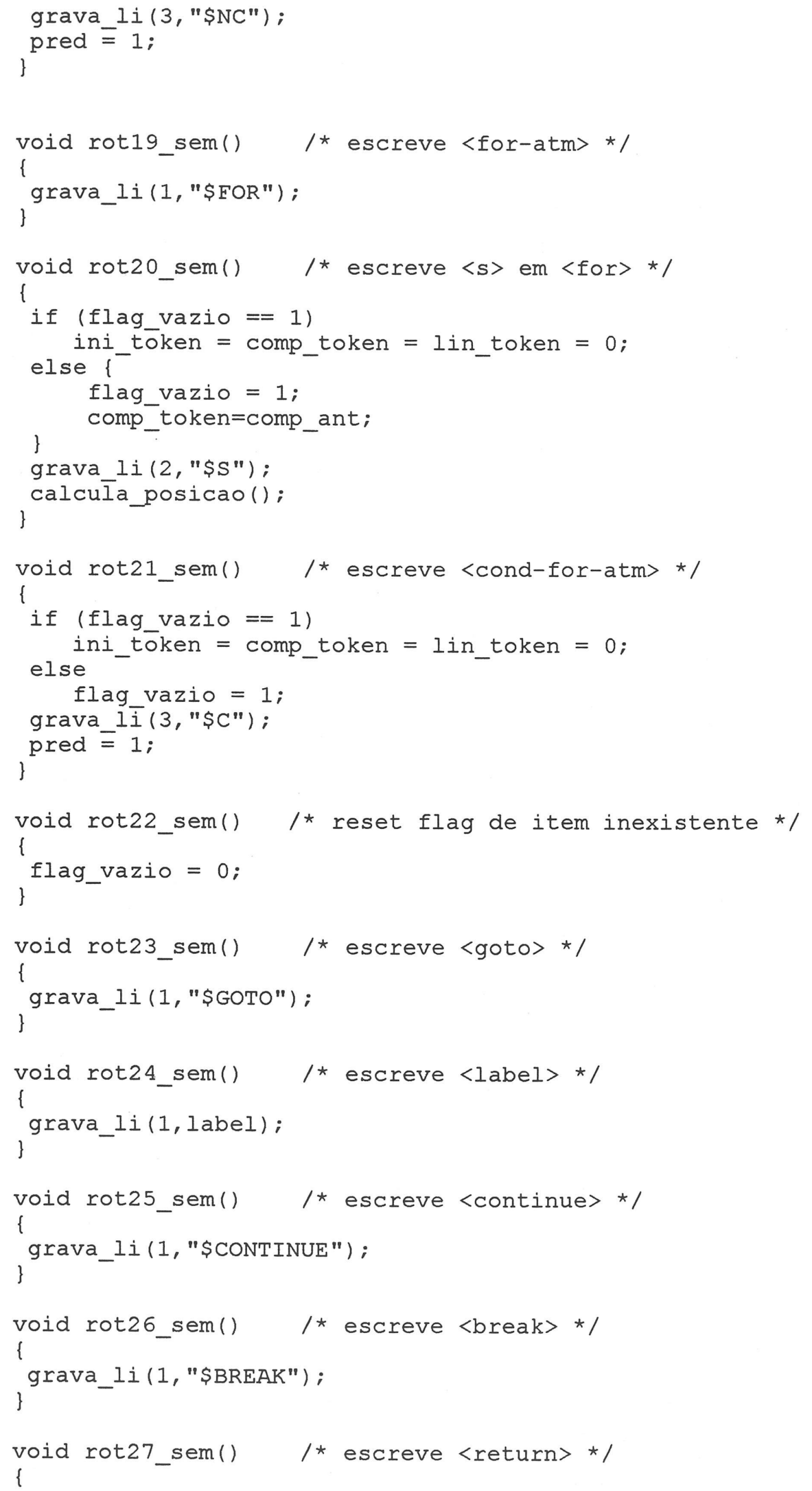




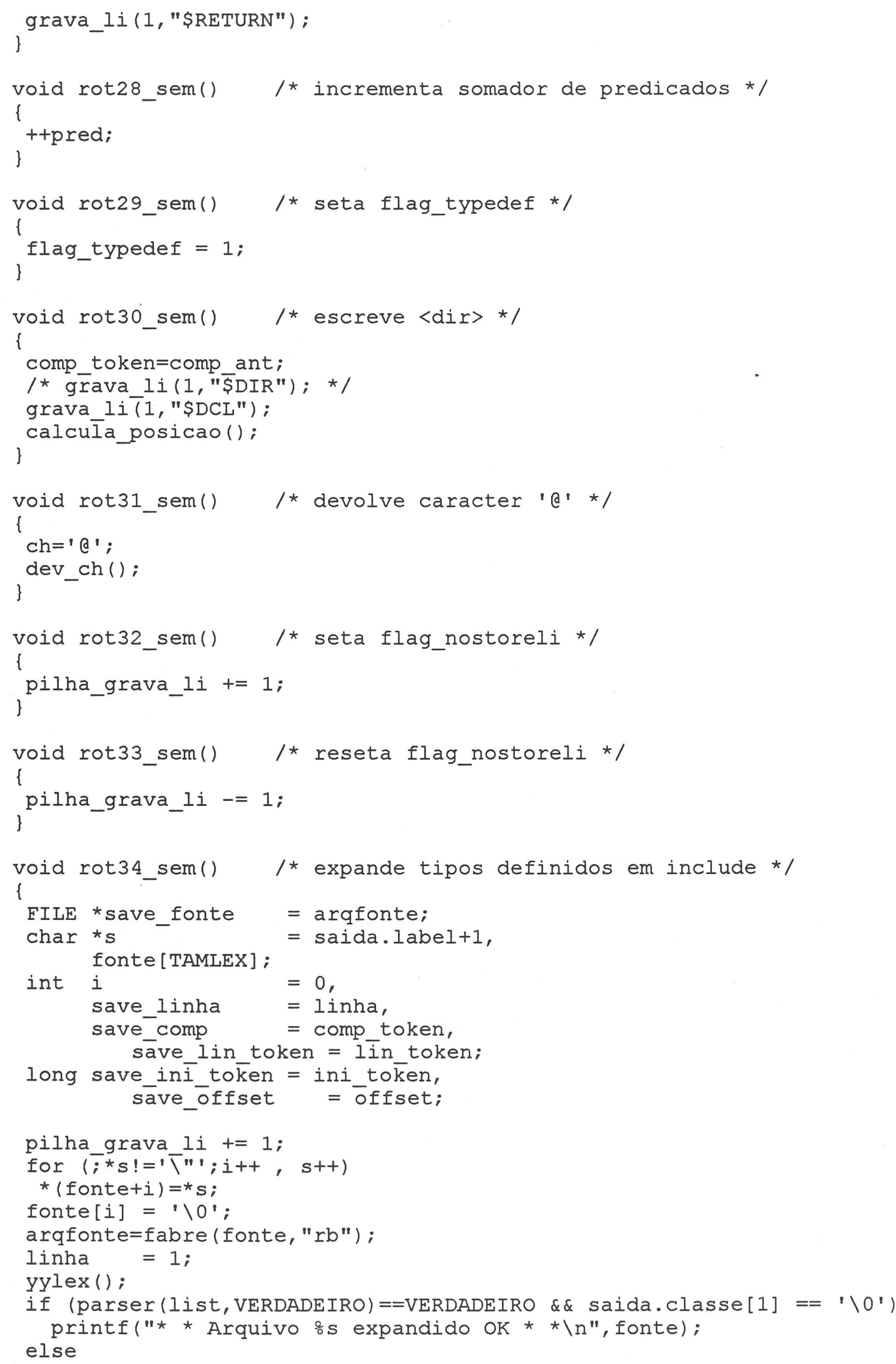




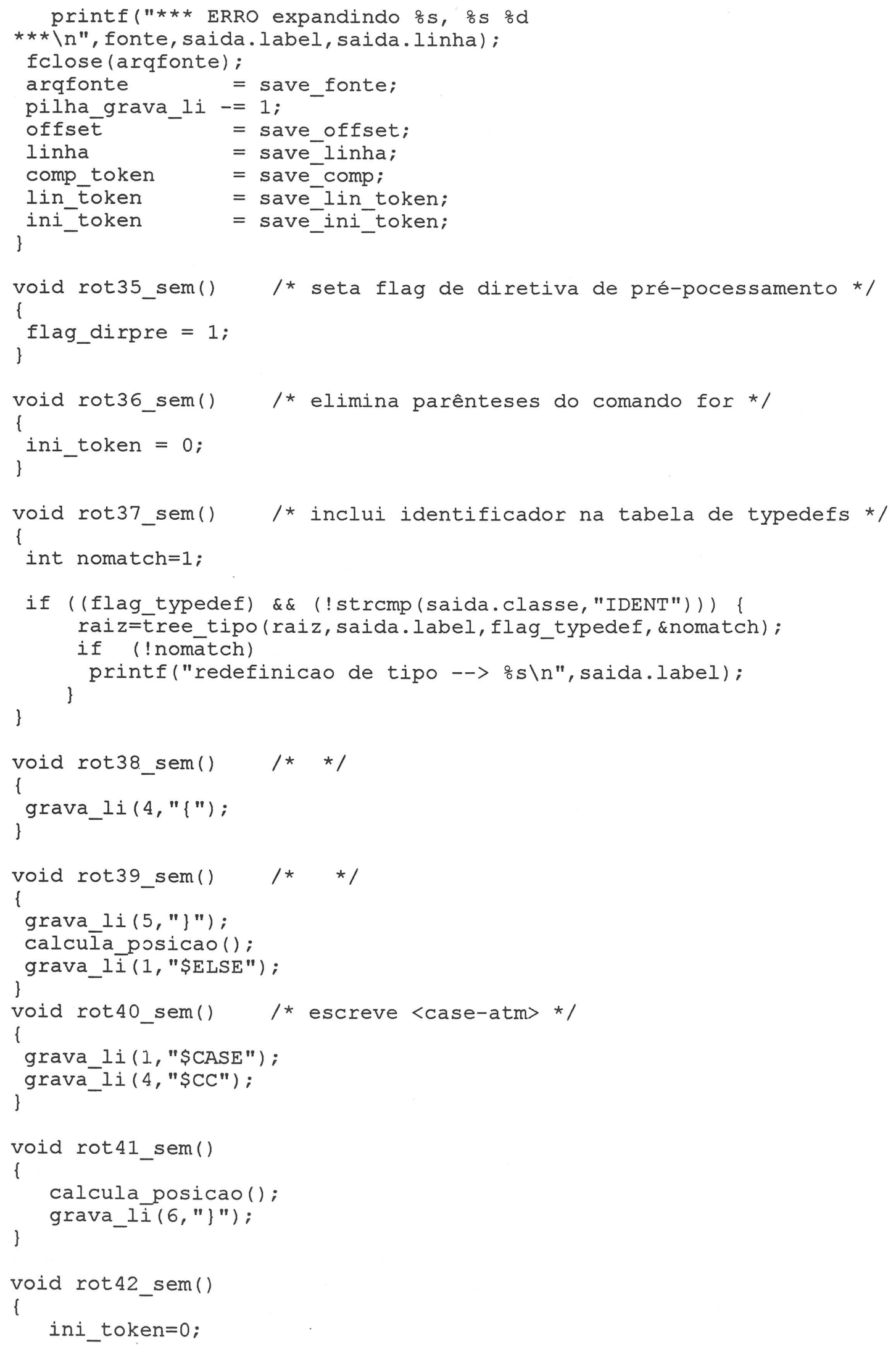




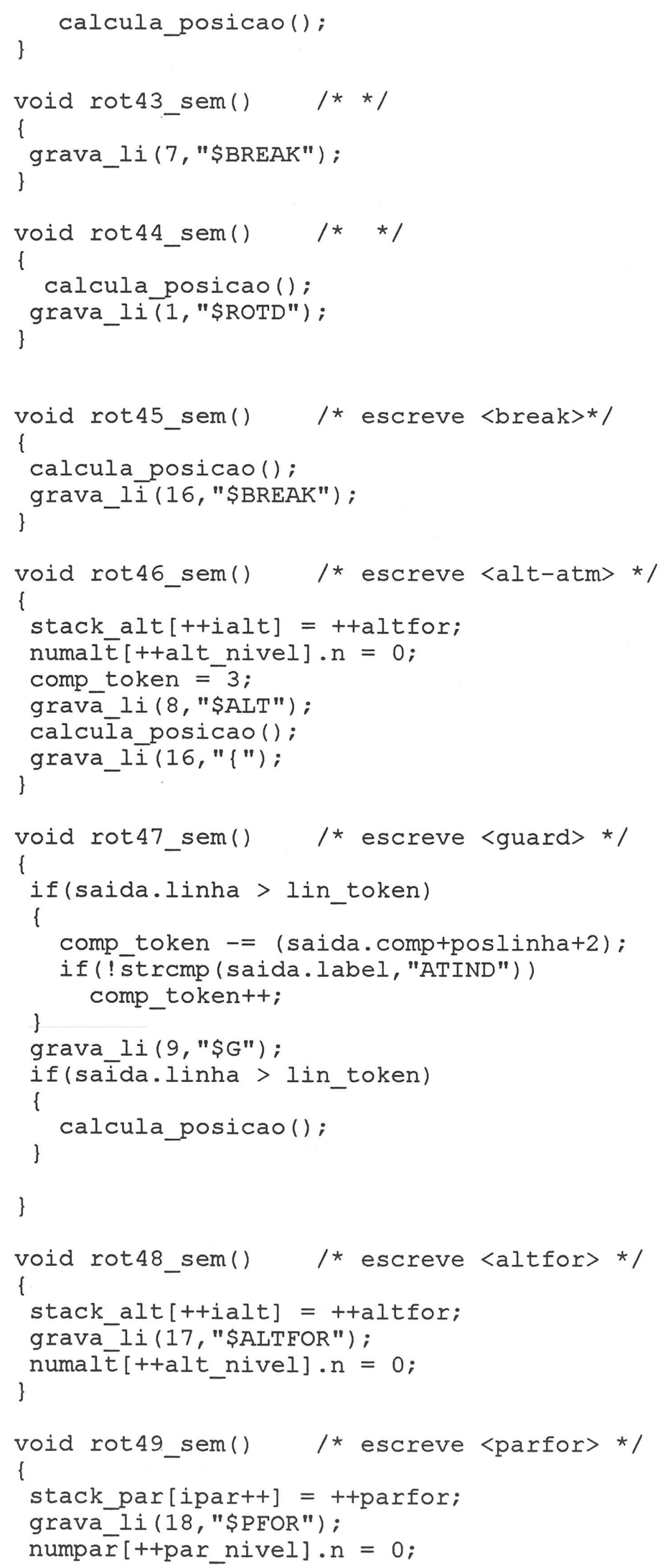




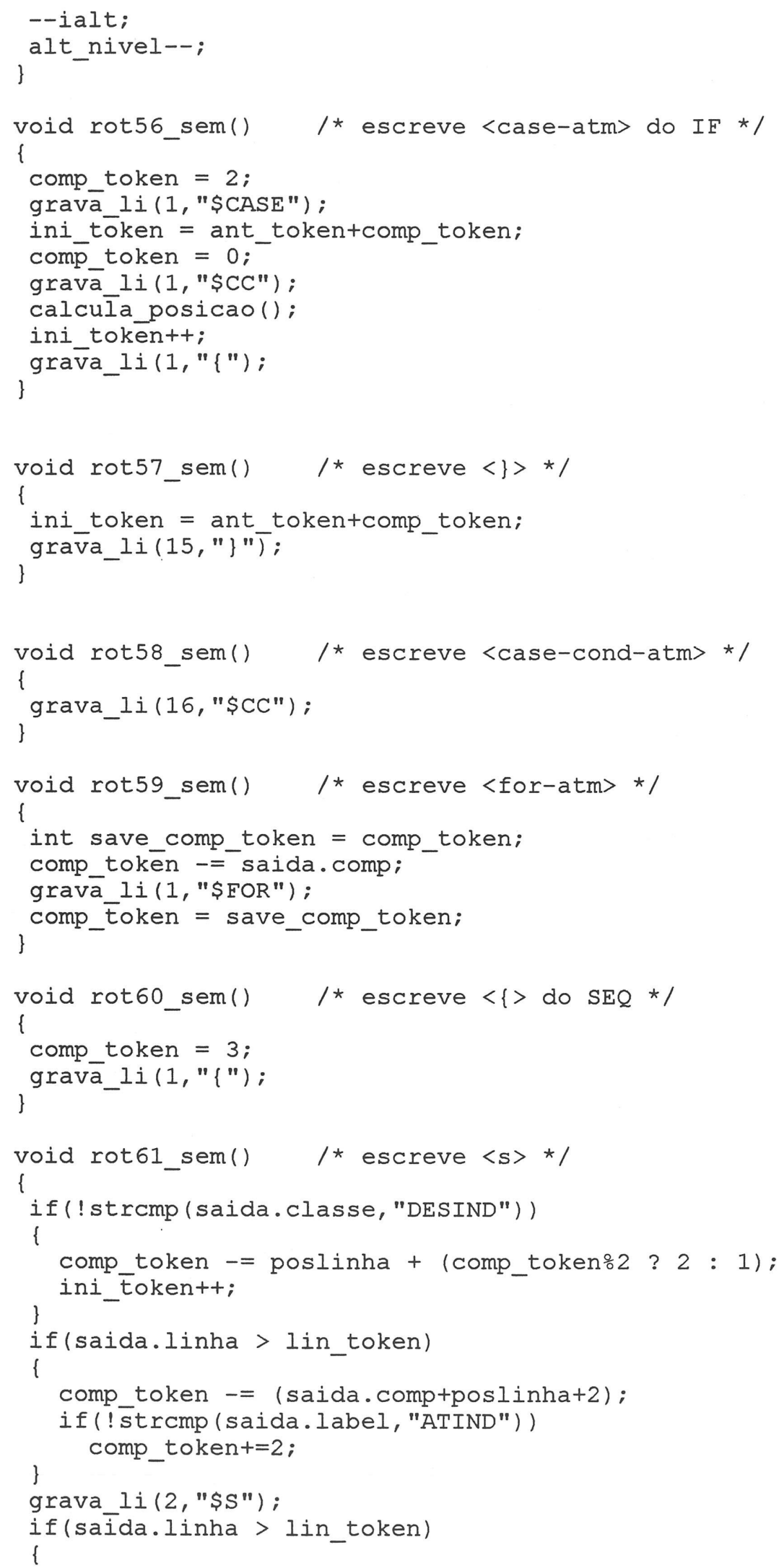




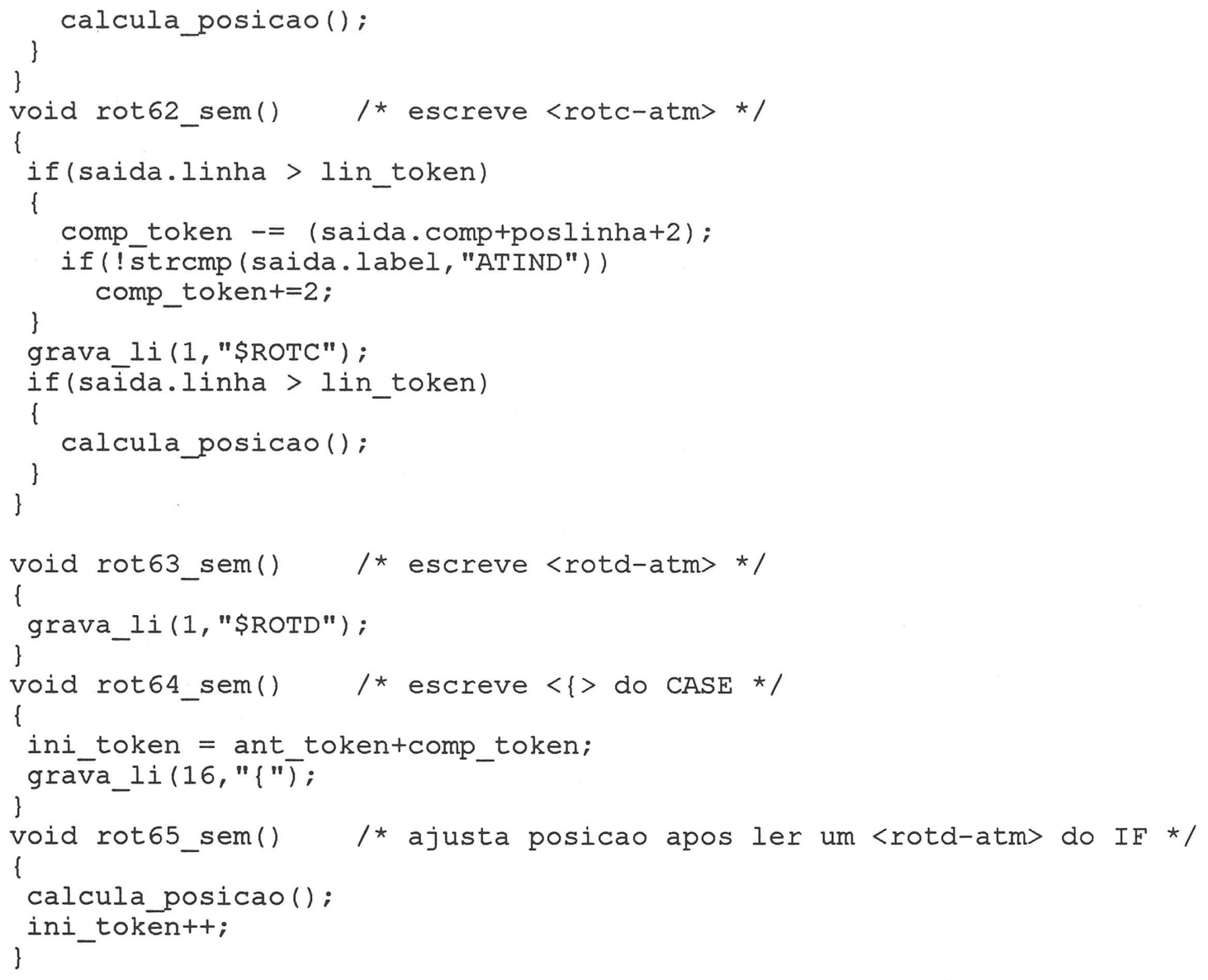

\section{C.2. Listagem do Arquivo GRAVALI.C}

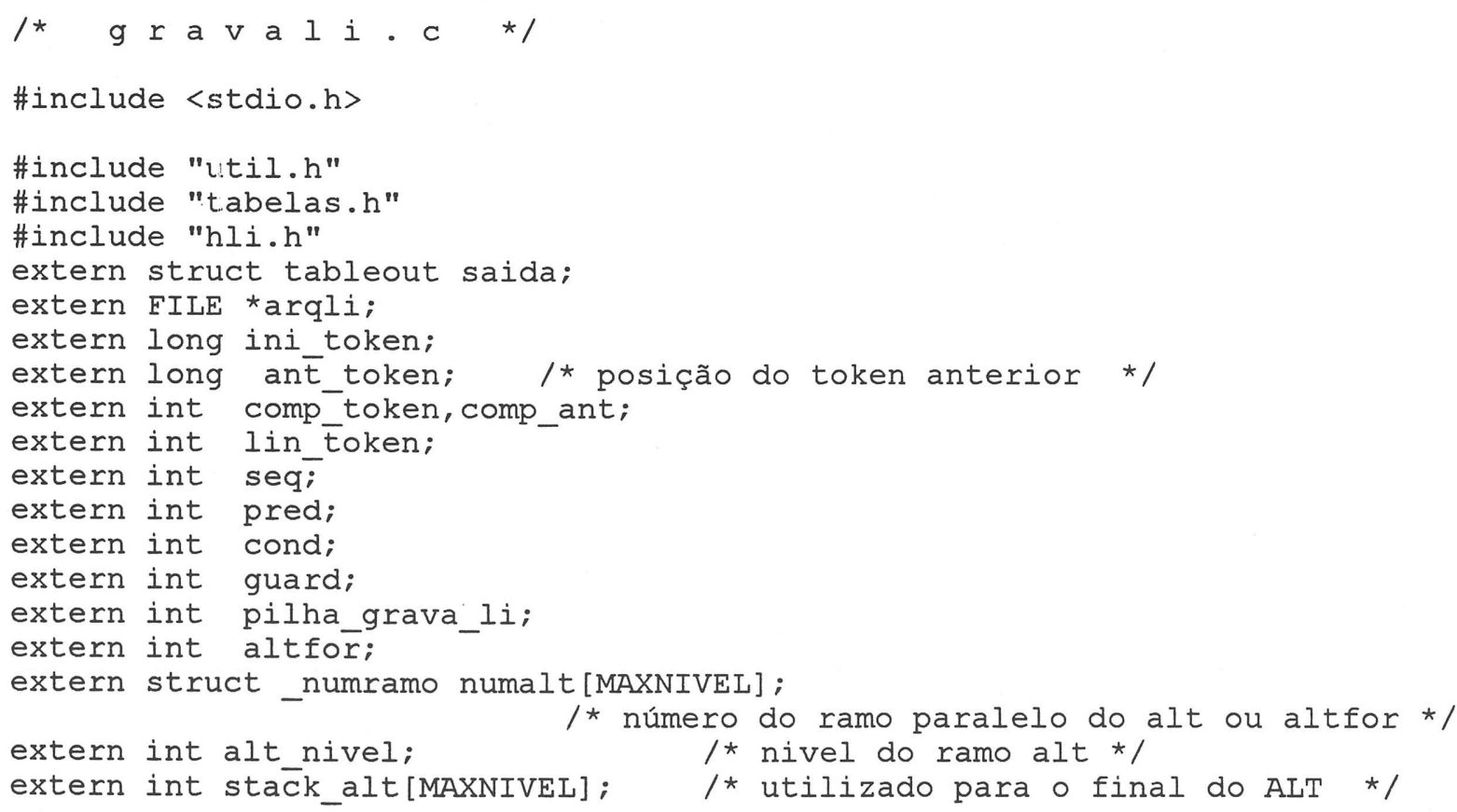




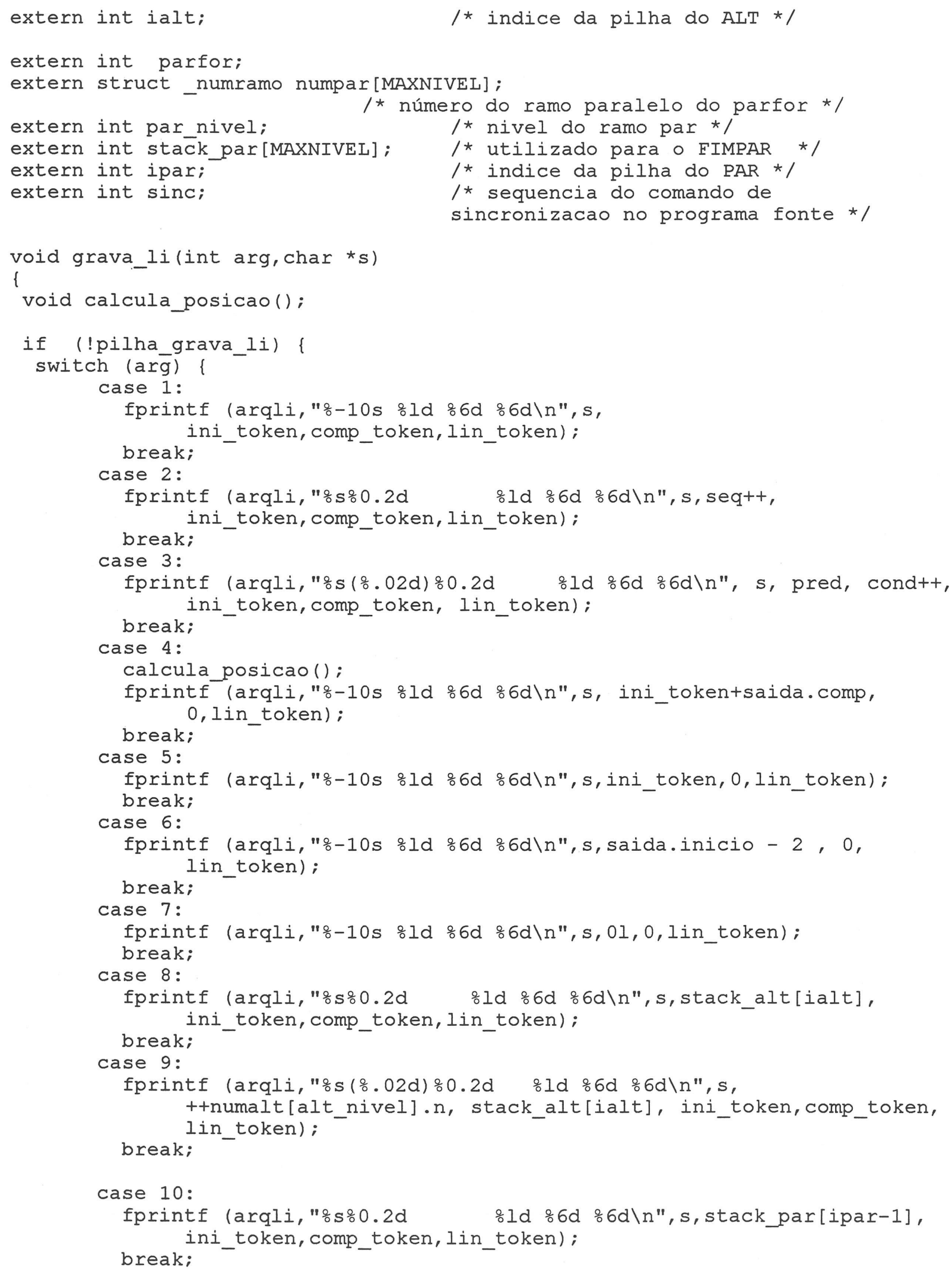




\section{Apêndice D. Um Exemplo Completo}

Neste apêndice ilustra-se com um exemplo as diretrizes para a aplicação dos modelos de fluxo de controle, de fluxo de dados e de instrumentação para programas Occam.

Um processo foi codificado, como se vê no exemplo abaixo. A seguir, tem-se o mapeamento desse exemplo para a LIConc, obtido com a execução do módulo implementado neste trabalho de mestrado. O fluxo de controle é representado pelo grafo de processo. Aos nós do grafo de processo são associadas definições de variáveis, que são listadas logo a seguir. Por fim, é exibido o programa instrumentado.

\section{O Exemplo}

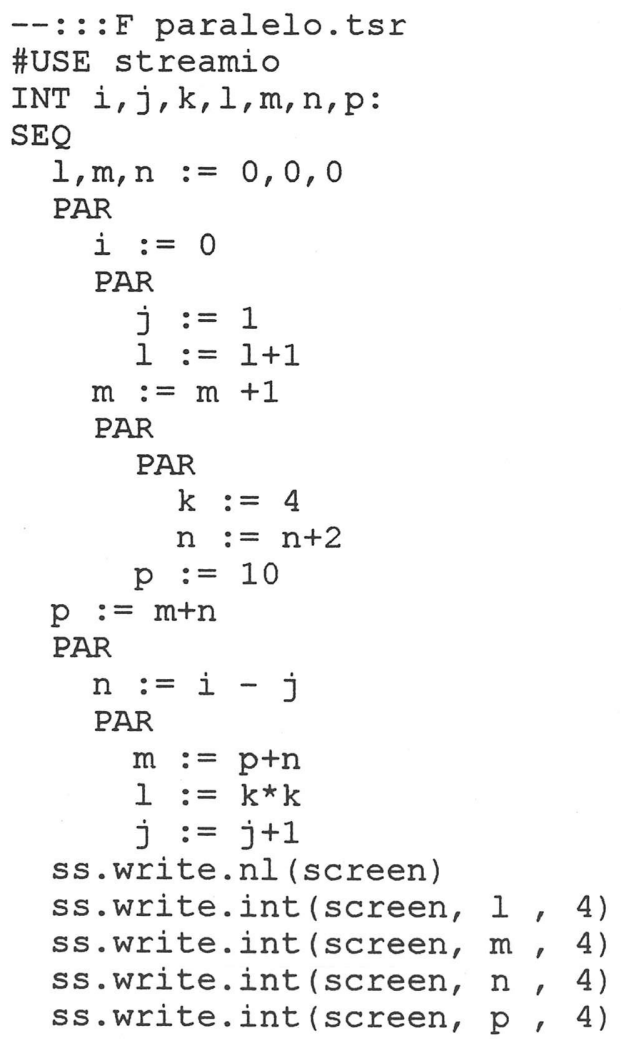


Versão em LIConc

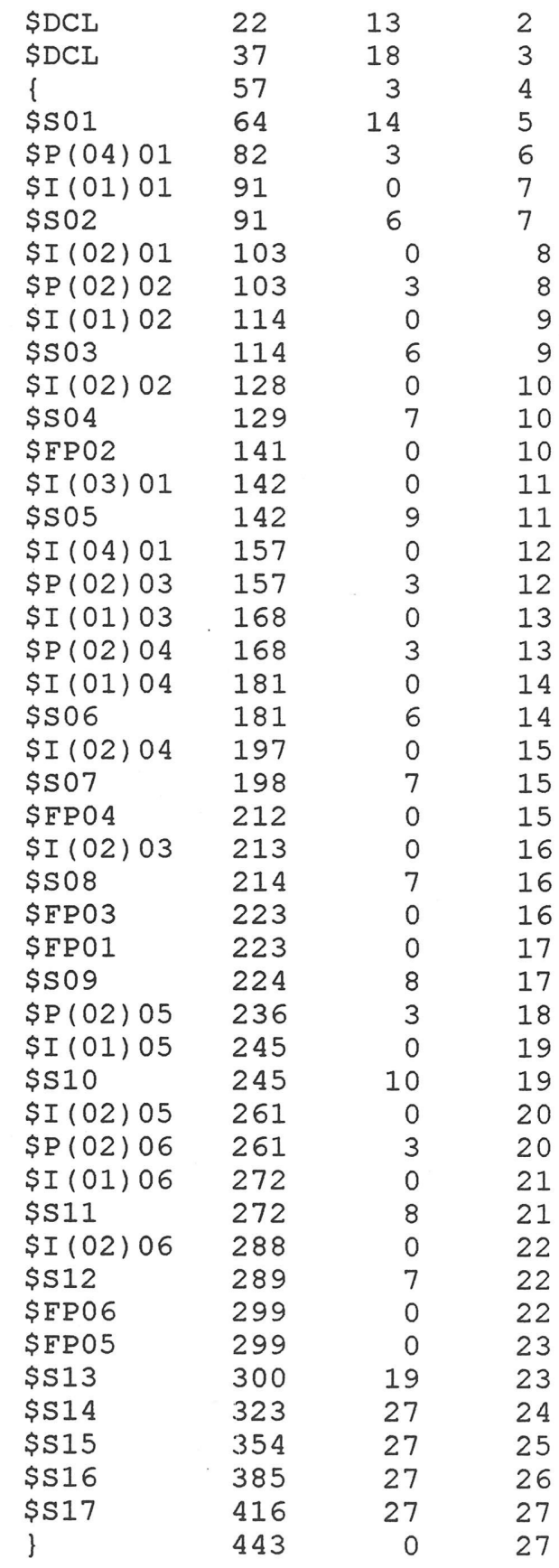




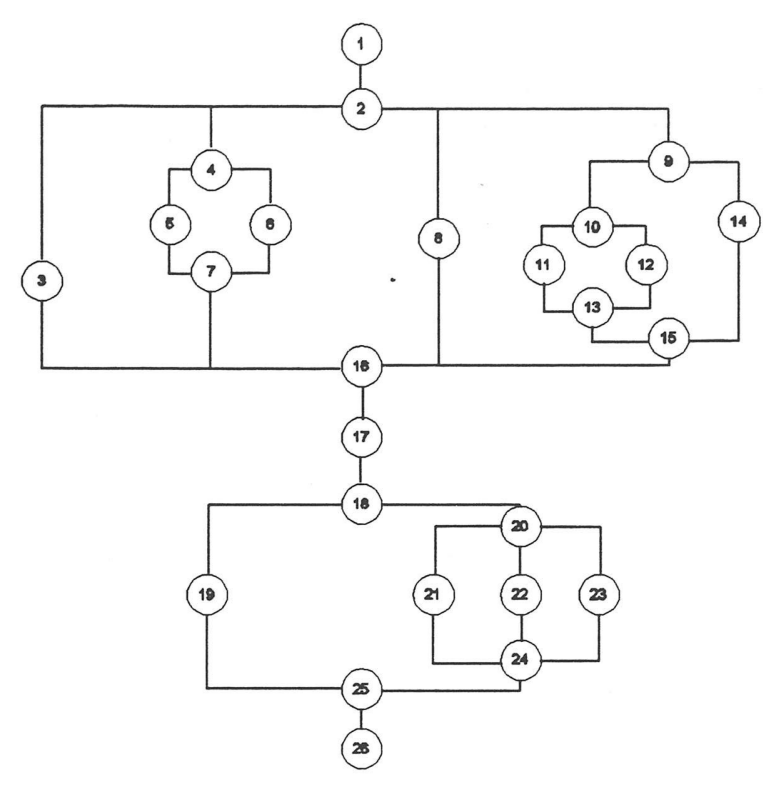

Figura C.1. Grafo de Processo

\section{Diretrizes para Construção do Grafo Def}

Abaixo são relacionados os nós do grafo de processo em que ocorrem definições de variáveis e quais são as variáveis definidas nesses nós.

$\begin{array}{cc}\text { Nó } & \text { Variáveis Definidas } \\ 1 & 1, \mathrm{~m}, \mathrm{n} \\ 3 & \mathrm{i} \\ 5 & \mathrm{j} \\ 6 & \mathrm{l} \\ 8 & \mathrm{~m} \\ 11 & \mathrm{k} \\ 12 & \mathrm{~h} \\ 14 & \mathrm{p} \\ 17 & \mathrm{p} \\ 19 & \mathrm{n} \\ 21 & \mathrm{~m} \\ 22 & 1 \\ 23 & \mathrm{j}\end{array}$




\section{Versão Instrumentada}

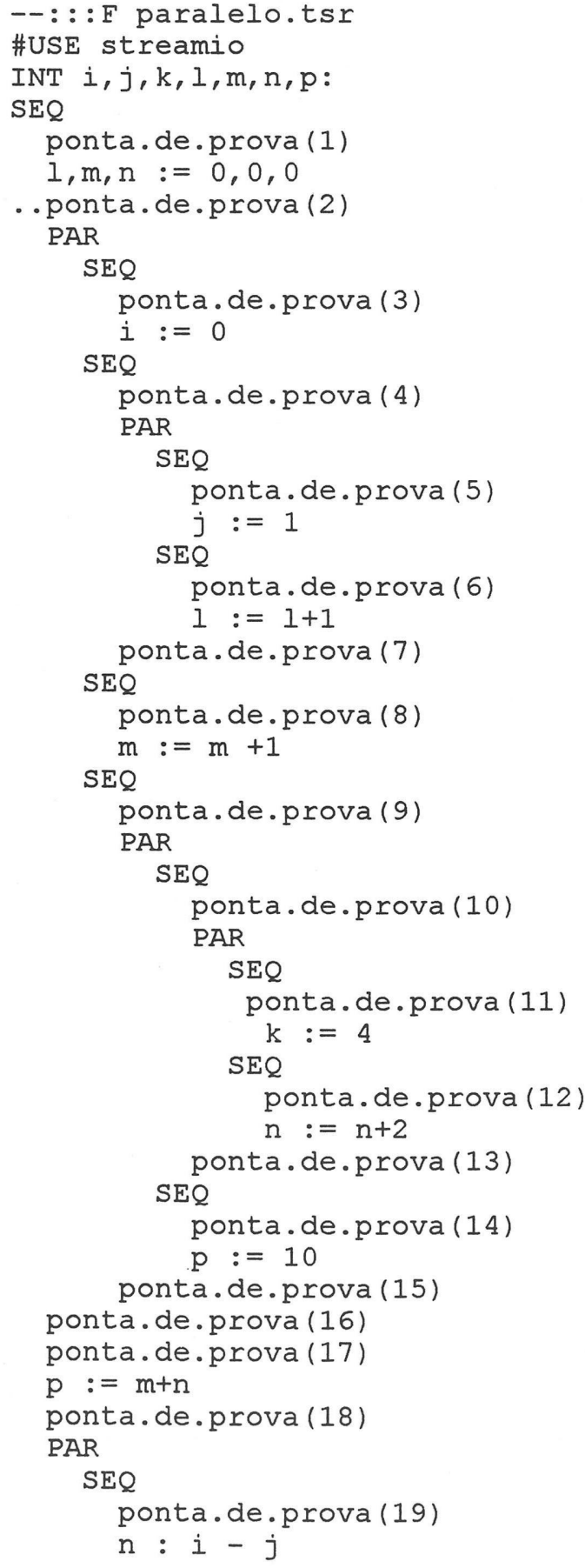


SEQ

ponta.de.prova (20)

PAR

$\mathrm{SEQ}$

ponta.de.prova (21)

$\mathrm{m}:=\mathrm{p}+\mathrm{n}$

SEQ

ponta.de.prova (22)

$1:=k^{\star} \mathrm{k}$

$\mathrm{SEQ}$

ponta.de.prova (23)

$j:=j+1$

ponta.de.prova (24)

ponta.de.prova (25)

ponta.de.prova (26)

ss.write.nl (screen)

ss.write.int (screen, 1,4 )

ss.write.int (screen, $m, 4$ )

ss.write.int (screen, $\mathrm{n}, 4$ )

ss.write.int (screen, p , 4) 